\title{
Life Sciences Division and Center for Human Genome Studies \\ 1992-1993
}

Compiled by

Morton Bradbury

Scott Cram

Carolyn Stafford

\section{Los Alamos




\section{ACKNOWLEDGMENTS}

We wish to thank all those who participated in the preparation of this document for their valuable assistance, in particular, Monica Fink, Noyola Scott, Tricia Lewis, Ruby Archuleta, Dusty DeAguero, Fawn Gore, and the Life Sciences Division principal investigators. 


\section{DISCLAIMER}

This report was prepared as an account of work sponsored by an agency of the United States Government. Neither the United States Government nor any agency thereof, nor any of their employees, make any warranty, express or implied, or assumes any legal liability or responsibility for the accuracy, completeness, or usefulness of any information, apparatus, product, or process disclosed, or represents that its use would not infringe privately owned rights. Reference herein to any specific commercial product, process, or service by trade name, trademark, manufacturer, or otherwise does not necessarily constitute or imply its endorsement, recommendation, or favoring by the United States Government or any agency thereof. The views and opinions of authors expressed herein do not necessarily state or reflect those of the United States Government or any agency thereof. 


\section{DISCLAIMER}

Portions of this document may be illegible in electronic image products. Images are produced from the best available original document. 


\section{CONTENTS}

Abstract. .........................................

Overview

Life Sciences Division.$\ldots \ldots \ldots \ldots \ldots \ldots \ldots \ldots \ldots \ldots \ldots$

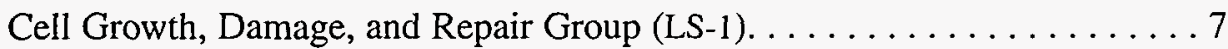

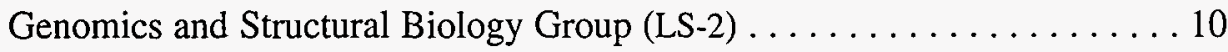

Selected Research Highlights

Identification of a Human Gene Involved in the Immortalization Step

During Carcinogenesis . . . . . . . . . . . . . . . . . 16

Strand-Specific FISH Reveals Long-Range Molecular Order in Tandemly

Repeated DNA Sequences. .................. 18

Intranuclear Localization of Human DNA Repair Protein XPGC/ERCC5 . . . 20

Effects of Amino Acid Substitutions on the Structure, Stability, and

Function of a Protein . . . . . . . . . . . . . . 24

The Effects of Histone Acetylation on the Structure of Reconstituted

Nucleosomes . . . . . . . . . . . . . . . . . 27

Research Projects

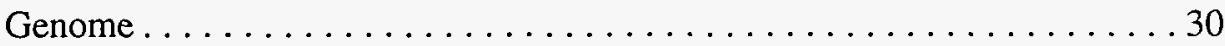

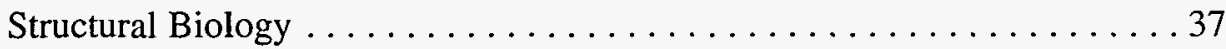

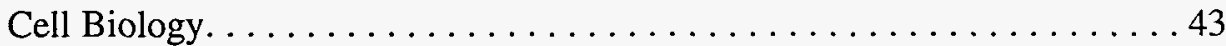

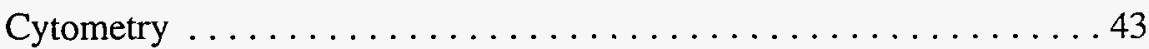

Cell Growth and Differentiation ................. 48

Radiation Biology and Carcinogenesis . . . . . . . . . . . . 55

Pulmonary Biology. ........................ 63

Facilities and Support Services

National Flow Cytometry Resource . . . . . . . . . . . . . 68

High, Medium, and Low Dose-Rate Gamma-Ray Irradiation Facility . . . . 69

Image Microscopy . . . . . . . . . . . . . . . . . . . . 69

Organization

Life Sciences Division Organizational Chart . . . . . . . . . 72

Funding Distribution: Life Sciences Division, FY $1994 \ldots \ldots \ldots \ldots \ldots 72$

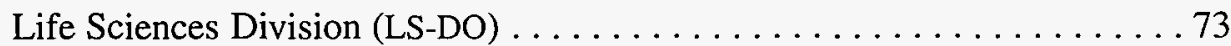

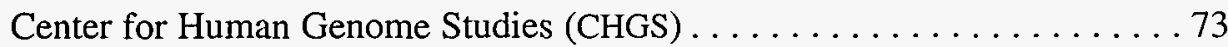

Cell Growth, Damage, and Repair Group (LS-1) . . . . . . . . . . 74

Genomics and Structural Biology Group (LS-2) . . . . . . . . . 75

Communications

Center for Human Genome Studies (CHGS) . . . . . . . . . . 78

Cell Growth, Damage, and Repair Group (LS-1). . . . . . . . . . . 79

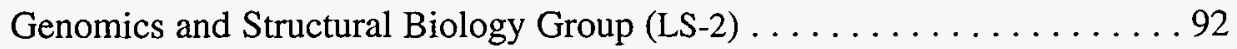




\title{
Life Sciences Division and Center for Human Genome Studies
}

\author{
$1992-1993$
}

\author{
Compiled by \\ Morton Bradbury, Scott Cram, and Carolyn Stafford
}

\begin{abstract}
This report summarizes the research and development activities of the Los Alamos National Laboratory's Life Sciences Division and the biological aspects of the Center for Human Genome Studies for the calendar years 1992 and 1993.

The technical portion of the report is divided into two parts: (1) selected research highlights and (2) research projects and accomplishments. The research highlights provide a more detailed description of a select set of projects. A technical description of all projects is presented in sufficient detail to permit the informed reader to assess their scope and significance. Summaries useful to the casual reader desiring general information have been prepared by the group leaders and appear in each group overview. Investigators on the staff of Life Sciences Division will be pleased to provide further information.
\end{abstract}



orerviow 


\section{LIFE SCIENCES DIVISION}

The mission of the Life Sciences (LS) Division at Los Alamos is to serve the nation's needs in health, energy, and national security by addressing a broad range of biological problems at the molecular, cellular, physiological, and wholeorganism levels. The division develops and uses the most advanced biological technologies and, whenever appropriate, exploits unique resources in the physical sciences found throughout Los Alamos National Laboratory.

Life Sciences Division consists of three technical groups: Cell Growth, Damage, and Repair (LS-1), Genomics and Structural Biology (LS-2), and the Center for Human Genome Studies (CHGS). These three organizations are responsible for approximately 90 projects. Support for the division's projects is largely from the Department of Energy's Office of Health and Environmental Research (OHER). A significant portion is derived from the National Institutes of Health (NIH) and the Department of Defense (DoD). Laboratory Directed Research and Development (LDRD) funds are also used to support new initiatives. Projects funded by all these sources are included in this report because they are integrated into the division's strategic plan and serve to strengthen and complement the core OHER effort.

\section{Energy and Health}

The primary mission of DOE is to ensure the energy needs of the nation. Major sources of energy are from nuclear fission and fossil fuel. Both processes generate by-products that can affect health largely through the induction of carcinogenesis caused by DNA damage. As a consequence of these concerns, a major objective of the Life Sciences Division is to understand the health effects of different radiations and chemicals. The basic biological principles will apply irrespective of whether the radiation and chemicals are artificially produced or are from natural sources. Research projects in the division address the molecular mechanisms of mutagenesis, DNA repair, and regulation of gene expression. Because carcinogenesis is characterized by genetic instability and aberrant cell growth, research projects are further directed toward understanding cell cycle controls, cell metabolism, differentiation, and the processes of tumor growth and tumor rejection. These projects are being directed toward an understanding of and an ability to predict, cancer risk. These projects use the latest technologies of molecular and cellular biology; recombinant DNA technology, tissue culture, DNA sequencing oligonucleotide synthesis, cytogenetic analysis, cell synchronization, flow cytometry (FCM); and pulsed-field electrophoresis and high-performance liquid chromatography. The National Flow Cytometry Resource located in the division provides unique FCM instrumentation for biomedical research programs and chromosome sorting for the Human Genome Project. All efforts are made to keep the FCM instrumentation at the highest level of performance by incorporating advances made in new data acquisition systems, new optical techniques, cutting edge electronics, and computer and programming techniques.

The Human Genome Project is part of a nationwide effort to physically map the 100,000 or so human genes and eventually to sequence human genomes. The project will provide the DNA sequence data base for biomedical research 
concerned with DNA damage from radiation and chemicals and with human susceptibilities to genetic diseases. Major research activities in LS Division are directed to chromosome sorting, to developing human chromosome libraries, and to the physical mapping of chromosome 16 and other chromosomes. In collaboration with CLS Division, a major effort is under way to develop advanced DNA sequencing methods based on single molecular detection. This venture has the potential to revolutionize DNA sequencing methods.

Whereas radiation-induced DNA damage is largely a random hit mechanism, this is not the case for chemically induced DNA damage that is determined in part by the accessibility of the DNA substrate to the chemicals. Thus understanding chemical damage to DNA will require an understanding of the packaging of DNA in chromosomes and changes in chromosome structure through the cell cycle. It is remarkable that although chromosomes have been central to biology since they were first observed almost two centuries ago, surprisingly little is known at the molecular level of their organization, structure, and functions. Such understanding is central to basic questions in biology, e.g., developmental cell biology, as well as to the mission of DOE. Major projects in LS Division are concerned with the organization of chromosomes, particularly the functions of repetitive DNA sequences.

The DNA sequence data base from the Human Genome Project is important for two major problems in structural biology. The first is the DNA organization, structure, and functions of chromosomes at all levels down to the nucleosome. The second is eventually to have the capabilities to go from linear DNA gene coding sequences to three-dimensional protein structures and their functions. The latter will require an enlarged protein sequence-conformation data base. To approach these long-term problems, DOE is developing a structural biology initiative that will utilize the unique facilities in the national laboratories such as high flux neutron and $\mathrm{x}$-ray beams and high-speed computers. It will be necessary to develop in-house capabilities in $\mathrm{x}$-ray scattering and high resolution nuclear magnetic resonance spectroscopy that will complement the high flux neutron and $\mathrm{x}$-ray sources. Because we lack even low resolution solutions to many of the structural questions concerning the folding path and packaging of DNA in chromosomes, imaging techniques with the potential to image hydrated states of nucleoproteins will have to be evaluated. Such techniques are scanning tunneling microscopy (STM) and atomic force microscopy (ATM).

The radiation biology program in the Life Sciences Division focuses on determining the molecular mechanisms of radiation damage in living organisms and the limits and consequences of low levels of radiation exposure. Projects concerning the mutagenicity of low doses of ionizing radiation address the problems of identifying the primary genetic lesions of radiation damage. Projects concerning the effects of radiation on chromatin structure address issues involving the role of protein-DNA interactions in radiation damage. Cytogenetic and flow cytometry studies on chromosomes are used to develop new methods of assessing radiation damage. The mechanisms of radiation damage are also studied at the cellular level using cultured cell models. These programs on low-level radiation effects provide an important data base for the assessment of national concerns about nuclear 
reactor accidents such as those at Three Mile Island and Chernobyl and fulfill the need to understand the consequences of radiation exposure resulting from national defense activities.

The exposure of whole animals to potential toxic substances of the energy industry is being conducted in the division's inhalation toxicology laboratory. Effects of toxic substances on lung cell-cell interactions and lung cell-matrix structures are also being studied in model lung cell cultures to determine the biochemical and cellular targets of these toxicants. Such studies provide a base of knowledge for accurately assessing health issues that might arise in energy industries and provide guidance for designing safe energy production processes. These studies will also provide a base of knowledge for assessing the impact of energy production on the environment.

Other environmental concerns are also addressed by the division's plant stress programs. The reclamation of land disturbed by energy production activities will require understanding of chronic effects of toxicity on vegetation. An example of basic research having spin-off into the problems of environmental cleanup is provided by plant genetics and molecular biology studies of Datura innoxia cells (jimsonweed). This is a model system used to understand molecular mechanisms underlying environmental stress in higher plants. The peptides, poly $(\gamma$-glutamylcysteinyl) glycine from these cells have been shown to bind $\mathrm{Cd}^{2+}$; the structure/ function relationships of this binding process are an integral part of the program. Practical applications that derive from the basic study are the use of resin immobilized peptides to bind $\mathrm{Cd}^{2+}$ and other metal ions and the use of Datura innoxia cells to bind $\mathrm{Ba}^{2+}$ and $\mathrm{Pu}^{4+}$ and remove those ions from laboratory waste. These cells also have the ability to take up 2,4,6 trinitrotoluene (TNT) and other explosive compounds from solution.

\section{National Security}

Life Sciences Division provides the nation with a technological base for several national security programs in the life sciences. The pulmonary toxicology program studies the effects of NOx exposure in animals to determine the mechanism of pulmonary injury by NOx inhalation and to generate a data base to assess health effects on soldiers in the field. These programs use our latest advances in cardiopulmonary physiology and the National Flow Cytometry Resource.

Our genetics program strengthens our national security with its plant genetics projects that use cell culture and recombinant DNA technology to genetically engineer plants for tolerance to arid regions. These projects increase our national security by providing the technological base for developing food production under adverse agricultural conditions and for maintaining American competitiveness in the agricultural sector.

In conclusion, the Life Sciences Division uses its biomedical technology base to support the mission of both the Department of Energy and Los Alamos National Laboratory, which is to conduct basic and applied research of importance to the nation's security, with emphasis on defense science, technology, and energy needs. 


\section{CELL GROWTH, DAMAGE, AND REPAIR GROUP (LS-1)}

The Cell Growth, Damage, and Repair Group (LS-1) is composed of three research sections: cell biology and flow cytometry, molecular and cellular radiobiology, and pulmonary biology/toxicology. The group's programmatic efforts are directed towards a mechanistic understanding of biological processes involved in the regulation of cellular growth and differentiation and how imbalances in these processes mediate the genetic and epigenetic effects of radiation and energyrelated chemical. Ongoing research utilizes sophisticated techniques in cellular genetics and molecular biology coupled with state-of-the-art instrumentation in understanding the complex series of biochemical events associated with the regulation of cellular proliferation and the process of DNA repair in the preservation of genetic information.

A considerable ongoing effort in Group LS-1 is devoted to the development, refinement, and application of laser-based analytical techniques primarily involving flow cytometry (FCM). At the hub of this effort is the NIH-sponsored National Flow Cytometry Resource (NFCR). This program is active in various areas including R\&D, collaborative research, service projects, training, and information dissemination. The NFCR at Los Alamos is currently in its third 5-year renewal period. Four projects constitute its core R\&D. They are (1) development of a flow cytometric method (phase-sensitive FCM) capable of separating fluorescent emission signals based on differences in fluorescence lifetimes; (2) application of new approaches to multivariate cluster analysis in FCM immunophenotyping for various clinical applications, including disease prognosis and therapy; (3) development of a high-speed optical sorting FCM based on a "chromosome inactivation" approach that will permit sorting speeds 50-100 times those currently achievable by commercial sorters; and (4) implementation of high-speed data acquisition, analysis, and sort control systems in upgrading and improving the capabilities of our NFCR instrumentation.

In addition, we have an ongoing effort in the development of a stoppedflow FCM that allows the mixing and delivering of biological samples and the acquisition of a sample within a time frame of a few hundred milliseconds. This design will offer a new approach with which to examine ligand-receptor interactions in living cells, especially in those cases where the binding affinities are so low as to be undetected by conventional methods.

The NFCR provides these advanced flow cytometric capabilities to the biomedical community through research collaborations, consultations, and sabbaticals; training that includes workshops, invited speakers, and visiting scientists; undergraduate, graduate, and postdoctoral fellowship programs; and the cosponsoring, organization, and presentation of an annual flow cytometry course. Information pertaining to various NFCR activities is disseminated quarterly in our newsletter.

The National Laboratory Gene Library Project is also located within Group LS-1. The goals of this DOE-funded project are the construction of various recombinant DNA libraries for each of the human chromosomes and the 
distribution of these libraries to researchers worldwide through a contract with the American Type Culture Collection in Rockville, Maryland. Coupled closely with this project is an ongoing effort that provides a resource for mapping unique DNA sequences (probes) to specific human chromosomes. At the hub of this effort is an image microscopy facility dedicated to the development of improved fluorescent in situ hybridization (FISH) methods and the application of computer-assisted digital imaging microscopy to facilitate the speed and accuracy of the chromosome physical mapping. FISH techniques are effective tools for mapping DNA sequences to their corresponding chromosomal locations. We have recently developed a variation of this technique referred to as Chromosomal Orientation FISH or CO-FISH that is strand specific. It reveals the relative orientation of the targeted sequences on the chromosome and has immediate application to the gene mapping effort and provides a new physical approach for examining altered gene expression. Identification and characterization of unique, chromosome-specific human DNA probes will be invaluable tools in the ongoing physical and genetic mapping efforts of the Human Genome Initiative as well as in genetic disease diagnosis.

Within Group LS-1 we are currently developing a new initiative in cell biology that will focus on mechanisms controlling growth and differentiation. Objectives of this team investigation are the understanding of the biochemical and molecular events and the isolation and characterization of genes controlling cell cycle traverse. Our efforts will focus on the interrelationship of various protein kinases that are responsible for the cascade of biochemical events, including the commitment to DNA replication, which is associated with the regulation of cell cycle traverse. As an example, our previous findings identified a series of staurosporine-sensitive kinase genes that control progression through the $\mathrm{G} 1$ phase of the cell cycle. This drug-induced inhibitory effect was seen in immortalized cells but not in tumorigenic cells. We are attempting to isolate and define those staurosporine-sensitive genes utilizing cDNA libraries constructed from both immortalized and tumorigenic cells.

Chromosome instability resulting in the rearrangement or deletion of critical genes, including those involved in cell cycle control, is suspect in the transformation process leading to neoplasia. We are attempting to identify, isolate, and characterize genes and gene products that directly influence karyotype instability and cellular immortalization. Our model system of choice is human cells expressing the SV40 large T-antigen, a process known to promote chromosome instability. Our recent attention has been focused on a region of the q-arm of human chromosome 6 , which is particularly subject to deletion or translocation by the SV40 T-antigen.

In another study we are developing a model system employing multicellular tumor cell spheroids to elucidate the mechanisms controlling the proliferation of malignant cells in solid tumors. State-of-the-art NMR spectroscopy and imaging techniques are being employed to investigate the regulation of tumor cell metabolism and viability using the in vitro spheroid tumor model system.

The underlying mission of our research programs supported by the DOE's Office of Health and Environmental Research is to provide a fundamental 
understanding of the long-term health and environmental risks associated with energy and national security activities and to develop approaches and methodologies that mediate the response to potentially hazardous agents. For example, a considerable controversy continues in the U.S. regarding public exposure to radon and its decay products (radon progeny). The major uncertainty underlying this conflicting issue is the health effects resulting from low level radon exposure. It is known that chromosome aberrations are radiation-induced genetic damage as well as sensitive indicators of low-level radiation exposure. We are applying the method of premature chromosome condensation to compare radiation-induced chromosome breaks induced by densely ionizing, radon-like alpha particles to those generated by low LET gamma rays. Our model system employs cultured human skin cells that are exposed to alpha particles at doses as low as $1 \mathrm{rad}$. The relevance of this work will be the generation of new, comparative experimental data obtained under conditions mimicking actual human environmental exposures.

Within the group we have an ongoing team research effort that is focused on understanding the interaction of radiation and energy-associated chemicals with DNA and the metabolic processes involved with the recognition, processing, and/or fixation of resultant DNA damage. A major area of interest is the mapping of radiation repair genes in the human genome and the development of molecular/cellular genetic strategies to isolate human DNA repair genes. Ongoing efforts at Los Alamos have been focused on the excision repair gene ERCC5 and the ionizing radiation repair gene XRCC5, which is putatively involved in the reparation of DNA double-strand breaks.

In addition, we are employing a variety of molecular, macromolecular, and cellular approaches in examining the biochemical nature of DNA damage induced by radiation and radiomimetic agents. In a recently initiated project, we are developing an ultrasensitive and rapid DNA repair assay for excision repair capacity. Such an assay will have immediate potential applications in clinical screening of individuals for higher risks of skin cancer, environmental surveillance for UV-mimetic chemical mutagens, and for use in biochemical purification schemes of excision repair enzyme proteins.

Ultimately, our molecular/cellular results must be related to phenomena at the organismal level. We are currently establishing gene-targeted transgenic cellular and animal systems in order to ascertain the biochemical, genetic, and developmental consequences associated with repair gene deficiency.

Our Pulmonary Biology/Toxicology Program consists of research projects funded by both the DOE and the DoD. The general objective of the program is to elucidate the cellular and molecular mechanisms that are involved in providing the lung with defense against inhaled particles, in mediating acute lung injurious responses to environmental insults, and in mediating the development of pulmonary fibrosis induced by the intrapulmonary deposition of profibrogenic particles. Specific areas of focus include (1) investigations of the roles pulmonary macrophages play in the alveolar clearance and retention of deposited particles; (2) the development of mathematical models of macrophage-mediated particle clearance for future application in analyses of lung dosimetry, microdosimetry, 
and risk assessment; (3) investigations of mechanisms that regulate gene expression for and the production of proinflammatory cytokines by subpopulations of lung cells during the development of acute pulmonary edematous responses to environmental insults; (4) the characterization of the cytokine network that occurs between pulmonary macrophages and lung fibroblasts following the deposition of fibrogenic particles; and (5) investigations of how such cellular dialogues regulate the proliferative and profibrogenic activities of the lung's macrophages and fibroblasts in pulmonary fibrogenesis. The Pulmonary Biology/Toxicology Program is an extensive user of the National Flow Cytometry Resource. The program maintains a state-of-the-art Small Animal Exposure, Cardiopulmonary Function and Exercise Facility, and it is responsible for partial support of an Electron Microscopy/Image Analysis Facility within the Life Sciences Division.

At the time of this writing, Group LS- 1 is composed of 23 staff members (nineteen of whom have $\mathrm{Ph} . \mathrm{D}$. degrees in the biological sciences, physics, or a related field and are principal investigators with technical responsibility for one or more research projects), 18 technicians, and 12 postdoctoral fellows. In addition, we currently employ 19 LANL-sponsored Graduate Research Associates (GRAs), seven of whom are actively enrolled in a M.S. or Ph.D. degree program through a cooperative arrangement with the University of New Mexico's School of Medicine. We also have several students with appointments in the LANL-sponsored University Cooperative Program, which provides limited-term laboratory work experiences for third- and fourth-year college undergraduate students. Finally, we also provide short-term, research employment opportunities for undergraduate students in the LANL-sponsored Undergraduate Student Program (UGS). Yearly, we employ between 15 and 20 highly qualified students, who participate in ongoing research projects during their summer break.

\section{GENOMICS AND STRUCTURAL BIOLOGY GROUP (LS-2)}

The Genomics and Structural Biology Group (LS-2) conducts basic research programs in two major areas-genomics and structural biology. In the genomics research programs, studies are conducted to understand the organization, replication, and regulation of complex genomes with an emphasis on the human genome. In the structural biology research programs, advanced biophysical techniques are employed to study the structure, function, and interactions of biological macromolecules. The genomics and structural biology programs are highly interactive. For example, one result of the Human Genome Project is a continually increasing data base of DNA sequence data, which is important for two of the major problems in structural biology. The first problem is that of understanding the organization and structure of DNA at all levels of organization, from chromosomes down to the nucleosome. The second problem is the protein folding problem, in which three-dimensional protein structures, and eventually their function, can be predicted from the linear DNA gene coding sequences. Both genomics and structural biology are major programmatic areas in the research program of the DOE's Office of Health and Environmental Research. 
The goal of all of our genomics research programs is to understand the organization, structure, and function of complex genomes. Accordingly, these efforts focus on gaining fundamental knowledge concerning the evolution of DNA as a self-replicating, information-encoding molecule; on elucidating the mechanisms underlying the regulation of gene expression; and on understanding the responses of complex genomes to environmental insults. Addressing these problems requires the development and implementation of state-of-the-art capabilities in molecular biology, cell biology, biochemistry, genetics, and recombinant DNA technology as well as computerized approaches to data acquisition, analysis, management, and communication. These research efforts address the DOE's mission to understand the molecular basis for heritable biological effects of materials related to energy production and are multidisciplinary and highly interactive within the Laboratory. The genomics programs interact closely with the Los Alamos Center for Human Genome Studies as well as collaborators in Group LS-1, Theoretical Division, Engineering Sciences and Applications Division, Computing, Information, and Communications Division, and Chemical Science and Technology Division.

The genomics research activities cover two main areas. First are studies of the organization, replication, and regulation of complex genomes. These studies focus on the identification, isolation, and understanding of specific DNA sequences or features that are involved in modulating chromosome structure and/or the regulation of differential gene expression. In this area, the identification, cloning, and characterization of several human telomeres have provided the basic tools for exploring the structural and functional behavior of this region of the vertebrate genome. Our efforts in the National Laboratory Gene Library Project concentrate on the construction of recombinant DNA libraries from individual human chromosomes isolated by fluorescence activated flow sorting. Of particular interest to us is the development and application of large DNA fragment cloning methodology such as yeast artificial chromosomes (YACs). One of the goals of the Human Genome Project at Los Alamos is to develop technology for genomic physical mapping and to construct a physical map of chromosome 16 , as well as collaborative evaluation of physical mapping of other human chromosomes using new mapping technology. In this initiative, phage, cosmid, and YAC cloning vectors are being employed to produce an ordered set of overlapping DNA fragments that will encompass the chromosome. Partial sequencing of the ends of selected DNA fragments is providing information on potential sequence tagged sites (STSs).

The second area of genomics research focuses on the regulation of gene expression. While previous studies have investigated both model mammalian and plant cell systems, our current experiments are focused on the genetic systems responsible for the induction of resistance or tolerance of plant cells to heavy metals. These studies are elucidating the biochemical details of the mechanisms by which plant cells protect themselves against heavy metal toxicity and investigating the regulation of the expression of the putative metallothionein gene in response to metal ions. As a result of these studies, environmental applications of metal ion binding to plant cells and metabolism of organic compounds by plant cells are being pursued. 
The common goal of our structural biology programs is to understand the structure, function, and interactions of biological macromolecules. Some of the advanced biophysical techniques employed in these studies are small-angle neutron scattering, small-angle $x$-ray scattering, Fourier transform infrared spectroscopy, circular dichroism, scanning tunneling microscopy, and atomic force microscopy. One general area of interest in our structural biology programs is that of DNA structure at its various levels of organization, from chromosomes to nucleosomes. The second general area of interest is that of protein structure and structural descriptions of protein-protein interactions and protein-DNA interactions. This knowledge of the structure of DNA-protein complexes should provide us with a deeper understanding of the molecular mechanisms by which chemicals react with DNA in cells.

Small-angle neutron scattering and small-angle $\mathrm{x}$-ray scattering measurements provide low resolution information concerning the shapes of biological macromolecules in solution. Our neutron scattering experiments are conducted at the Manuel Lujan, Jr. Neutron Scattering Center at Los Alamos (LANSCE), a high-flux, pulsed-neutron source. Proteins and DNA have intrinsic differences in their neutron scattering densities. As a result, their scattering density can be matched to the scattering density of the solvent using different $\mathrm{H}_{2} \mathrm{O}: \mathrm{D}_{2} \mathrm{O}$ ratios, and thus do not contribute to the neutron scattering pattern. In this technique of contrast variation with neutron scattering, variation of the $\mathrm{H}_{2} \mathrm{O}-\mathrm{D}_{2} \mathrm{O}$ solvent composition in a solution of a DNA-protein complex allows one to observe independently the scattering from the DNA component, the protein component, and the DNA-protein complex itself. This technique has proven quite valuable in studies on nucleosomes, which are continuing. In the case of protein-protein complexes, deuteration of one of the proteins is necessary to employ the contrast variation technique in neutron scattering experiments.

High resolution information about biological macromolecules can be obtained by other techniques, such as x-ray diffraction and scanning probe microscopy. We acquired $\mathrm{x}$-ray crystallography instrumentation that is now operational within the next year. The scanning probe microscopy techniques of scanning tunneling microscopy, which probes for changes in surface conductivity, and scanning force microscopy, which probes forces between the scanning stylus and the surface, are being investigated for the imaging of biological macromolecules. Because these techniques are subject to sample preparation artifacts, the current focus of this program is on the development of well-defined, reproducible methods for the binding of nucleic acids to surfaces.

There are additional areas of research in the group that are related to our core structural biology program. One area of interest is understanding the modifications that occur to nuclear proteins as a result of exposure to chemical insults or ionizing radiation and how these modifications affect chromatin structure. These studies employ both high performance liquid chromatography (HPLC) and high performance capillary electrophoresis (HPCE) for the analysis of histones and high mobility group nuclear proteins. These same analytical techniques are also applied to studies to identify protein changes associated with chromosome instability and 
studies to describe the changes in proteins found in the lung following exposure to insults. A second area of interest is the chelation of actinide elements by extracellular chelating materials produced by soil microorganisms, which may contribute significantly to their environmental mobility. The chelation of $\mathrm{Pu}+4$ by an iron complexing siderophore is being studied to address this question. Additional studies are being conducted to determine the structure of the siderophore, which was isolated near the proposed Yucca Mountain nuclear waste repository site. 
$\circ$

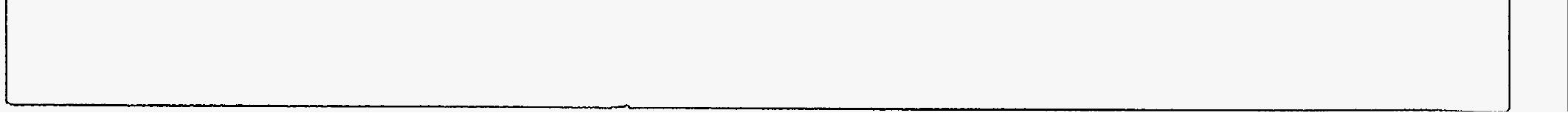




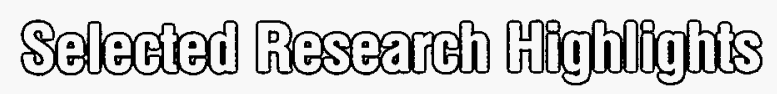




\section{Identification of a Human Gene Involved in the Immortalization Step During Carcinogenesis (DOE)}

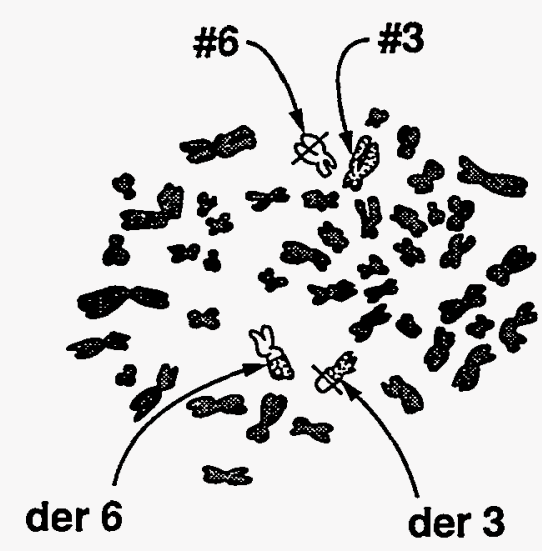

A
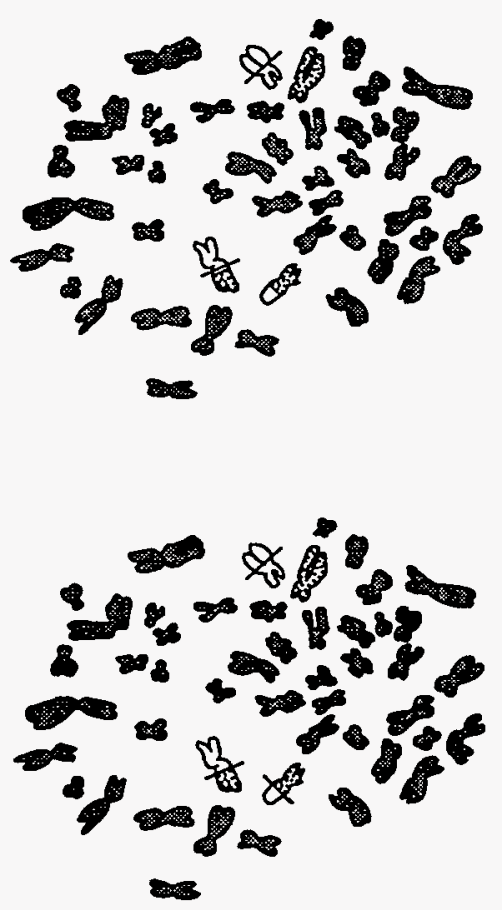

Fig. 1. Breakpoint analysis method using CEPH mega YAC clones. A: Metaphase spread painted with \#3 (speckled) and "\#6 (white) FISH probes and depicting normal and derivative chromosomes; slashes indicate the localization of a YAC probe below the breakpoint. $B$ : Same as $A$ except the YAC probe localizes signal above the breakpoint. C: Same as Z except the YAC probe localizes at the breakpoint and yields signal on both derivative chromosomes.

\section{Paul M. Kraemer, F. Andrew Ray, and Mary Jo Waltman}

Normal somatic cells have a limited proliferative life-span; for instance, human fibroblasts undergo genetically programmed cellular senescence within approximately fifty population doublings. The cellular senescence program is a limiting factor in neoplastic progression because the latter is a multi-step process involving multiple de facto recloning events separated in time by clonal expansion of selected cellular variants. Thus, while cancer involves genetic changes in many "oncogenes," the genetic changes that abrogate cellular senescence are of critical importance to the process as a whole.

The human fibroblast-large $T$ antigen model of carcinogenesis has special features that permit it to be exploited for investigations of the immortalization step (Ref. 1). Human fibroblasts transfected with the large $\mathrm{T}$ antigen are not directly immortalized; rather they show an extended life span but then enter "crisis," and with rare exceptions, all the cells die without being blocked in G1 as they would be if they had become senescent. The rare cells that survive this

B process can be expanded and can be shown to be serially clonogenic, that is, immortal and capable of passage as permanent cell lines. We now have a large set of independently immortalized cell populations, cryopreserved as "newly immortalized" cells (Ref. 2). These cells require further genetic changes before they become transformed or tumorigenic (Ref. 3); thus, they constitute appropriate experimental material for focused investigations on the abrogation of cellular senescence. Scott Peterson has recently made the interesting observation that even at this early stage, newly immortalized cells do not form normal quarternary complexes of the cyclin-dependent kinases. These complexes are thought to be important in normal cell cycle control (Ref. 4).

We have completed detailed cytogenetic analyses of these newly immortalized cell populations. These analyses included a combination of $\mathrm{G}$ banded karyotyping, fluorescence in situ hybridization with whole chromosome painting probes and (in collaboration with Harvey Ozer) molecular analyses for losses of heterozygosity. Eleven independently -immortalized cell populations were studied and several clonal cytogenetic changes were commonly found. The most common findings were deletions and other lesions involving the 
long arm of chromosome \#6. Microscopically visible changes of eight of these cell populations are listed in Table I. The commonly found deletions and losses of heterozygosity implicated large portions of the long arm of one \#6 chromosome, while the other allele generally appeared normal. Hence, these instances would not be useful for gene localization and isolation. However, three cases were found in which the inactivation of the putative gene at $6 \mathrm{q} 21$ apparently occurred by breakage and translocation of the locus to two or more derivative chromosomes. Our plan is to exploit these cases by isolating and characterizing these breakpoints.

For this purpose we have (with the collaboration of Genome Center personnel) used a PCR method to isolate clones from the "CEPH" mega YAC library. The PCR primers were designed using the Human Genome Data Base to define 278 bp of a collagen (alpha 1, type X) gene that has been mapped to the human $6 \mathrm{q} 21$ locus. Two YAC clones were isolated by this means and are serving as the entry level probes for isolating the breakpoints.

The method being used is illustrated in Fig. 1, using the CT10-10 NI cells with the 3;6 translocation diagrammed (and illustrated on the cover after FISH staining with \#6 orange and \#3 green painting probes). After mapping the entry YAC probe on the marker chromosomes, walking techniques will be used to isolate a YAC clone that spans the breakpoint, that is, that gives a signal at the breakpoint on both marker chromosomes. Such a YAC clone will then be used to isolate \#6 cosmid clones that form the smallest contig that also spans the breakpoint. The molecular characterization of the region will then be done with this cosmid contig.

\section{References}

1. F. A. Ray and P. M. Kraemer, "Iterative Chromosome Mutation and Selection as a Mechanism of Complete Transformation of Human Fibroblasts by SV40 Large T Antigen," Carcinogenesis 14, 1511-1516 (1993).

2. F. A. Ray and P. M. Kraemer, "Frequent Deletions in Nine Newly Immortal Human Cell Lines," Cancer Genet. and Cytogenet. 59, 39-44 (1992).

3. P. M. Kraemer and E. M. Bradbury, "Abrogation of a Kinase Mediated G1 Cell Arrest Point Is a Late Event in the Neoplastic Progression of Human Fibroblasts Transfected with the SV40 Large T Antigen Gene," Exp. Cell Research 207, 206-210 (1993) .

4. Y. Xiong, H. Zhang, and D. Beach. "Subunit Rearrangement of the Cyclin-Dependent Kinases Is Associated with Cellular Transformation," Genes and Develop. 7, 1572-1583 (1993).
TABLE I. Possible Inactivating Lesions of the 6q21 Region of Independently

Cell Population Lesion

CT 10-2 NI del(6)(q21)

CT 10-2A NI del(6)(q21)

CT 10-2C NI del(6)(q21)

to-10 NI

E 8 NI $\quad \frac{t(1 ; 6)}{\operatorname{del(6)(q21)~}}$

E 10 NI $\stackrel{t(15 ; 6)}{\underline{\underline{(e t(6)(q 21}}}$

E 17 NI del(6)(q21)

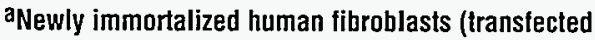
$40 \mathrm{~T}$ antigen constructs) almost always often deletions were observed, but in a few instances (indicated with double underline), translocations involving a 6q21 breakpoint allow us to attempt isolation of a human gene involved in immortalization. 


\section{Strand-Specific FISH Reveals Long-Range Molecular Order in Tandemly Repeated DNA Sequences (DOE, LANL)}

Edwin H. Goodwin, Julianne Meyne, Susan M. Bailey, Rachel Tennyson, Loanne Biddison, and Robert K. Moyzis

At mitosis, the genetic material of human cells can be visualized by light microscopy techniques. The 6 billion nucleotide base pairs that compose the human genome are seen to be distributed among 46 condensed chromosomes. It is widely accepted that each sister chromatid of a mitotic chromosome contains a single continuous DNA double helix varying from tens to hundreds of megabases in length. Thus, the genes and other functional units of a chromosome are arranged linearly from telomere to telomere. Fortunately, the chromosome condensation process is such that it largely maintains a correspondence between the order of specific sequences on the DNA molecule and the physical location of these sequences along the length of a condensed chromosome. This correspondence is the basis of efforts to map specific DNA 'sequences to their respective chromosomal locations by fluorescence in situ hybridization (FISH).

FISH relies on nucleotide base pairing through hydrogen bonding between a labeled probe and a complementary chromosomal target sequence. During hybridization, base pairing is established between homologous probe and target sequences. Fluorescent reagents having affinity to labeled probes allow detection by light microscopy. A conspicuous limitation of the standard FISH procedure is its inability to determine the 5'-to-3' direction of any single-stranded DNA sequence (for example, the sense strand of a gene) with respect to chromosomal reference points, such as telomeres or the centromere. This limitation has been removed by a technique invented within the Life Sciences Division at LANL.

The process begins with cultivating normal human skin fibroblasts in medium containing bromodeoxyuridine (BrdU) for a single round of DNA replication. During semiconservative DNA synthesis, BrdU partially replaces thymidine in the newly replicated DNA strands. Every replicated chromosome is now composed of sister chromatids that are singly substituted with BrdU in opposite strands of the DNA molecule. Cell cycle progression is blocked in mitosis with Colcemid, a microtubule inhibitor. Cells are harvested and fixed, and microscope slides are prepared by standard cytological procedures.

After staining with the fluorescent DNA-binding dye Hoechst 33258 , cells are exposed to long-wave ultraviolet light. UV exposure induces nicks in the BrdU-substituted DNA strand. Nicked DNA serves as a substrate for exonuclease III (Exo III), an enzyme that excises nucleotides from one strand of double-stranded DNA. Following UV exposure, Exo III digestion removes nucleotides from the BrdU-substituted DNA strand of each chromosome. Complementary single-stranded regions are created on sister chromatids.

Single-stranded nucleic acid probes can now be hybridized without thermal denaturation. For a single copy sequence, the expected result is a hybridization signal on one chromatid only; base pairing cannot occur with the complementary 
sequence on the sister chromatid. Hybridization is "strand-specific" in the sense that the target sequence resides on one strand of the double helix. When a probe is hybridized to a multiple-copy target, such as a tandemly repeated satellite DNA sequence, a signal will appear on one chromatid only if the repeats have a head-totail arrangement on the chromosome. In contrast, if the repeats exist in a mixed orientation, a signal will appear across both chromatids. The procedure was named Chromosomal Orientation FISH (CO-FISH) since it reveals the relative orientation of target sequences on the same chromosome (Ref. 1). This information is not obtainable with standard FISH.

In a visually appealing variation of the CO-FISH method, two complementary, single-stranded probes having homology to the same chromosomal sequence are synthesized but differentially labeled for two-color fluorescence. In this version of CO-FISH, hybridization to a head-to-tail tandem array leads to partitioning of colors between sister chromatids. To obtain the complementary synthetic oligomers with homology to two repetitive DNA sequences on chromosome 1 were constructed for use as probes. One pair of probes hybridized to centromeric heterochromatin and the other, to a repetitive sequence near the telomere of the short arm in the 1 p36 band. One probe of each pair was labeled with biotinylated dUTP while the complementary probe was labeled with digoxigenin. Detection reagents were avidin/FITC, which binds to biotin and fluoresces yellow (or green), and anti-digoxigenin-antibody/Texas red, which binds to digoxigenin and fluoresces red. DAPI (4,6-diamidino-2-phenylindole), a blue-fluorescing DNA-binding dye, served as a counterstain to image whole chromosomes.

We have used one- and two-color CO-FISH to investigate numerous repetitive satellite DNA sequences. By far the predominant hybridization pattern of tandem repeats is consistent with a head-to-tail orientation. In contrast, the dispersed repeats (such as Alu) show no preferential orientation, at least at the level of light microscopy. These observations place constraints on mechanisms proposed to explain the origin of repetitive DNA sequences.

CO-FISH reveals the relative orientation of chromosomal target sequences, but not their absolute 5'-to-3' direction. This limitation can be removed by simultaneously hybridizing a probe to a target sequence with known direction. A telomeric probe is ideal for this purpose since telomeres are known to consist of head-to-tail TTAGGG repeats having a 5'-to-3' vector directed towards the end of the chromosome. Where the goal is to determine the absolute direction of target sequences, a modified acronym has been chosen, Chromosomal Orientation and Direction FISH (COD-FISH). With its ability to determine both chromosomal location and direction, COD-FISH should facilitate genomic mapping.

\section{Reference}

I. E. H. Goodwin and J. Meyne, "Strand-Specific FISH Reveals Orientation of Chromosome 18 Alphoid DNA," Cytogenet. and Cell Genet. 63, 126-127 (1993). 


\title{
Intranuclear Localization of Human DNA Repair Protein XPGC/ERCC5 (DOE)
}

\author{
Min S. Park, Robert J. Sebring, Jeffrey A. Knauf, Gary F. Strniste, and
} Mark A. MacInnes

\section{Introduction}

The nucleotide excision repair pathway is a major DNA repair system in human cells. This pathway removes a wide range of DNA lesions, including UVinduced photo-products and bulky chemical adducts. Defects in the excision repair system may have serious consequences for the organism, such as the human cancer prone syndrome xeroderma pigmentosum (XP). This disorder is a recessive, hereditary disease in which most patients have a defect in the early steps of the excision repair pathway. We recently cloned the XPGC/ERCC5 gene on the basis of its ability to correct the excision-repair defect in CHO UV135 cells (Ref. 1). Subsequently, it was discovered that the ERCC5 gene complemented the excision repair defect in XP-G cells. The XPGC/ERCC5 protein has extensive sequence similarities, in bipartite domains $A$ and $B$, to products of the $R A D$ repair genes of two yeasts, Saccharomyces cerevisiae RAD2 and Schizosaccharomyces pombe Rad13 (Ref. 2) (Fig. 1). Sequence, structural, and functional data taken together indicate that XPGC/ERCC5 and its relatives are probably functional homologs. Recently, it was found that RAD2 protein is a single strand-specific endonuclease and is absolutely required for the incision step of the excision repair process (Ref. 3). This indicates that the XPGC/ERCC5 is a catalytic component that incises the

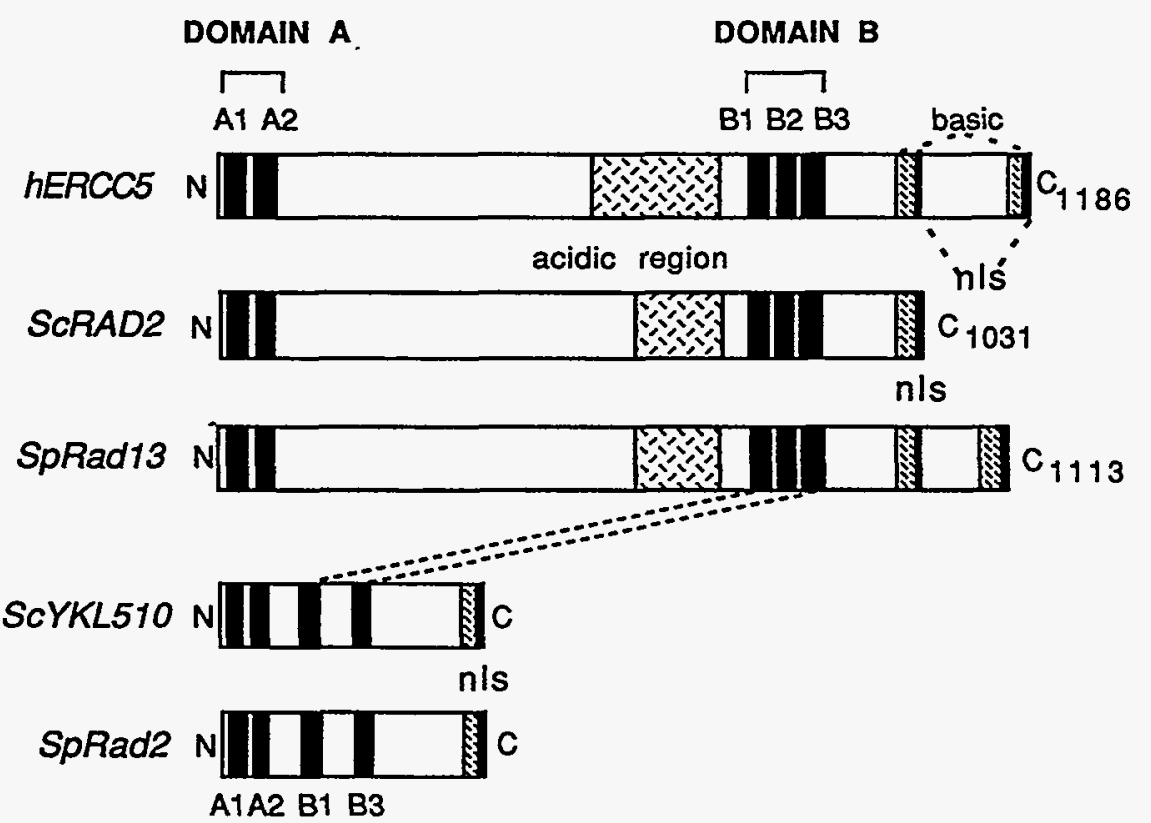

Fig. 1. Structural similarities between XPGC/ERCC5 protein and several yeast DNA repair proteins. A diagram of XPGC/ERCC5 protein is compared with structures for SCRAD2, ScYKL510, SpRad13 and SpRad2 genes. Two segments in XPGC/ERCC5 and its relatives are enriched in basic amino acids (stippled). The central region of three deduced proteins are acidic (cross hatched). Conserved segments within the $A$ and $B$ domains are indicated by vertical solid bars. Putative nuclear location signals are indicated (NLS) and at the $C$-terminus of all five deduced proteins. 
damaged DNA strand during excision repair. As a part of our effort to understand the molecular basis for complex pathophysiological symptoms of XP-G patients defective in excision repair, we identified XPGC/ERCC5 protein in human cells by immunoassays and found that XPGC/ERCC5 is localized as speckles in the nucleus by associating with intranuclear structures, quite possibly the nuclear matrix.

\section{Current progress}

- Identification of XPGC/ERCC5 protein in nuclear extracts from human cells: A polyclonal antibody specific to XPGC/ERCC5 protein recognized a protein in the nuclear extracts of the TK- 6 human lymphoblastoid cell lines. The XPGC/ERCC5 protein ( $120 \mathrm{kDa})$ migrates faster than the predicted size (136 $\mathrm{kDa}$ ) under denaturing conditions. A protein with an expected size of $250 \mathrm{kDa}$ was also recognized by the antibody on the native electrophoretic gel. This indicates that XPGC/ERCC5 can form homodimeric structures. Conceivably, such homodimerization may also occur in the in vivo condition as well, inasmuch as biochemical and structural lines of evidence obtained in our laboratory indicate homodimerization could be driven by the helix-loop-helix motif of the XPGC/ERCC5 protein.

- In situ localization of XPGC/ERCC5 protein in human cells: The monospecific nature of the above antibody prompted us to study the intracellular localization of the XPGC/ERCC5 protein by indirect immunofluorescence microscopy. The XPGC/ERCC5 protein localizes predominantly in the nucleus as speckles, with the number of nuclear speckles ranging from 15 to 100 . Our further analyses with slides prepared by various fixation/permeabilization procedures did not affect the pattern of distribution of labeling for the XPGC/ ERCC5 protein. These results suggest a possible association of XPGC/ERCC5 protein with the nuclear substructure termed the nuclear matrix, e.g., interchromatin granules and perichromatin fibrils.

- Confocal laser scanning of XPGC/ERCC5 protein in the nucleus: The unusual distribution and stable immunostaining characteristics of XPGC/ERCC5 protein led us to further examine the geometric distribution of XPGC/ERCC5 protein in the nucleus. Laser confocal laser dissection $(0.7 \mathrm{~mm}$ increment $)$ of the nucleus proved that XPGC/ERCC5 is present throughout the entire nucleus (Fig. 2).

- Localization of XPGC/ERCC5 by biochemical fractionation of nuclear components: In order to further characterize the intranuclear location of XPGC/ ERCC5, nuclear components were fractionated by extractions procedures using various concentrations of salt. The dissociation of the XPGC/ERCC5 protein from intranuclear structures was found to begin at a salt concentration of $0.5 \mathrm{M} \mathrm{NaCl}$, with complete removal occurring at $2 \mathrm{M} \mathrm{NaCl}$. These results lend support to the possibility that the XPGC/ERCC5 protein binds with constituents of the nuclear matrix. These findings also suggest that the protein may not become a permanent component of the matrix per se in that the binding of the XPGC/ERCC5 to the nuclear skeleton appears to be a reversible process. 


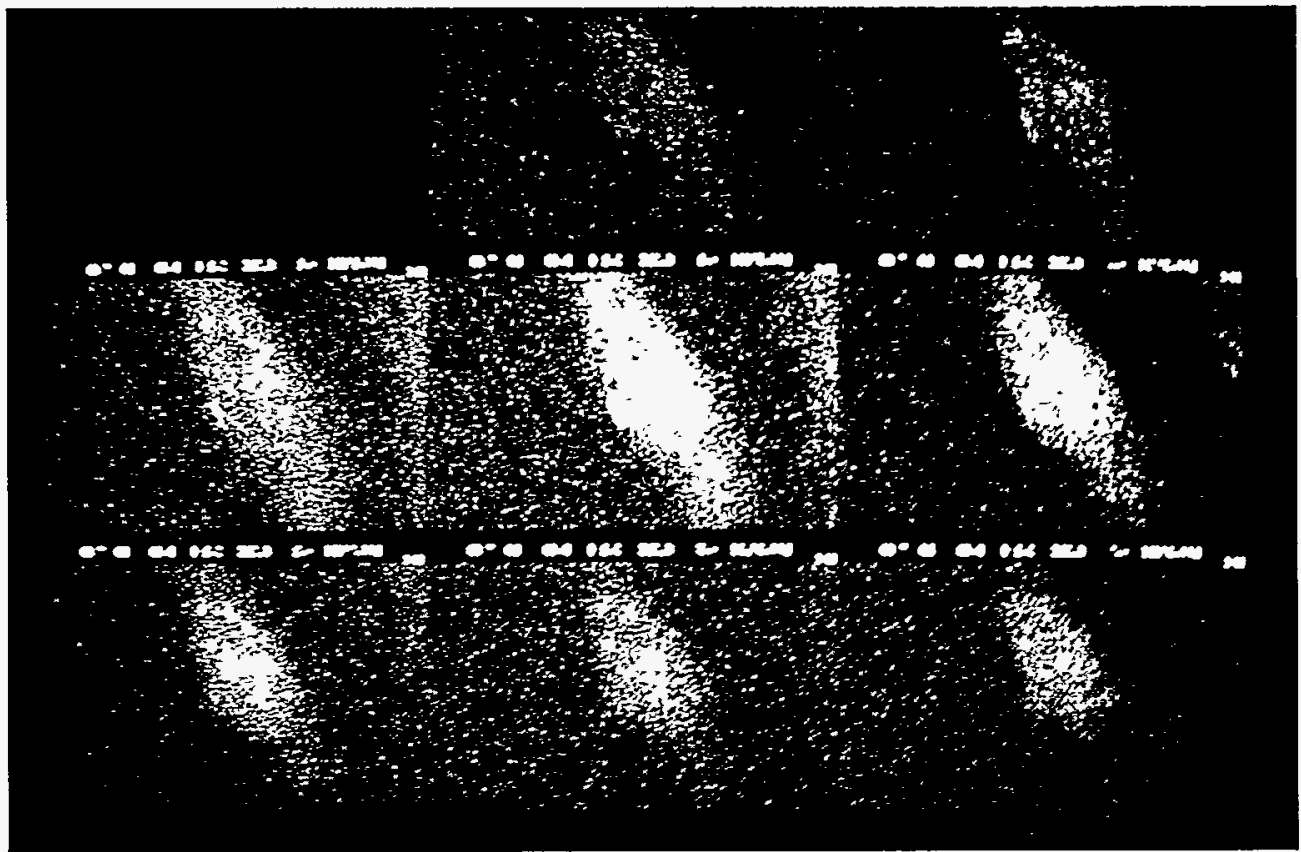

Fig. 2. Confocal laser scanning microscopic images of XPGC/ERCC5 protein in the nucleus. Human fibroblast cells were fixed and permeabilized in ethanol and acetone at $-20^{\circ} \mathrm{C}$. Cells were stained with a polyclonal antibody specific to XPGC/ERCC5 and the FITC conjugated goat anti-rabbit IgG. For confocal microscopic analysis, 8 optical sections at 0.7 um increments were obtained using a Zeiss confocal laser scanning microscope (LSM-10) equipped with a x100, 1.3-n.a. objective lens, and an argon ion laser (488 nm). Results suggest that XPGC/ERCC5 protein is present throughout the entire plane of the nucleus.

\section{Discussion}

The apparent association of DNA repair protein XPGC/ERCC5 with the nuclear matrix has led us to hypothesize that such interactions may be involved in the preferential repair of transcriptionally active region of the genome. Substantial progress has been made over the past two decades in understanding the basic structure of the nucleus and its involvement in specific nuclear processes, e.g., transcription and replication (reviewed in Ref. 4). Morphologically, the nuclear matrix in animal cells is composed of a lamina, residual nucleoli, and an interconnecting network that biochemically consists of a limited number of non-histone proteins. Several lines of evidence indicate that DNA is arranged in highly supercoiled domains or loops, and that the repeating loops are constrained by attachments of DNA to the nuclear matrix.

Currently, information concerning the possible roles of nuclear matrix in DNA repair is scant, and no studies have been reported that describe the spatial distribution of any particular DNA repair protein in the nucleus. Thus, this is the first study that indicates a direct association of DNA repair protein with one or more nuclear matrix constituents. Transcriptionally active DNA is also found in close association with the nuclear matrix (Ref. 5). In that chromatin containing transcriptionally active genes are more susceptible to digestion by DNAase $\mathrm{I}$, it is reasonable to suggest that this DNA is more accessible for DNA repair enzymes as well. Consistent with this postulate, cyclobutane pyrimidine dimers (CPDs) 
induced in the DNA of rodent cells by ultraviolet light (UV) have been reported to be removed more efficiently from transcriptionally active genes than from inactive regions of the genome (Ref. 6). If the damaged sites in the transcriptionally active genes are more immediately detrimental to cells than those at transcriptionally inactive sites, a nuclear matrix-mediated, localized distribution of DNA repair enzymes, e.g., XPGC/ERCC5 protein, may be a previously unrecognized controlling mechanism for preferential repair.

\section{References}

1. J. S. Mudgett and M. A. MacInnes, Genomics 8, 623-633 (1990).

2. M. A. MacInnes, Mol. Cell. Biol. 13, 6393-6402 (1993).

3. Y. Habaraken, Nature 366, 365-368 (1993).

4. M. Rosbash and R. H. Singer, Cell. 75, 399-401 (1993).

5. J. Bode and K. Maass, Biochemistry 27, 4706-4711 (1988).

6. V. A. Bohr et al., Cell. 40, 359-369 (1985). 


\title{
Effects of Amino Acid Substitutions on the Structure, Stability, and Function of a Protein
} (LANL)

\author{
T. C. Terwilliger
}

\section{Importance of understanding protein stability and structure}

Recently it has become clear that altered versions of natural protein molecules have enormous potential for catalysis of chemical reactions and for highly specific recognition of target molecules. This potential is certain to be important in a wide variety of applications ranging from detoxification of environmental pollutants to cancer prevention and therapy to synthesis of organic compounds. To realize this potential, however, it will be necessary to increase our understanding of the fundamental properties of protein molecules. It has been known for some time that the amino acid sequences of polypeptide chains determine the folding of the corresponding proteins as well as most of their functional properties. Nevertheless, the interactions that stabilize and determine the structures of proteins, as well as the interactions between proteins and other macromolecules, are only roughly understood.

\section{Gene 5 protein as a model system for studying protein stability and structure}

Our research group has made a major effort over the past few years to develop the tools necessary to use the gene 5 protein as a model system for studying protein stability and structure. This involved constructing an expression system including a synthetic gene (Refs. 1,2), devising several procedures for genetic selection based on the activities of the gene 5 protein (Ref. 3 ), characterizing the unfolding and refolding of the gene 5 protein in vitro (Ref. 4), developing techniques for estimating the stabilities of gene 5 proteins with amino acid substitutions (Refs. 4, 5), and most recently, determining the structure of the gene 5 protein at a resolution of $1.8 \AA$ (Ref. 6). As the gene 5 protein is small and wellcharacterized, its structure known, mutants easily constructed, and assays developed for measuring stabilities of mutants, it is a good system for examining the effects of amino acid substitutions on protein stability and structure.

\section{Structural determinations of gene $\mathbf{5}$ protein and mutants of gene $\mathbf{5}$ protein}

One of the key goals of protein design is to rationally alter a protein molecule, tailoring it to bind to a specific molecule such as a drug, another protein, or a nucleic acid. To do this effectively, it will be necessary to develop knowledge of how to engineer a surface, to shape it as desired around the contours of its intended target. This will require not just the adjustment of amino acid side chains on the protein surface, but of the protein backbone that defines this surface.

We are now in a position to examine in a very systematic way how internal amino acid substitutions affect protein structure, because we have isolated and characterized sets of proteins that have each of four different apolar residues with different shapes and sizes at particular internal sites in the gene 5 protein (Fig. 1). We are in the process of determining the structures of these proteins by $\mathrm{x}$-ray crystallographic means, beginning with the structure of the wild-type gene 5 protein that we have recently determined (Ref. 6). 


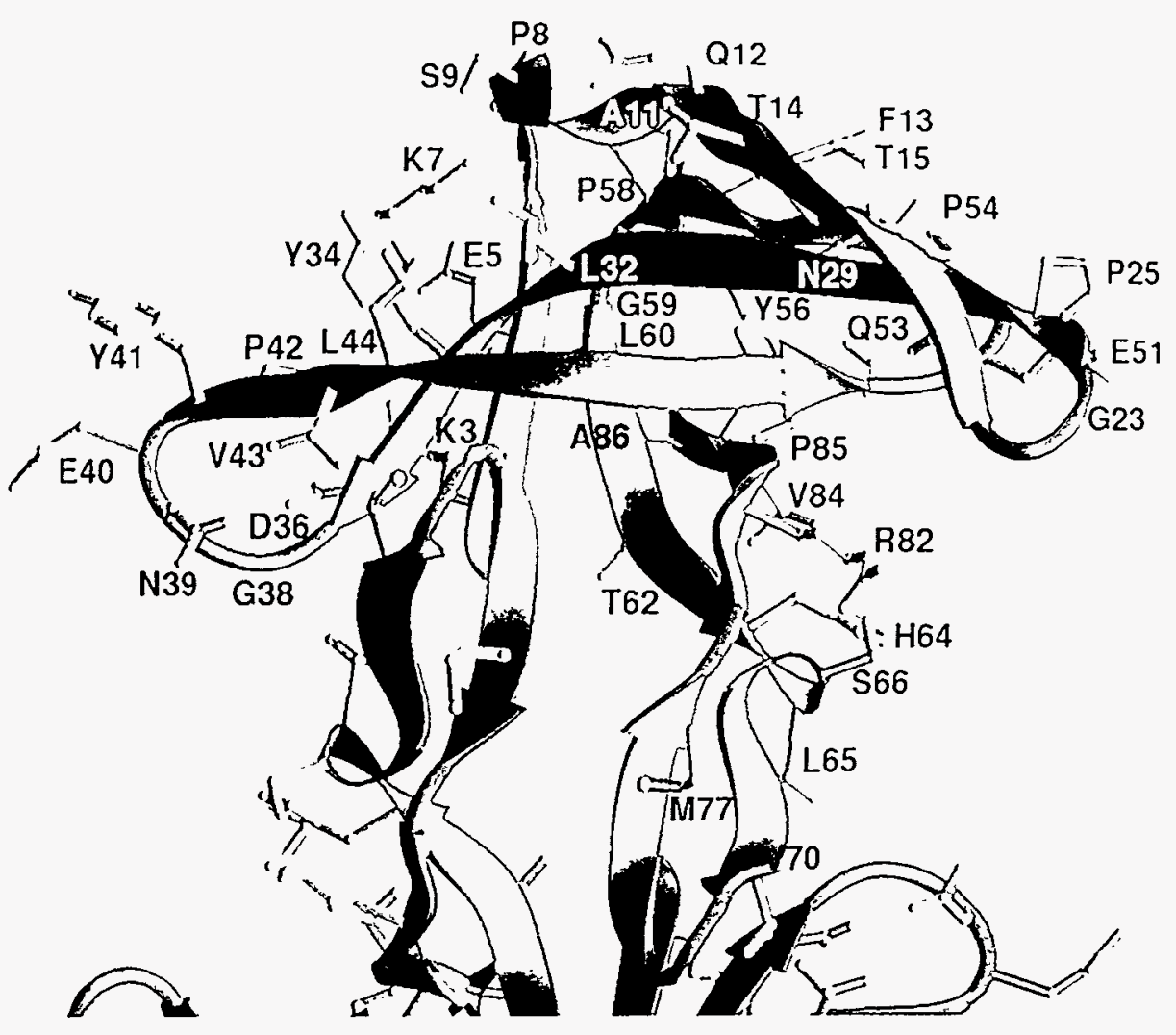

Our principal accomplishment of the past year has been to determine the structure of the wild-type (natural) gene 5 protein. This is very important because having an accurate structure of the wild-type protein is a prerequisite for determining the structures of altered versions of the protein with amino acid substitutions.

The multiwavelength anomalous-dispersion (MAD) technique was ideally suited for determining the gene 5 protein structure, as the wild-type protein contains two methionines (Met-1 and Met-77) that might be substituted in vivo in $E$. coli by selenomethionine. The selenium atoms incorporated into the gene 5 protein in this way could serve both as the anomalously scattering atoms in the MAD experiment and as markers for the positions of the corresponding side chains.

In a collaboration led by our group, we have now determined the gene 5 protein structure using the MAD technique on both the selenomethionine-containing wild-type protein and on a mutant in which isoleucine- 47 was replaced with a methionine (Ref. 6). The gene 5 protein electron density map based on MAD phases and wild-type structure factor amplitudes had an overall figure of merit of 0.63 to $2.5 \AA$. This map was readily interpretable and had clear density for backbone atoms of all of the 87 residues except for residue 1, the loop at positions 21 to 24 , and residues $85-87$. The selenium site A was found to correspond to Met77 , whereas Met-1 (the second selenium site) was disordered. The model was then refined at a resolution of $1.8 \AA$ to a final R-factor of $19.2 \%$.
Fig. 1. Ribbon diagram

of one complete subunit and part of the second subunit of the gene 5 protein, with selected surface amino acid side chains labeled. 
Although Met-1 was disordered in the crystals, Met-77 in the selenomethionine-containing wild-type protein and Met-47 and Met-77 in the mutant protein were well ordered and provided MAD phasing information. These selenium sites were also used to identify the locations of these two side chains in the structure. The gene 5 protein is composed of strands of beta-sheet, and the two subunits of the protein are symmetrically related and closely associated.

Now that we have an accurate structure of the natural gene 5 protein, we are in a good position to determine the structures of mutant versions of the protein. We have already purified sufficient amounts for crystallization of over 30 mutant gene 5 proteins, and intend to continue purification of additional mutants. Our collaborator, Prof. Andrew H.-J. Wang at the University of Illinois, has found that most of the 12 mutant gene 5 proteins that we sent him several years ago have crystallized readily, indicating that the structure determinations of mutants of the gene 5 protein are likely to be successful.

\section{References}

1. T. C. Terwilliger, Gene 69, 317-324 (1988).

2. T. C. Terwilliger, Gene 61, 41-47 (1988).

3. T. C. Terwilliger, W. D. Fulford, and H. B. Zabin, Nucl. Acids Res. 16, 9027-9039 (1988).

4. H. Liang and T. C. Terwilliger, Biochemistry 30, 2772-2782 (1991).

5. W. S. Sandberg, and T. C. Terwilliger, Science 245, 54-57 (1989).

6. M. M. Skinner, H. Zhang, D. H. Leschnitzer, Y. Guan, H. Bellamy, R. M. Sweet, C. W. Gray, R. N. H. Konings, A. H.-J. Wang, and T. C. Terwilliger, to be published in Proc. Natl. Acad. Sci. USA, (1993). 


\title{
The Effects of Histone Acetylation on the Structure of Reconstituted Nucleosomes (LANL)
}

\author{
Brian S. Imai, Joe M. Gatewood, Joseph S. Siino, E. Morton Bradbury, Peter M. Yau,* \\ Susan Krueger;** and Charles Glinka**
}

Histone hyperacetylation has been associated with transcriptional activity and replication, although the exact mechanism of action is unclear. A popular hypothesis is that histone hyperacetylation leads to a destabilization of the nucleosome, which in turn leads to a more open chromatin structure that facilitates transcription and replication. Previous studies on native nucleosome core particles with various mixed levels of acetylation have shown possible subtle effects on the thermal stability, electrophoretic mobility, and hydrodynamic properties of particles with higher levels of acetylation. Neutron scattering studies, however, failed to show a difference in the radius of gyration of particles with high and low levels of acetylation within the error of the measurements. These studies were hampered by the fact that these particles were derived from bulk nucleosomes with nondefined DNA sequences and histone subtypes, as well as a spread of acetylation levels. We set out to circumvent these problems through the use of histone purification and DNA cloning techniques in order to reconstitute a fully defined nucleosome core particle onto a specific 195 b.p. nucleosome positioning DNA sequence.

Large scale tissue culture provided sufficient HeLa cells as starting material for histone isolation and large scale HPLC purification into the various subtypes and individual acetylation states. The DNA was obtained from a cloned nucleosome positioning sequence (kindly provided by Robert Simpson). Fully acetylated and nonacetylated nucleosomes were reconstituted by established protocols, purified, and subjected to neutron (at NIST) and x-ray (at SSRL) solution scattering analysis. The neutron scattering experiments were additionally conducted using the technique of contrast variation, which allows the protein scatter to be separated from the DNA scatter. An attempt was made to fit the measured scatter curves to curves predicted from various models of the nucleosomes. The neutron scattering data analysis is still in progress. The $\mathrm{x}$-ray scattering data best fit models of the nucleosomes that had less DNA wrapped around the fully acetylated nucleosome core, compared with the nonacetylated core (1.75 turns versus 2.33). This result is very exciting since this may indicate the mechanism by which histone acetylation may modulate chromatin structure. The histone tails, which are the sites of acetylation, may actually prefer to interact with DNA that lies beyond the minimum 1.75 turns defining the minimum nucleosome core particle. This may explain why true 146 b.p. nucleosome core particles seem to be largely structurally unaffected by histone acetylation. This analysis is complicated by the fact that the reconstituted particles were actually positioned on more than one position. We have since modified our reconstitution protocol so that there is only one predominant position and intend to repeat these experiments in the coming year.

*University of California-Davis, Davis, California

**National Institute of Standards and Technology, Gaithersburg, Maryland 



\section{Reseaneh Projerters}




\title{
GENOME
}

\section{Human Recombinant DNA Library (DOE)}

\author{
Principal Investigator: L. L. Deaven
}

Co-Investigator: J. L. Longmire

The goals of the National Laboratory Gene Library Project are the construction of recombinant DNA libraries for each of the human chromosomal types and the distribution of these libraries to user groups throughout the world. We have constructed a series of DNA libraries from flow sorted chromosomes. Small insert, complete digest libraries cloned into the EcoRI insertion site of Charon 21A are available from the American Type Culture Collection, Rockville, Maryland. Partial digest libraries cloned into cosmid (sCos1) or phage (Charon 40 ) vectors have been constructed for chromosomes 4, 5, 6, 8, 10,11, 13, 14, 16, 17, 20, and X. Purity estimates by in situ analysis of sorted chromosomes, flow karyotype analysis, and plaque or colony hybridization indicate that most of these libraries are $90-95 \%$ pure. Additional cosmid library constructions, 5-10X arrays of libraries into microtiter plates, and high density membrane arrays of libraries are in progress.

Recently, we have constructed YAC libraries for chromosomes 5, 9, 16, and 21. These libraries are made from complete DNA digests using the rare cutters ClaI, SacII, EagI, or NotI/NheI. The average insert size is $\sim 200 \mathrm{~kb}$, and chimera frequencies are low (1-10\%).

Libraries have also been constructed using M13 or bluescript vectors (chromosomes $5,7,17$ ) to generate STS markers for the selection of chromosomespecific inserts from total genomic YAC libraries.

Because of the advantages of insert size and stability associated with $\mathrm{BAC}$ and PAC cloning systems, we are currently attempting to adapt pBAC108L and pCYPAC1 vectors for use with flow-sorted chromosomal DNA.

\section{Human Genome Physical Mapping (DOE)}

\author{
Principal Investigator: $R . K$. Moyzis \\ Co-Investigators: R. L. Stallings, C. E. Hildebrand, L. L. Deaven, J. H. Jett, \\ N. A. Doggett, and M. K. McCormick
}

The Los Alamos Center for Human Genome Studies will provide coordination, technical oversight, and direction for the following interdisciplinary elements of the Human Genome Program at Los Alamos: physical mapping, new technology development, and informatics. The center will also develop collaborative research and development programs with the private sector and with other centers for human genome research.

The goals of this project are (1) to develop concepts and to advance technology for genomic physical mapping, (2) to construct a contig physical map of human chromosome 16 that will include an ordered set of overlapping DNA fragments and STS markers encompassing the chromosome, and (3) apply novel technology to the construction of physical maps of other chromosomes. Currently, 
collaborations with outside investigators on chromosomes 5,7 , and 21 are in progress. The significance of this work lies in the immediate application of the knowledge (1) to understand human genetic disease; (2) to clarify the molecular bases for genetic disease susceptibility, especially in regard to energy-related chemical or radiation exposures; and (3) to reveal the molecular details underlying long-range chromosome architecture and dynamics.

\title{
Genome Organization and Function (DOE)
}

\author{
Principal Investigator: $R$. K. Moyzis
}

Co-Investigators: J. Meyne, R. L. Ratliff, and D. L. Grady

The ultimate objective of this program is to determine the molecular mechanisms by which higher organisms organize and express their genetic information. Applications of these basic investigations will include the development of novel approaches for (a) the detection of human genetic diseases and (b) measuring the effects of low-level ionizing radiation and/or carcinogen exposure. A combination of biochemical, biophysical, and recombinant DNA techniques are being used to identify, isolate, and determine the roles of DNA sequences involved in long-range genomic order. Currently, major efforts are focused on determining the organization and function of human repetitive DNA sequences. Major findings in the last year included (a) the demonstration that the human telomere sequence (TTAGGG) $)_{\mathfrak{n}}$, identified and isolated by our laboratory, is the vertebrate telomere and (b) the cloning of 100-250 kb human telomere fragments as yeast artificial chromosomes (YACs). Future studies will be directed toward the further definition and isolation of "functional" repetitive DNA regions such as centromeres. Defining the mechanisms responsible for organizing the mammalian genome and the genetic and nonmutational alterations accompanying abnormal phenotypic change is an important aspect of defining the effects of energy related technologies.

Determining the genetic variability in these mechanisms provides a rational basis for establishing thresholds for toxic substances, for making valid cross species extrapolations, and ultimately, identifying individuals at risk.

\section{Directly Labeled Fluorescent DNA Probes for Chromosome Mapping (LANL)}

\author{
Principal Investigator: B. L. Marrone
}

Co-Investigators: S. L. Anzick, C. L. Potter, G. C. Salzman, and L. L. Deaven

This project supports technology development for human chromosome mapping using the methods of fluorescence in situ hybridization (FISH) and digital imaging microscopy. In FISH, a probe made from a DNA sequence is labeled with a fluorescent tag and then bound, or hybridized, to its complementary sequence on normal human metaphase chromosomes spread on a microscope slide. The fluorescence seen by fluorescence microscopy gives the location of the DNA sequence, which is then quantitated by computer analysis of a digitized image of the labeled 
chromosome. The quantitation of probe location is called the fractional length measurement. The goals are (1) to improve methods for labeling DNA sequence probes with fluorescent tags in order to facilitate the speed and accuracy of chromosome physical mapping efforts and (2) to implement and automate procedures for analysis and quantitation of fluorescently labeled DNA probes on chromosomes using computer-assisted digital imaging microscopy.

\section{Plant Stress Tolerance (DOE)}

\section{Principal Investigator: C. R. Kuske}

Higher plants and certain algae are the only eukaryotes to assimilate inorganic sulfur into organic molecules. Sulfur-containing metabolites play critical roles in the plant's ability to withstand stress induced by toxic metals, pathogens, herbivores, and other environmental conditions. Very little is known about the biochemistry, genetics, or molecular regulation of plant sulfur metabolism and responses to stress involving sulfur-containing metabolites. The enzyme $O$ acetylserine sulfhydrylase (OASS) produces L-cysteine from sulfide and $O$ acetylserine and thus is responsible for the final step in sulfur assimilation into organic molecules in plants. This enzyme plays a pivotal role in regulating sulfur uptake and availability of reduced sulfur (cysteine) for various functions in the plant cell. Three isoenzymes of OASS were purified from Datura innoxia plant cells. These isoenzymes have different mass and subunit structure, and each is located in a different subcellular compartment: one each in the cytosol, mitochondria, and chloroplasts. Spectral and kinetic analyses indicate that the three isoenzymes require pyridoxal-5'-phosphate as a co-factor that binds the $O$-acetylserine substrate and have two active sites. The OASS isoenzymes are allosterically regulated, exhibit positive cooperativity with respect to both substrates, and are inhibited by sulfide concentrations above $200 \mu \mathrm{M}$.

It is likely that the three differentially compartmentalized OASS isoenzymes have specific roles in sulfur partitioning in the plant cell and will be differentially regulated. Current investigations are addressing this hypothesis through examination of OASS gene expression, protein synthesis, and enzyme activity in response to cell stress and growth conditions requiring cysteine for different cellular functions. One OASS cDNA has been identified and sequenced. Preliminary data suggests it encodes the cytosolic OASS form. Sequence comparison to other OASS cDNAs will identify sequences involved in organelle targeting and posttranslational transport of OASS proteins into their respective organelles. The genomic OASS sequence has been identified in Southern blot analysis, and we are currently trying to identify this gene in a lambda library. 


\title{
Molecular Biology of Cell Cycle Dependent Genomic Structure (DOE)
}

\author{
Principal Investigator: L. R. Gurley and H. A. Crissman
}

\section{Co-Investigators: J. G. Valdez}

The objective of this program is to identify those constituents and biochemical processes in chromatin that, when altered or damaged, may result in neoplasia. To accomplish this objective, we have developed new analytical methods for flow cytometry (FCM), high performance liquid chromatography (HPLC), and high performance capillary electrophoresis (HPCE) that will permit us to determine how various by-products of energy technology interact with chromatin and disrupt its structural integrity, causing alteration in DNA's normal control of cell proliferation. By developing 3-laser FCM techniques, we can now identify and isolate cells having distinctive alterations in their chromatin structure following exposure to agents such as radiation and toxic chemicals. Then, through utilization of high sensitivity HPLC and HPCE methods developed in our laboratory, we can determine how nuclear protein components have been altered to destroy cell proliferation control. These activities are expected to establish a factual basis for our hypothesis that cell proliferation and metabolism are controlled through modulations of DNA transcription, replication, and segregation brought about by alterations in the complex interactions between DNA and nucleoproteins that are driven by chemical modifications of nucleoproteins such as phosphorylation and acetylation. Results from this program should lead to (1) identification of specific targets within the nucleus that are sensitive to attack by radiation and toxic chemicals, (2) identification of specific molecular alterations in chromatin structure that are manifested as damaged chromosomes at mitosis, (3) formulation of a model of the biochemical mechanisms of actions of $x$-rays and chemical toxic agents, and (4) development of new techniques for damage assessment.

\section{Positional Cloning of Disease Genes on Chromosome 16 (LANL)}

\section{Principal lnvestigator: N. A. Doggett}

The intrinsic value of the human genome project lies in what is learned about genome structure and function and in what medically or scientifically important genes are identified in the process mapping and sequencing. The mapping of chromosome 16 is a major component of the genome effort at Los Alamos. This LDRD project proposes to accelerate the cloning of important disease genes on chromosome 16 by utilizing the 16 mapping resources in positional cloning strategies.

The main aim of this project is to elucidate the molecular basis of Batten disease, a progressive and debilitating brain disease of adolescence, by molecular cloning of the affected gene with the aid of chromosome 16 maps and resources of the Los Alamos Human Genome Program. An overlapping clone map covering much of chromosome 16 provides the basis for completing an ordered clone map through the Batten disease gene region of this chromosome. 
During the past year significant progress has been made in completing an ordered clone map through the Batten disease region. This clone map consists of 20 yeast artificial chromosome (YAC) clones and 67 bacterial cosmid clones. This map covers approximately $2 \mathrm{Mb}$ (million base pairs) of a 2.5 to $3 \mathrm{Mb}$ interval. Closure of this region should be completed during the next six months. In collaboration with the Batten Disease Consortium, this interval will be refined genetically to reduce the size of the region that will need to be searched for candidate genes. A variety of approaches will then be pursued to identify candidate genes in the region.

\section{An Investigation of Gene Organization within the Human Genome Utilizing cDNA Sequencing (DOE)}

\section{Principal Investigator: Joe Gatewood}

We are examining gene expression in an unusual human pregnancy (hydatidiform mole) by cDNA library construction and cDNA sequencing. This pregnancy is exclusively of paternal genetic origin and results from paternal genetic imprinting. A goal of this project is to determine if the genes expressed uniquely in hydatidiform mole are encoded for by a subset of sperm chromatin that hypothetically may be involved in paternal imprinting.

Complete hydatidiform moles are abnormal diploid pregnancies that result from the fertilization of an enucleated ovum. The pregnancies are characterized by hypertrophy of the trophoblast, hydropic degeneration of all placental villi, absence of a fetus, and a propensity to become malignant. The moles have maternal mitochondrial DNA but paternal chromosomes. Diploidy is restored by either fertilization by two sperm, or in the majority of cases, fertilization by one sperm that undergoes duplication without cytokinesis.

An analysis of over $2000 \mathrm{cDNA}$ clones from a directionally cloned and arrayed nonamplified cDNA library indicates that approximately $10 \%$ are homologous to known DNA sequences, $10 \%$ contain repetitive elements, less than $1 \%$ lack inserts, and the remainder represent newly identified genes. Of the newly identified genes, approximately $40 \%$ contain regions of limited homology, which may indicate function. The homologous sequences are also providing information on tissue specific RNA splicing.

In collaboration with Dr. Julie Korenberg, chromosomal localization of cDNA clones using fluorescent in situ hybridization (FISH) has been initiated. This approach has successfully been used to map over 100 single copy genes with high fidelity. STSs are generated for the cDNAs that are mapped using FISH. The STS primers are then used to determine the organization of the gene in human sperm chromatin by a PCR based assay. Using this assay, cDNAs have been localized to distinct sperm chromatin components.

The computer support aspects of this project have included the development and implementation of software for automatically conducting homology comparisons with storage of results in a relational database, identification and removal of homology information due only to the presence of repetitive elements, and improved homology comparison routines. 


\title{
Molecular Genetics (DOE)
}

\author{
Principal Investigator: Michael R. Altherr
}

The motivating force in my laboratory is the basis of human genetic disease. As participants in the Human Genome Initiative, the members of my laboratory provide a variety of services, including the localization of small DNA fragments (STSs) to specific subregions of chromosomes 4 and 16 using somatic cell hybrids containing natural rearrangements of these chromosomes; the development and implementation of techniques to generate a "sequence ready" collection of DNA clones; and the development of an expressed sequence map using the strategy of exon trapping. In addition, my laboratory has an interest in identifying the molecular basis of a number of distinct human maladies, including the Wolf Hirschhorn syndrome and facioscapulohumeral muscular dystrophy. Finally, members of the laboratory are using transgenic mice to look at the biology of suspected chromosomal structural elements (i.e., centromere and telomere) and the affects that these elements have on development and gene expression.

\section{Research Accomplishments}

- FISH and fractional length maps of chromosomes 21 and 16 were completed using yeast artificial chromosome (YAC) libraries cloned from flow-sorted chromosomes.

- Cosmids from a region of chromosome 16 around the Batten's disease gene location were screened and quantitatively mapped by FISH and fractional length measurement.

- A DNA repair gene (XRCC5) was mapped by FISH and quantitative microscopy to its location on chromosome 2 and a band assignment of $2 \mathrm{q} 35$ was given.

- A semi-automated procedure was developed for calculating and recording fractional length measurements from digitized images of chromosomes labeled by FISH.

- Fifteen phosphopeptides obtained from histone $\mathrm{HI}$ have been classified by their rate of ${ }^{32} \mathrm{P}$-phosphate incorporation into 5 greater, 4 intermediate, and 6 lesser phosphorylated peptides. The lesser phosphorylated peptides probably are derived from the minor $\mathrm{H} 1$ variations. The 15 phosphopeptides could be grouped into 5 classes having different cell cycle phosphorylation kinetics. The first class contained 2 peptides, which reached a maximum phosphorylation rate in S phase and then declined through G2 and $M$. The second class contained 5 peptides, which reached a maximum phosphorylation rate in G2 and then remained constant or declined in M. The third class contained 2 peptides, which increased throughout $S$ and $G 2$, reaching a maximum phosphorylation rate in $\mathrm{M}$. The fourth class contained only 1 peptide, which was phosphorylated only in $\mathrm{M}$. The fifth class contained 5 peptides, which had a low level of phosphorylation, which remained constant throughout S, G2 and $\mathrm{M}$. These different phosphorylation kinetics suggest that different $\mathrm{Hl}$ kinases 
may be responsible for the phosphorylation of $\mathrm{H} 1$ at different sites during the cell cycle.

- Amino acid analysis was performed on the mitotic-specific phosphopeptides of histone $\mathrm{H} 1$ from $\mathrm{CHO}$ cells. It was demonstrated that these phosphopeptides are the 16 amino acid $\mathrm{N}$-terminal tryptic of $\mathrm{H} 1$, which contains both the serine and threonine mitotic-specific phosphorylation sites. These data demonstrate that the mitotic-specific phospohorylantion of the $\mathrm{H} 1$ is located entirely in the basic flexible N-terminal region (the "nose") of the molecule. This suggests a model of chromosome consideration that involves release of the $\mathrm{H} 1$ "nose" from the internucleosomal DNA through negative repulsion of DNA and $\mathrm{H} 1$ phosphates, which in turn facilitates nucleosomal compaction.

- Amino acid sequence analysis demonstrated that the mitotic-specific $\mathrm{H} 1$ phosphopeptides are Ac-SETAPAAPAAAPPAEK. This peptide does not contain the consensus sequence S/T-P-X-Z (where $X$ is any amino acid and $Z$ is a basic amino acid), which is thought to be required for phosphorylation by the cyclin-P34 cdc2kinase. It is concluded that either this kinase does not have an obligatory requirement for the consensus sequence as generally thought or this kinase is not the enzyme responsible for mitotic-specific $\mathrm{H} 1$ phosphorylation.

- A physical map consisting of cosmid and YAC clones and covering approximately $2 \mathrm{Mb}$ (million base pairs) has been constructed through the Batten disease region of chromosome 16 . 


\section{STRUCTURAL BIOLOGY}

\section{Structure of the Tandem Repeat Domain of Human Mucin Muc-1 (LANL)}

Principal Investigator: Goutam Gupta

Co-Investigators: J. D. Fontenot, S. V. Santhana Mariappan, P. Catasti, and J. M. Gatewood

Tandemly repeated sequences exist in proteins as diverse as human mucins, kinesins, ankyrins, cell cycle control proteins, and many plant proteins. This study focuses on the proline rich tandem repeat domain of human mucin muc- 1 . We are using two-dimensional nuclear magnetic resonance (2D NMR) experiments on chemically synthesized mucin tandem repeats, (PDTRPAPGSTAPPAHGVTSA) $n, n=1$ (ITR), 3 (3TR), in order to understand the role of tandem repeats in the development of secondary and tertiary protein structure. The muc-1 tandem repeats are immunogenic when expressed in breast and pancreatic cancer where defects in glycosylation unmask the normally glycosylated protein cores. The exposure of the protein core of certain mucins found on malignant cells, combined with the ability of the immune system to respond to these structures, offers a unique opportunity to utilize mucin-based vaccines for specific immunotherapy of tumors. For this approach to be viable, a more detailed structural understanding of the precise mucin epitopes present on tumors and normal tissues must be acquired. These structural studies on mucin tandem repeats reveal that multiple repeats enhance the definition of the antigenic determinant site A0-P1-D2-T3-R4 and how the global folding of mucin modulates the relative spatial position and orientation of the antigenic site.

We are also performing two-dimensional nuclear magnetic resonance (2D NMR) experiments, circular dichroism and antibody binding studies on in vitro glycosylated 3TR in order to determine the effect of GalNac residues on the protein structure, epitope presentation, and dynamics of muc-1.

\section{HIV Vaccine Design Using Protein Engineering of Human Mucin Muc-1 (LANL)}

\section{Principal Investigator: Goutam Gupta}

Co-Investigators: J. D. Fontenot, P. Catasti, S. V. Santhana Mariappan, and J. M. Gatewood

The unique structural and immunological properties associated with human mucin muc-1 suggests that the tandem repeat protein core may be an effective framework for designing and presenting novel immunogens for HIV. The sequence of the muc-1 TR domain is (PDTRPAPGSTAPPAHGVTSA) $n$, where $n=$ 40-150 copies. We have determined the 3-dimensional structure of a muc-1 tandem repeat peptide containing 3 tandem repeats (3TR) and various principal neutralizing determinants (PNDs) found within the third variable region (V3 loop) of HIVgp120, using two-dimensional nuclear magnetic resonance (2D NMR) techniques. The secondary structure of the proline rich tandem repeats of muc-1 consists of a series of consecutive reverse turns, which form a large loop, followed by a 
polyproline II like region which is very extended. The 20 amino acid repeat forms an arc or disclike shape. The most important observation is that at the intersection of two arcs is a large loop region forming a knoblike protrusion at right angles to the long axis of the molecule. It is known that the primary antibody binding site for neutralizing antibodies to HIV is 4-5 residues flanking either side of the GPGR turn at the crest of the V3 loop. We are currently replacing specific sites of muc-1 with HIV V3 loop sequences and have successfully created chimeric proteins that can present the critical V3 loop epitope in native form, as determined by binding to a neutralizing humanized monoclonal antibody to HIV in ELISA.

The next phase of this work will be to determine the structure of the V3 loop epitope within the mucin framework and to begin in vivo studies in mice and primates to evaluate the immunogenicity of mucin V3 chimeric proteins.

\section{The Effect of Sequence Variation on HIV-1 V-3 Loop Structure and Folding (NIH)}

\section{Principal Investigator: Goutam Gupta}

\section{Co-Investigators: P. Catasti, J. D. Fontenot, J. M. Gatewood, and E. Morton Bradbury}

In order to better understand morphogenesis, infectivity, and cytopathogenicity of the human immunodeficiency virus (HIV), it is necessary to accurately define the structures and interactions of viral proteins in intimate molecular detail. In this project we address the important questions: How is variability of the amino acid sequence of the principal neutralizing domain (PND) of HIV manifested in its three-dimensional structures and specificity toward its antibodies? How can we direct immune responses specifically to the structural elements that are conserved throughout multiple PNDs? To answer these questions, we are combining molecular modeling, physico-chemical, immunological, and two-dimensional magnetic resonance (2D NMR) techniques to examine global and local changes in the 3-dimensional structure of the PNDs in response to changes in amino acid sequence. In addition, we will determine the possible consequences of such changes for the specificity of PND-antibody complexes, a major focus of vaccine development. These results will also explain various other functional aspects of the PND of gp120, including the effect of sequence on the structure of the proteolytic cleavage site located inside the PND (proteolysis is an important step in HIV infection) and the effect on the glycosylation site. Our unique and rigorous approach will help us to classify PNDs into different families of folding motifs. This will enable us to determine the conserved elements of structure within the V3 loop. From this information we will design antigens that present the PND conserved elements in native structures and therefore focus antibody responses toward conserved, and not variable, viral features. Our approach is not limited to PNDs (V3 Loops); it can be applied to the PND of SIV, to the V4 loop, or to any glycoprotein loop domain of immunolgical interest. 


\title{
Unusual Structures Formed by Fragile X Syndrome Triplet Repeats (LANL)
}

\author{
Principal Investigator: Goutam Gupta
}

Co-Investigators: Santhana Mariappan, Paolo Catasti, Xian Chen, Robert Ratliff, Robert K. Moyzis, and E. Morton Bradbury

The expansion of trinucleotide repeats, $(\mathrm{GGC})_{\mathrm{n}}$ and the complementary pyrimidine rich $(\mathrm{CCG})_{\mathrm{n}}$, are responsible for fragile $\mathrm{X}$ syndrome (FX). The structure of (GGC) $)_{n}$ ( ranging from 3 to 11 ) is characterized by 2D NMR spectroscopy and gel-electrophoresis. The data from gel-electrophoresis show two populations, duplex and hairpin, with the relative concentrations depending on the solution conditions. The ratio of duplex to hairpin population increases with an increase in DNA or salt concentration; however, the ratio decreases with an increasing number of triplet repeats. The NMR data under high DNA and low/high salt concentration indicates predominantly duplex structure with Watson-Crick GC and mismatch GG base pairs. The NOESY sequential connectivity pattern is unique with discontinuity between adjacent triplet repeats; we could assign GGC sequentially, but not CG. Also, in the direction of 5' to 3' end, the G preceding $C$ is in syn conformation. Simulated annealing followed by rapid temperature quenching is used to sample various duplex structures in agreement with the NMR data.

\section{Effects of Amino Acid Substitutions on the Structure, Stability, and Function of a Protein (LANL)}

\section{Principal Investigator: Thomas C. Terwilliger}

In this project the gene 5 protein of bacteriophage $\mathrm{f} 1$ is used as a model for developing an understanding of how to engineer a protein surface by repacking and deforming the underlying core. We intend to determine the structures of variants of the gene 5 protein that have, at each of several sites, amino acid side chains ranging in size from $25 \AA^{3}$ to $102 \AA^{3}$. We expect to identify structural changes that become progressively larger as the size of the side chain at a site becomes larger and to develop simple models for predicting which parts of a protein in the vicinity of an amino acid substitution are likely to move or deform in such a case. These results will be used to develop a framework for designing specific changes in a protein that will alter the protein surface in a predictable fashion.

\section{Engineering Sequence-Specific RNA and Single-Stranded-DNA Binding Proteins (LANL)}

\section{Principal Investigator: Thomas C. Terwilliger}

We propose to use the special properties of the gene 5 protein from bacteriophage $\mathrm{fl}$ along with our experience in protein engineering to create a set of proteins that will bind to any desired sequence of RNA or single-stranded DNA. We will first construct a group of protein modules, each of which recognizes a 
specific four nucleotide sequence of RNA or single-stranded DNA. We will then develop the technology to link four or more of these modules in any order so as to generate proteins that bind specifically to any 16 or more nucleotide sequence of RNA or single-stranded DNA.

The technology to design a protein that would bind to any given RNA or single-stranded DNA sequence would have major applications in areas ranging from treatment of diseases to sequencing of DNA. Additionally, in the process of constructing sequence-specific RNA and single-stranded DNA binding proteins, we expect to develop an understanding of the interactions between single-stranded nucleic acids and proteins that define this specificity.

\title{
Folding and Stability of the Gene V Protein of Phage f1 (NIH)
}

\section{Principal Investigator: Thomas C. Terwilliger}

The aims of this project are to determine the structure of the gene $\mathrm{V}$ protein, to use this structure to interpret our previous experimental observations on the stabilities of variant gene $\mathrm{V}$ proteins with amino acid substitutions, to determine the structures of gene $\mathrm{V}$ proteins with substitutions that change the polarity of a side chain (valine $\rightarrow>$ threonine substitutions), and to use these structures to estimate the effective polarity of a protein interior, and to determine the structures of variant gene $\mathrm{V}$ proteins that have amino acid substitutions that lead to altered stability and to use these structures to identify interactions that are important in determining the stability of a protein.

\section{Modulation of Chromatin Structure with Cyclic AMP (DOE)}

\author{
Principal Investigators: L. R. Gurley and T. T. Puck
}

\section{Co-Investigators: J. G. Valdez, A. L. Jandacek, J. A. D'Anna, and R. J. Sebring}

When CHO cells are treated with CAMP, a large portion of the chromatin at the periphery of the nucleus is transformed from a condensed state (Ref. 1). This chromatin decondensation is accompanied by the conversion of these tumor cells to cells having a more normal morphology and a density control of growth. This process has been referred to as "reverse transformation." The objective of this program is to determine the cell cycle response of chromatin structure to cAMP so that this biological system can be used to study the mechanisms of histone phosphorylation-driven chromatin condensation. Characterization of this biological system will also facilitate studies of the interrelationships between the structural state of the cytoskeleton and the structural state of chromatin, because cAMP induces reorganization of its fibrous elements simultaneously with chromatin structural changes. Information from these studies will be used to determine the relationships between histone phosphorylation, chromatin structural modulation, and the carcinogenesis process. 


\section{Research Accomplishments}

- We have completed the first structure of a protein tandem repeat domain and have gained insight into the immunogenicity of this human tumor antigen (muc-1). The conserved structural features of the tandem repeat domain of muc-1 include repeating and protruding knoblike structures consisting of sequential reverse turns that span tandem repeat interfaces, followed by an extended region composed of polyproline II and $\beta$-strand structure.

- The observed antibody immunodominance of APDTR and MHC unrestricted activation of $\mathrm{T}$ cells by unglycosyalted mucin on tumors could be explained because the stable turn structure and protruding nature of the repeating epitope APDTR could obscure access to the remainder of the molecule by $\mathrm{B}$ and $\mathrm{T}$ cell antigen receptors.

- We have designed and chemically synthesized six mucin V3 loop chimeric proteins of 60 amino acids in length by solid-phase manual peptide synthesis.

- We have created two mucin V3 loop chimeric proteins that can present the HIV principal neutralizing determinant to a neutralizing monoclonal antibody (MAb1511) specific for the native HIV-gp120 V3 loop derived from an AIDS patient.

- We have determined the complete 3-dimensional structure of 4 cyclic forms of the HIV principal neutralizing determinants of HIV-gp120 (V3 loop). These structures reveal certain conserved structural features of these domains, including an $\mathrm{N}$-terminal reverse turn spanning an $\mathrm{N}$-glycosylation site; a type II reverse turn in the center of the loop, which is the primary binding site for neutralizing antibodies; and a C-terminal helix.

- We have chemically synthesized a panel of cyclic and linear V3 loop peptides corresponding to the major North American isolates of HIV (RF, MN, SF2 and the North American Consensus), as well as the major global consensus sequences $(A, C$, and $D)$.

- The structure of the gene 5 protein of bacteriophage $\mathrm{fl}$ has been determined by $\mathrm{x}$-ray crystallographic means at a resolution of $1.8 \AA$.

- Improved methods for protein structure determination using multiwavelength anomalous diffraction have been developed.

- A procedure for simultaneously engineering multiple properties of a protein has been developed, based on the additivity of effects of mutations on protein structure and function.

- An engineered version of the gene 5 protein of bacteriophage $\mathrm{f} 1$, in which the two subunits are connected by a short linker peptide, has been constructed and shown to be substantially more stable than the wild-type protein.

- The structures of three mutants of gene 5 protein with amino acid substitutions in the protein core have been determined by $\mathrm{x}$-ray crystallographic means. These structures show that the effects of an amino acid substitution depends strongly on the location within the protein where it is made. 
- Malignant CHO cells grown in suspension can be arrested in G1 by isoleucine deprivation. Restoration of complete medium causes the cells to resume proliferation, traversing the cell cycle in a synchronized wave. Such synchronized cultures were treated with $0.5 \mathrm{mM} 8 \mathrm{Br}$-adenosine cyclic 3':5' monophosphate (Br-cAMP) simultaneously with the change to complete medium. Half of these $\mathrm{Br}$-cAMP treated cells traversed S, G2, and $\mathrm{M}$ in apparently normal fashion and then arrested in G1. The other half remained in G1 and never traversed the cell cycle. It is concluded that cAMP blocks the cell cycle in early G1 and that isoleucine deprivation blocks cells in a broad band in $\mathrm{G} 1$ both before and after the cAMP block point. It was demonstrated that cAMP does not block cells in $\mathrm{S}, \mathrm{G} 2$, or $\mathrm{M}$.

- Flow cytometry analysis revealed that those synchronized $\mathrm{CHO}$ cells that traversed late-G1, S, G2, and M produced cells with >2C DNA content, suggesting they underwent apoptosis.

- DNA extraction from the Br-cAMP treated cells produced a nucleosomal "ladder pattern" when subjected to gel electrophoresis, indicating the DNA degradation was produced by apoptosis.

- Flow cytometry analysis revealed that cAMP induces apoptosis immediately after cell division. cAMP did not induce apoptosis in S and G2. Cells that were blocked in G1 by cAMP were spared from apoptosis. It is concluded that apoptosis is induced in early G1, whereas cAMP-induced G1 arrest occurs later in G1.

- Flow cytometry analysis of the kinetics of DNA loss from dividing cells demonstrated that the apoptotic process is rapid in early G1. Acridine orange staining revealed that micronuclei formation followed this rapid loss of DNA, indicating that the apoptotic process affects the nuclear topography organization with respect to the nuclear membrane.

\section{Reference}

1. T. T. Puck and A. Krystosek, Internat'l Rev. Cytol. 132, 75-108 (1992). 
CELL BIOLOGY

\title{
CYTOMETRY
}

\section{Expert Systems for Flow Cytometry Data Analysis (NIH)}

\author{
Principal Investigator: G. C. Salzman
}

Co-investigators: R. J. Beckman* and C. C. Stewart**

Flow cytometric immunophenotyping has become the preferred method for determining the immunophenotypes of cell populations in the bone marrow of patients with leukemia. As many as 30 different monoclonal antibodies are used to determine the immunophenotypes. The antibodies are used in cocktails of three antibodies, each with a different fluorochrome attached. The complex three-color data from the flow cytometer requires long analysis times by a skilled investigator. A Macintosh computer program named AutoGate has been developed, which uses cluster analysis to tag the cell populations. The program features cluster editing, which enables the investigator to move labels of groups of cells from one cluster to another.

The strategy developed for analyzing leukemic bone marrow is as follows: Several data files from normal bone marrow donors are combined to create a normal bone marrow template. The template data are clustered and edited to define the cell populations present in normal bone marrow. A classification and regression tree training algorithm (CART) is then used to define a set of hyperplanes defining the boundaries of each cell population in the normal bone marrow. A leukemia patient data file is then classified using CART, and cell populations that fall outside the boundaries of the normal bone marrow template are classified as exhibiting inappropriate expression. The immunophenotypes of these abnormal populations can then be determined.

Because the CART boundaries are rigid, the patient data files must be normalized. This is done using the normal mature monocytes present in virtually all bone marrow specimens. The normalization is done using a Macintosh program called Normalize. This program has made possible the use of older clinical data collected when some of the fluorochromes were not as bright as they are at present.

AutoGate and Normalize are being used in the clinic to monitor residual disease and to provide an objective means for adjusting therapy on an individual patient basis.

*Analysis and Assessment Division

**Roswell Park Cancer Institute, Buffalo, New York 


\title{
National Flow Cytometry Resource (NIH)
}

\author{
Principal Investigator: J. H. Jett
}

Co-Investigators: R. Beckman, * C. Bell-Prince, L. S. Cram, H. A. Crissman, J. J. Fawcett, R. C. Habbersett, J. C. Martin, J. D. Parson, R. Posner, G. C. Salzman, M. J. Smyth, J. A. Steinkamp, A. P. Stevenson, and M. E. Wilder

The National Flow Cytometry Resource (NFCR) is active in all five program areas as required by NIH: core research and development, collaborative research, service projects, training, and dissemination. The NFCR has now completed its eleventh year and has begun the second renewal period, which will carry it through the fifteenth year. The renewal came after submission of a second version of the renewal proposal in the fall of 1992. A site visit was held in the spring of 1993, which resulted in a priority score of 104 . Subsequently, the NCRR council approved funding through June 1997.

The following quotation is taken directly from the special study section summary statement:

The Resource serves as a center for advanced research and development in flow cytometry instrumentation and expansion into the application of novel physical and optical techniques to molecular genetics, cell differentiation and sophisticated data analysis of clinical materials. Flow cytometry has seen a rapid expansion into clinical procedures, disease research, molecular and cell biology, biotechnology and the analysis of the human genome. The NFCR at LANL has become an internationally recognized center of excellence, with some of the world's best experts and traditional leaders in technology and biological research methodology. The NFCR forms a creative and productive group providing national and international leadership in the development of this important field. The movement of the Resource into the mainstream of cytogenetics, cell biology and disease research in the last few years is notable.

The renewal proposal included three core research and development projects that centered upon development of new approaches to multivariate data analysis; a new approach to chromosome sorting; and development of a modern data acquisition, analysis, and sort control system. In addition, several technologies such as the phase sensitive flow cytometer and the fast kinetics cytometer are part of the instrumental base that is available to NFCR collaborators. At the present time the NFCR has 55 active collaborative projects along with 11 service projects. Several of the collaborative projects were brought to the resource by Dr. Larry Sklar, the co-director of the resource, through his affiliation with the University of New Mexico School of Medicine.

The five year bibliography compiled for the renewal site visit reflects the impact of the NFCR and the level of dissemination activities. The bibliography contained 217 reviewed papers with an average citation rate of 8 citations per article. The annual course in flow cytometry, sponsored by the NFCR, was held in Los Alamos in June 1993. The course, taught by the NFCR staff and invited faculty, was filled by 50 students from the United States and 3 foreign countries.

*Analysis and Assessment Division 


\title{
Advanced Flow Cytometric Development (DOE)
}

\author{
Principal Investigator: J. H. Jett
}

Co-Investigators: R. C. Habbersett, J. C. Martin, M. A. Navier, T. L. Olivier, J. A. Steinkamp, J. D. Parson, and M. E. Wilder

The goal of this program is to advance the state of the art in flow cytometry instrumentation for the analysis and sorting of biological particles. Developments are providing new measurement techniques at three levels: cellular, chromosomal, and molecular. A.t the cellular level, the phase sensitive flow cytometer has demonstrated the capability for measuring fluorescence lifetimes in a flowing system. This capability can be used as a spectroscopic tool to quantify physiological parameters of cells. In addition, the phase sensitive system can be operated in a mode in which undesired fluorescence is rejected and thus "tuned" to the desired fluorescent species. This capability will find application in experiments that require rejection of autofluorescence or in cases of overlapping fluorescence emission spectra.

One of the operational characteristics of the DiDAC data acquisition system currently under development is that the analog signal from the photo detector is continuously digitized with a minimum of intervening analog electronics. The stream of digital information is processed by custom circuits to calculate the desired parameters from the input signal. Initially, the pulse processing circuitry was designed to extract the height, width, and area of the input pulse. A preliminary design has been completed to extract the phase and lifetime information from the modulated signals of the phase sensitive flow cytometer. When the new pulse processor is constructed, it will be compatible with the DiDAC system and will use all its capabilities for data display, storage, and sort control.

Analysis at the molecular level has been advanced by the development of the ability to measure the size of DNA fragments. Sizing of DNA fragments between 10 and 50 kilobases has been reported (Ref. 1). The flow measurement was made in three minutes with approximately 12,000 fragments of DNA and resulted in a linear response curve over the 10 to $50 \mathrm{~kb}$ range. Current efforts are centered on extending the range of fragment sizes that can be measured in both directions; that is, to larger as well as smaller fragments.

\section{Flow Cytometer for Quantifying Fluorescence Lifetime (NIH)}

\author{
Principle Investigator: J. A. Steinkamp \\ Co-Investigators: H. Crissman, C. Deka, B. Lehnert, J. Martin, L. Sklar, and \\ T. Yoshida
}

The goals of this project are to develop a flow cytometric method for (1) separating fluorescence emission signals based on differences in their lifetimes (phase shifts) and (2) quantifying lifetime(s) directly in fluorochrome-labeled cells and chromosomes. Our specific aims in accomplishing these goals are (1) to characterize the instrument in terms of measurement precision, sensitivity, dynamic 
range, and accuracy of lifetime measurement by phase shift and amplitude demodulation, i.e., frequency domain measurements; (2) to evaluate the instrument's ability to separate the emission signals from spectrally-overlapping fluorochromes and its effectiveness in suppressing background interferences caused by cellular autofluorescence, unbound/nonspecific dye-binding, and Raman/Rayleigh scattering; (3) to utilize the instrument as a spectroscopic tool for probing the interactions of fluorochromes with cells and chromosomes (structural information); and (4) to develop a more advanced instrument for use by the biomedical research community based on technological development/evaluation of the prototype system. A proof-of-principle instrument has been constructed and is being evaluated. Several biological applications are proposed that take advantage of the unique capabilities of this new technology.

\title{
Stopped-Flow Flow Cytometry (LANL)
}

\author{
Principle Investigator: L. A. Sklar
}

Co-Investigators: J. P. Nolan, R. Posner, J. C. Martin, R. C. Habbersett, and C. Deka

This project is intended to extend the application of flow cytometry to hundreds of important biological molecules that interact with cell surface receptors. In particular, the new instrument will make it possible to examine the interaction of hormones, peptides, peptidometics, and other small molecules with receptors when the affinities of the binding are too low to be examined by other methods.

We are modifying a commercial stepper-motor-driven, stopped-flow mixing system and integrating the mixer with a flow cytometer. The new device is designed to mix and deliver the biological sample within 100 msecs, then to acquire data with $100 \mathrm{msec}$ resolution. This time frame will detect ligand-receptor interactions in living cells for ligands in the affinity range of up to $1 \mu \mathrm{M}$. The new device is also expected to extend the use of flow cytometers to new communities of biomedical and health scientists, including pharmacologists, neuroscientists, and cell biologists.

In the first year of the project, we established computational tools for analysis of ligand-receptor interactions and applied these tools to the analysis of spectrofluorometric and flow-cytometric ligand-receptor binding data; we evaluated the commercial stopped-flow mixing system and made modifications in the sample mixing components to provide compatibility with the flow cytometer; and we developed a simple, single-valve concept to permit sample delivery from the mixer to a flow cytometer. The modifications in the mixer and the valve solved a crucial problem in sample delivery and allowed the output of the mixer (several hundred $\mu$ ls of sample in a few msecs) to be delivered into the flow cytometer at an appropriate rate of $\sim 1 \mu \mathrm{l} / \mathrm{sec}$. In the second year of the project, we implemented the modifications to the mixing and delivery system and tested the mixer independent of the flow cytometer; we integrated the mixing device with the flow cytometer and achieved mixing and delivery times in the range of 500-1000 msecs; and 
we established data-acquisition capabilities to collect data vs. time and display the data on a Sun Workstation. In the coming year, we propose to improve the system by decreasing the dead volume between the exit valve of the delivery system and the port of the flow system so as to achieve delivery times under $500 \mathrm{msec}$; to begin applying the new instrument to cells, where we will examine rapid association and dissociation of fluorescent ligands with their cell surface receptors; and to modify the device to permit two sequential mixing operations, allowing analysis of the complex time-dependent biological processes that occur during the activation of living cells. Successful completion of these steps should lead to a significant demand for our technology by investigators outside the Laboratory.

\section{Research Accomplishments}

- Resolution of fluorescence emission signals from rat thymus cells labeled with anti-Thy 1.1-phycoerythrin and propidium iodide ("dead cells") based on differences in their fluorescence lifetimes

- Direct measurement of fluorescence lifetime on "DNA check" alignment fluorospheres and cultured cells stained with fluorescein isothiocyanate (FITC) and propidium iodide by the two-phase ratiometric method

- Fluorescence lifetime measurements in flow on fluorescent particles by amplitude demodulation using a digital data acquisition technique

\section{Reference}

1. E. H. Goodwin et al., Nucleic Acids Research 21, 803. 


\title{
CELL GROWTH AND DIFFERENTIATION
}

\section{Regulation of Cellular Growth in Multicellular Spheroids (NCI)}

\author{
Principal Investigator: J. P. Freyer
}

Co-Investigator: S. Vuk-Pavlovic*

The objective of this project is to use the multicellular tumor spheroid model system to elucidate the mechanisms controlling the proliferation of malignant cells in the in vivo tumor. We are approaching this problem from several directions: (1) investigation of the regrowth kinetics of cells after removal from the spheroid microenvironment, (2) characterization of a protein growth inhibitor isolated from spheroids and tumors with extensive necrosis, (3) growth of spheroids from hormone-dependent cells in a defined medium at different hormone levels, and (4) development and testing of new mathematical models of tumor growth regulation. The results of this project are providing some important clues as to how tumor cells turn on and off the process of cellular proliferation in the stressful tumor environment. We are also clarifying the complex relationship between the regulation of cellular viability (conversely, the formation of necrosis) and the control of cellular proliferation. This project is closely related to our initiative using NMR techniques to study necrosis and energy metabolism in spheroids. A new approach that we have started is to culture spheroids of mixtures of different types of cells in order to investigate specific cell-cell interactions.

\section{NMR Spectroscopy and Imaging of Tumor Models (NCI, DOE)}

Principal Investigator: J. P. Freyer

Co-Investigator: L. O. Sillerud

The objective of this project is to use state-of-the-art NMR spectroscopy and imaging techniques to investigate the regulation of tumor cell metabolism and viability using three-dimensional in vitro tumor models. Model systems are available that mimic many of the properties of tumors in vivo, but they offer the advantages of better experimental control and the ability to isolate individual experimental variables. We are currently using two complimentary model systems: the multicellular spheroid and the hollow-fiber bioreactor. Multicellular spheroids are spherical clusters of tumor cells grown in suspension culture. They develop a nutrient deprived microenvironment within the cell mass, causing the cells in different regions to adapt by ceasing proliferation and eventually undergoing a necrotic cell death. Hollow-fiber bioreactors are composed of porous fibers encased in an outer, impermeable shell, with tumor cells growing between the fibers and nutrient medium flowing through the lumen of the fibers. Spheroids have the advantages of allowing natural cell growth and permitting the assay of cells from different regions of the nutrient-stressed microenvironment.

\footnotetext{
*Mayo Clinic, Rochester, Minnesota
} 
Hollow-fiber bioreactors are more akin to the capillary supply network present in tumors and are better suited to metabolic NMR imaging. Our NMR spectroscopy efforts are focusing on developing an understanding of the mechanisms controlling the appearance of phosphorous spectra of tumors, both as a function of tumor size and after therapeutic treatment. The proton imaging effort is directed at elucidating the mechanisms behind image contrast in tumors, with the idea of improving the application of NMR imaging to the evaluation of tumors and their response to therapy. There is also a more basic long-term goal: to combine spectroscopy and imaging of these model systems in order to address important mechanistic questions concerning the relationship between tumor cell energy metabolism and the regulation of cellular proliferation and viability.

\section{Loss of Mitogenic Responsiveness During Adipogenesis (DOE)}

\section{Principal Investigator: M. J. Smyth}

The inability of terminally differentiated cells to respond to mitogens is a common motif in the development of higher organisms, yet the molecular mechanisms underlying the terminal growth arrest state have not been defined. This research aims to understand the molecular mechanisms involved in the negative regulation of cell proliferation in mammalian fibroblasts. Towards this end, a cell system in which fibroblasts differentiate into adipocytes is used. This adipocyte differentiation system has a number of unique features that make it ideal for focusing on the mechanisms involved in induction of the mitogenic block in cells that have become terminally growth-arrested after commitment to the differentiation program. The primary feature is that irreversible loss of mitogenic responsiveness can be studied independent of expression of the differentiated phenotype. The ultimate aim of this project is the isolation of a gene involved in the negative regulation of cell proliferation.

Recent investigations of the molecular basis of the mitogenic block have focused on determining whether altered expression of growth-regulated genes contributes to the terminally growth-arrested phenotype. These investigations involve wild-type cells and differentiation-defective variants that have been isolated by a novel selection procedure. The specific hypothesis being tested is that terminal growth arrest is associated with selective subunit rearrangement of $\mathrm{G}_{1}$ cyclin-CDK complexes.

The initial characterization of candidate growth-inhibitory genes is being approached by employing protocols involving arbitrarily primed PCR fingerprinting of RNA. Differential expression of mRNAs between quiescent cells and those at various stages of the adipogenic program has been established. This approach has been expanded to include alternative arbitrary primers in addition to pairs of primers and homology primers.

An understanding of the mechanisms by which specific changes in gene expression occur in differentiating cells should lead to identification of genes that are of critical importance in growth control, differentiation, and tumorigenesis. 
Since uncoupling of the normally interdependent processes of proliferation and differentiation is an obligatory step in the generation of the transformed pheonotype, and hence of cancer, an understanding of the molecular coordination of differentiation and proliferation is imperative.

\section{Regulation of Cellular Proliferation (DOE, LDRD)}

\section{Principal Investigator: W. R. Wharton}

The initial events that regulate entry of $\mathrm{G} 0$-arrested cells into the proliferative cycle involve the transmission of a signal generated at the cell membrane by the binding of a peptide growth factor to the nucleus where the transcription of new genes is induced. Using the induction of the transcription of the proto-oncogene $c$-fos as a prototype, we have investigated several aspects of this pathway. In mouse fibroblasts, c-fos is induced rapidly after the stimulation of cells with EGF that initiates a tyrosine kinase signal at the membrane as well as PMA that directly activates protein kinase $C$. While agents that elevate cyclic AMP such as cholera toxin or forskolin cause only small increases in c-fos transcription when added alone, they markedly potentiate the induction mediated by either EGF or TPA. The $c$-fos promoter contains a cyclic AMP responsive element (CRE), a likely target of the potentiating signal. However, deletion of mutation of the CRE did not alter either the basal or induced levels of transcription. Instead, there appears to be a complex pattern of regulation involved in the synergism, with several elements surrounding the central serum response element (SRE) playing a role in the induction.

A second portion of this effort involves the identification of novel lowabundance transcripts that are induced either following the direct stimulation of cells with mitogens, or as cells traverse specific temporal checkpoints in the cell cycle. To facilitate the isolation of such transcripts, we developed a novel PCR based differential amplification procedure that involves the use of either random arbitrary primers or one arbitrary primer, as well as a primer complimentary to sequences encoding a known domain. We have isolated a series of clones representing genes whose transcripts are reproducibly amplified from RNA isolated from late G1 cells, using sets of arbitrary primers. The relationship between the differential amplification and differential expression of these genes is currently underway. In addition. we have isolated a series of genes containing zinc-fingers that represent transcripts that are both differentially amplified and differentially expressed rapidly after mitogenic stimulation of quiescent cells. Some of these genes have been previously characterized, such as a transcription factor that regulates metallothione expression, while others represent novel sequences. The technique that we have developed has already been used by others to characterize differential gene expression in a number of systems. 


\title{
Analysis of Staurosporine in Blood: The Kinetics of lts Distribution in Plasma and Erythrocytes in Vitro and in Vivo (DOE)
}

\author{
Principal Investigators: L. R. Gurley and B. E. Lehnert
}

Co-Investigators: K. O. Umbarger, J. M. Kim, and E. M. Bradbury

Staurosporine (Stsp), a protein kinase inhibitor, has been found to have a differential effect on the proliferation of normal and transformed cells in vitro (Ref. 1). Hence, Stsp might be useful in cell-cycle specific cancer therapy to arrest transiently normal proliferating cells in G1, while permitting tumor cells to continue proliferation. The patient could then be treated with a therapeutic regimen of maximum toxicity for actively proliferating tumor cells if it can be administered to target sites at concentrations that do not result in untoward hypotension.

Essentially, nothing is known, however, about the distribution and pharmacokinetics of Stsp in the body. To facilitate such in vivo investigations of Stsp, we have developed an HPLC method for measuring the levels of Stsp in blood. We have used this analytical method to measure the kinetics of Stsp depletion in the plasma of rats following intravenous bolus injections of Stsp. We have also used it to determine that the erythrocytes are a major source of sequestration of Stsp immediately following injection. The information from these studies will be used to determine the therapeutic regimen for the delivery of an effective dose of Stsp to tumor tissues.

\section{Regulation of Mammalian Cell Cycle Progression (DOE)}

\author{
Principal Investigators: L. R. Gurley and J. A. D'Anna \\ Co-Investigators: D. A. Chen, J. Meyne, and J. M. Cobo
}

The objective is to determine the molecular mechanisms that regulate cell cycle progression in response to ionizing radiation. The investigations are focused on the regulation of cdc2-function kinases and their substrates, which play a central role in cell cycle progression and on the molecular mechanisms that regulate initiation of DNA synthesis at mammalian origins of DNA replication.

HPLC has been used to identify and determine relative rates of phosphorylation in 15 peptides of histone $\mathrm{H} 1$ (a major substrate of cdc2-function kinases) that are phosphorylated during different parts of the cell cycle. This HPLC system is being used to identify the radiosensitive sites of histone $\mathrm{H} 1$ phosphorylation and to identify the respective kinases that are regulated in response to ionizing radiation.

The earliest replicating part of the rhodopsin gene locus in CHO cells (Ref. 2) is being used as a model to understand the molecular mechanisms that might effect damage-induced delay of initiation at mammalian origins of DNA replication. Initiation of DNA replication can occur within at least $50 \mathrm{~kb}$ of the region, but the most probable sites of initiation are located within or near the rhodopsin gene itself. Since the rhodopsin gene region also contains several $\mathrm{A} / \mathrm{T}$-rich and other in vitro DNA-protein binding sites that might be important to initiation of DNA replication, we are constructing chromosomal replacement vec- 
tors to investigate whether the gene-region DNA can be deleted to alter DNA replication in the native chromosomal environment of the living cell.

The results of this program are expected to determine whether the cdc2 kinases and the DNA origin regulatory mechanisms are operative under conditions of minimal perturbation produced by low doses of ionizing radiation in radiosensitive mutants.

\section{Research Accomplishments}

- Using pure populations of proliferating and quiescent cells isolated from multicellular spheroids, we have demonstrated characteristic and reproducible alterations in phosphomonoesters when tumor cells are arrested by microenvironmental stress. This strongly suggests that cellular proliferative status in a tumor may be monitored by NMR spectroscopy and used to noninvasively predict therapeutic response in an individual patient.

- Previous work has shown that quiescent cells in spheroids adapt their energy metabolism to adjust to microenvironmental stress by reducing their rate of oxygen consumption. Using mitochondrial-specific fluorochromes and flow cytometry, we have now shown that these cells do not lose or degrade their mitochondria but rather down-regulate mitochondrial function in a reversible manner. Preliminary studies suggest that full recovery of mitochondrial function takes at least 12 hours after removal of cells from the stressful environment, perhaps explaining the long lag period observed before quiescent cells re-enter the cell cycle.

- We have developed a co-cultured spheroid system consisting of human breast tumor cells and normal fibroblasts mixed in the same aggregate. This model will be very useful for investigating the role of cell-cell interactions in regulating the proliferation of tumor cells. Specifically, we are currently testing whether antiestrogen treatment induces the fibroblasts to produce TGF $\beta$, thus inhibiting the growth of tumor cells that do not respond to the antiestrogen directly.

- We have tested a variety of mathematical models of tumor growth to see whether they could fit both spheroid and tumor growth curves from a large number of different cell lines. This comparison clearly demonstrated that many empirical models could fit the data but that real progress in this area was only going to be made using biologically-based models which provide some parameters that can be experimentally tested. A model developed by us to incorporate both positive and negative cell-cell interactions in tumor growth fit all of the data well. This model also provided estimates of biological parameters, such as cell doubling times and proliferating fractions, which corresponded well with independent measurements of these parameters.

- An HPLC method has been developed to measure the levels of staurosporine (Stsp) in blood. Using the rat model, plasma containing Stsp is treated with acetone to precipitate proteins. The acetone extract containing Stsp is diluted 2:1 with aqueous $0.2 \%$ trifluoroacetic acid (TFA), and it is then subjected to 
reversed-phase HPLC on a $\mu$ Bondapak $\mathrm{C} 18$ column. An elution gradient of acetonitrile running from water/0.2\% TFA to acetonitrile/0.2\% TFA in $60 \mathrm{~min}$ at $1 \mathrm{ml} / \mathrm{min}$ elutes Stsp as a sharp peak at $\sim 35 \mathrm{~min}$. Stsp is detected by UV absorption at $292 \mathrm{~nm}$. HPLC of plasma spiked with Stsp standards produced a linear quantification calibration curve. This procedure works equally well to measure the Stsp content of erythrocytes centrifuged from the plasma of whole blood.

- Using the HPLC method for measuring Stsp in blood, no Stsp could be detected in the plasma of rats shortly after they were given intravenous bolus injections of $200 \mu \mathrm{g} \mathrm{Stsp} / \mathrm{rat}(\sim 20 \mu \mathrm{g} / \mathrm{ml}$ blood). In vitro studies in which whole blood was incubated with Stsp indicated that red blood cells sequester the Stsp at a rapid rate, thereby diminishing its concentration in plasma.

- Computer enhancement of the UV absorption signal of Stsp eluting in the HPLC effluent has enabled us to measure Stsp concentrations in blood at levels below those normally detectable by most spectrophotometric monitors. We have demonstrated that this system can detect Stsp in blood in the $\mathrm{ng} / \mathrm{ml}$ range and that the Stsp can be quantified with a linear calibration curve.

- Using the computer enhanced, HPLC method of Stsp analysis, it was determined that Stsp has a plasma half life of $52 \mathrm{~min}$ and an erythrocyte half life of $62 \mathrm{~min}$ in vivo in rats. These measurements will be used to design the therapeutic regimen for the delivery of an effective dose of Stsp to block cell proliferation in normal tissue but to permit proliferation in tumor tissues.

- HPLC has been utilized to investigate changes in histone $\mathrm{H} 1$ phosphorylation during the cell cycle of CHO cells. Synchronized cultures were exposed to ${ }^{32} \mathrm{P}$ orthophosphate, and ${ }^{32} \mathrm{P}$ labeled histone $\mathrm{H} 1$ was isolated and purified by reserved-phase HPLC on a $\mu$ Bondapak $\mathrm{CN}$ column. $\mathrm{H} 1$ tryptic digests were then subjected to HPLC using a Delta-Pak C18 reversed-phase column to resolve individual peptide fragments. The phosphopeptides were identified by on-line monitoring of ${ }^{32} \mathrm{P}$ using flow liquid scintillation counting of the column effluent. The relative rates of phosphorylation in 15 peptides of histone H1 (a major substrate of cdc2-function kinases) have been measured in each phase of the cell cycle. Results from this type experiment will be used to identify the $\mathrm{H} 1$ phosphorylation sites specifically inhibited by protein kinase inhibitors such as staurosporine, by x-irradiation, and by toxic chemicals.

- Sodium arsenite induces cell division delay followed by spontaneous recovery of cell division in a radiomimetic manner. Thus, it can be used to simulate $\mathrm{x}$-irradiation effects at the cellular level and to trace biochemical mechanisms of $\mathrm{x}$-ray damage at the molecular level. Using HPLC analysis, the phosphorylation of histones was measured in each phase of the cell cycle in the presence of sodium arsenite. It was found that arsenite inhibited only the mitotic-specific histone $\mathrm{H} 1$ and $\mathrm{H} 3$ phosphorylations, having no effects on interphase $\mathrm{H} 1$ or $\mathrm{H} 2 \mathrm{~A}$ phosphorylation. It is concluded that the controls of cell proliferation affected by radiomimetic agents involve phosphorylation of mitotic-specific phosphorylation sites on histones $\mathrm{H} 1$ and $\mathrm{H} 3$ by the cdc2-function kinases. 
- In collaboration with P. Dijkwel and J. Hamlin of the University of Virginia, we have performed two dimensional gel analysis of DNA replication intermediates that indicate that DNA initiation occurs over a very large region of DNA, which extends from about $20 \mathrm{~kb}$ downstream of the $5 \mathrm{~kb}$ rhodopsin gene to $>33 \mathrm{~kb}$ upstream where initiation extends beyond the characterized region.

- Current results raise the possibility that the rhodopsin gene region may be important to the initiation of DNA replication in the region. A chromosomal replacement vector has been constructed to determine whether the $5 \mathrm{~kb}$ rhodopsin gene region can be deleted to alter DNA replication in the native chromosomal environment of the living cell.

- A preferred physical origin of DNA replication is located near to or within the rhodopsin gene locus in $\mathrm{CHO}$ cells. Although genomic maps do not indicate the presence of polymorphisms, fluorescence in situ DNA hybridization indicates that the rhodopsin gene locus is found in two nonidentical chromosomes of the 21 chromosome CHO karyotype.

\section{References}

1. Crissman et al., Proc. Natl. Acad. Sci. USA 88, 7580 (1991).

2. Gale et al., J. Mol. Biol. 224, 343 (1992). 


\title{
RADIATION BIOLOGY AND CARCINOGENESIS
}

\section{Mechanisms of Radiation and Chemical Genetic Toxicology (DOE)}

\author{
Principal Investigator: G. F. Strniste
}

Co-Investigators: M. A. MacInnes, R. T. Okinaka, M. S. Park, and R. J. Reynolds

The purpose of this program is to determine the molecular mechanisms by which radiation and environmental chemicals induce heritable genetic change. Research efforts are focused toward understanding the metabolic processes responsible for the recognition, processing, and fixation of DNA damage. Specific objectives include (1) isolation and characterization of the human ERCC5 gene and its encoded protein, which is necessary for the incision step of excision repair; (2) elucidation of the role that the ERCC5 gene product plays in maintaining cellular resistance to genotoxic agents; (3) elucidation of the structural and functional properties of the ERCC5 protein and the relationship of these features to the biochemical properties of this protein; and (4) characterization at the molecular level of the relationship between nucleotide excision repair deficiency and increased susceptibility to mutation induction. As part of this effort, we have isolated and characterized genomic and CDNA clones of the human ERCC5 gene and used probes developed from these clones to map this gene to human chromosome 13q31.3-33. Sequence analysis indicates that this gene may code for a nuclear localization signal and that the ERCC5 protein may contain a helix-loop-helix domain capable of participating in protein-protein interactions. The cDNA sequence has been cloned into mammalian expression vectors to provide a functional minigene and into Baculo virus constructs for overexpression of the protein. Current and future efforts will be directed toward verification of the relationship of the ERCC5 gene to the human genetic disorder xeroderma pigmentosum complementation group $\mathrm{G}$, construction and expression of altered ERCC5 genes in expression vectors, and utilization of these constructs to determine the relationship of ERCC5 protein structure to its function in nucleotide excision repair.

\section{Molecular Mechanisms of Radiation-Induced Mutations in Human Cells (DOE)}

\section{Principal Investigator: D. J.-C. Chen}

This research project was concluded in FY93. The purpose of this project has been to investigate the cellular and molecular mechanism of high LET radiation-induced mutagenesis in human cells. This includes (1) the analysis of RBE for mutation using $\alpha$-particles from ${ }^{238} \mathrm{Pu}$ (LET $120 \mathrm{keV} / \mu \mathrm{m}$ ), (2) the definition of the spectrum of point mutations induced by $\alpha$-particles, and (3) the characterization of the magnitude of deletion events induced by $\alpha$-particles. 


\title{
Molecular Genetics of Human Radiation Repair Genes (DOE)
}

\author{
Principal Investigator: D. J.-C. Chen
}

Ionizing radiation induces various types of DNA damage in mammalian cells, including DNA single-strand breaks, DNA double-strand breaks, DNA protein cross links, DNA-DNA interstrand cross links, and altered bases. Although it is obvious that human cells can repair many of these lesions, there is little detailed knowledge as to the nature of the genes and the encoded enzymes that control these repair processes. The objective of this program is to utilize somatic cell genetics coupled with recombinant DNA technology to identify specific genes responsible for the repair of ionizing radiation-induced DNA lesions in human cells. Our specific goals are (1) mapping of radiation repair genes in the human genome, (2) development of molecular genetics strategies to identify and clone human DNA repair genes, and (3) establishment of atransgenic model system for the determination of the gene function in vivo.

\section{Molecular Cloning of a Human Radiation Repair Gene (NIH)}

\author{
Principal Investigator: D. J.-C. Chen
}

The objective of this project is to utilize recombinant DNA techniques to isolate a specific human gene (XRCC5) involved in the repair of DNA doublestrand breaks induced by ionizing radiation. We have accomplished several important steps in the process of isolating this gene: (1) the XRCC5 gene has been localized in the human chromosome $2 q 35$ region; (2) chromosome $2 q 35$ markers mapped within $2.5 \mathrm{Mb}$ region of the XRCC5 have been isolated and sequenced; and (3) yeast artificial chromosome (YAC) clones that correspond to these genetic markers have also been identified. Experiments including positional cloning and exon trapping are being used for the cloning of human XRCC5 gene.

\section{Radiation-Induced Mutation Spectra at the Human HPRT Locus (NIH)}

\section{Principal Investigator: D. J.-C. Chen}

The objective of this proposed research is to determine whether characteristic mutation spectra (types and frequencies) can be induced at or proximal to the HPRT locus in normal human fibroblasts exposed to low- and high-LET radiations. If unique mutational spectra can be demonstrated, then this can serve as a molecular signature to differentiate low and high LET radiation-induced genetic damage from that which occurs spontaneously. The specific aims of this project are (1) to determine whether the spectra of point mutations (base substitutions, frameshifts, and small deletions) induced by $\gamma$-rays and high LET radiation are significantly different from those which occur spontaneously and (2) to determine whether the size distribution of deletions induced by various forms of radiation is dependent on the quality of radiation and can be differentiated from that which occurs spontaneously. 


\title{
Transgenic Cell Models of Human Radiation Sensitivity (DOE)
}

\author{
Principal Investigator: M. A. MacInnes
}

Other investigator: Ana V. Perez, Postdoctoral Research Associate

The aim of this research is to determine the cellular, biochemical and mutagenic consequences of gene-targeted transgenic mutations of mammalian cell DNA excision repair (ER). Our research objectives include (1) to develop transgenic knock out (KO) mutations of the mouse ERCC5 gene for introduction into mouse embryonic stem (ES) cells, in vitro; (2) to develop specific site mutations in mERCC5 gene constructs that will mimic the human DNA repair defectxeroderma pigmentosum group G (XP-G) in ES cells; (3) to determine the susceptibilities of these transgenic ES cells to UV radiation, ionizing radiation, and chemically induced cytotoxicity, and the genetic and developmental consequences of mERCC5 deficiencies; and (4) to evaluate the feasibility of breeding a mouse with DNA repair deficiency equivalent to the human XP-G syndrome. Our progress includes construction of $\mathrm{KO}$-mutant constructs in the mERCC5 first translated exon for introduction into mouse ES cells. A putative missense mutation in the hERCC5/XP-G gene has also been identified. We expect that a doubly heterozygous ES cell line containing KQ mutation and an XP-G point mutation will mimic well the cellular defect in some XP-G patients. The anticipated benefits of this work include determining the feasibility of breeding a transgenic mouse with DNA repair deficiency equivalent to XP-G. A complete embryological facility for mouse transgenics is now available at Los Alamos. Transgenic ES cells will also be of use in assessing the relevance of the ERCC5/XP-G gene to cell growth and early embryonic development.

\section{Chromosomal Damage in the One Rad Region: Cytogenetic Detection Following Ultra-Low Doses and Dose Rate (DOE)}

\section{Principal Investigator: E. H. Goodwin}

Chromosome aberration measurements provide a sensitive indication of genetic damage induced by radiation. The objective of this research effort is to obtain quantitative data concerning induction of chromosomal damage by densely ionizing alpha particles at doses as low as $1 \mathrm{rad}$ and to monitor cellular attempts to repair that damage. It is felt that this objective represents a scientifically sound approach to the problem of improving radiological risk assessment in human populations exposed to realistic levels of radon and radon daughter products. As an experimental system, normal human fibroblast cells are exposed to $5 \mathrm{MeV}$ alpha particles from a ${ }^{238} \mathrm{Pu}$ source. Specific aims are (1) to use premature chromosome condensation to measure radiation-induced breaks and to follow the time course of their repair and (2) to use mitotic chromosome analysis and micronuclei measurements to quantitate unrepaired or misrepaired chromosome damage. Innovative approaches are being developed to increase the information content of these cytogenetic techniques and to allow detection of chromosome damage at lower doses than previously possible. Data obtained using these methods will lead to an 
accurate determination of the biological effectiveness of alpha particles. These measurements are being extended down to the dose range where single particle effects predominate. In this low dose range, the estimated effectiveness per unit dose of alpha particle radiation is no longer a function of dose or dose rate and therefore is expected to remain constant at even lower doses characteristic of actual radon exposure levels. The alpha particle data will be compared to similar data for gamma rays, about which carcinogenic potential is thought to be better understood.

\title{
Repair of Bifilar DNA Damage Induced by Radiation (NIH)
}

\author{
Principal Investigator: $R$. J. Reynolds
}

The bifilar nature of closely-opposed cyclobutyl pyrimidine dimers complicates their elimination from cellular DNA by normal enzymatic repair mechanisms. As a result of these complications, it is believed that the induction of dimers at closely-opposed positions may have greater biologic significance than the induction of dimers at relatively isolated positions. The overall objectives of this proposal are to examine factors affecting the induction of closely-opposed pyrimidine dimers and to determine the mechanisms by which they are repaired and the consequences of their induction and repair in eukaryotic cells. Sensitive enzymatic assays, developed in this laboratory, have facilitated the detection and quantization of closely-opposed dimers and have been used to partially characterize the cellular functions necessary for their repair. Current studies are concerned with the replication of DNA past closely-opposed dimers, the effects of DNA sequence on the induction of closely-opposed dimers, and the role of closelyopposed dimers in the induction of genetic recombination by UV radiation.

\section{Recombinational Mechanisms in the Genesis of Chromosomal Exchange Aberrations (LANL)}

Principal Investigator: $R$. J. Reynolds

Co-Investigator: E. H. Goodwin

Chromosomal rearrangement is an important genetic consequence of radiation exposure that is not only relevant to the biologic effects of ionizing radiation but also to national and international risk assessment efforts. Recent experimental findings indicate that nonhomologous recombination at the molecular level may be a good experimental model for fundamental processes mediating the formation of exchange aberrations. The objectives of this research proposal are (1) to increase our understanding of the molecular processes leading to chromosomal rearrangement and (2) to determine the extent to which nonhomologous recombination serves as an experimental model for chromosomal exchange. Current studies are directed towards determining the nature of primary events resulting in the induction of chromosomal rearrangement and nonhomologous recombination. 


\title{
Karyotype Instability and Neoplasia (DOE, LANL)
}

\author{
Principal Investigator: P. M. Kraemer
}

Co-Investigator: F. A. Ray

Much recent evidence has shown an interrelatedness of the cellular programs involved in the control of proliferation and the response to DNA damage; these, in turn, have been shown to have relevance to the genomic instability that appears to be a driver of neoplastic progression. For instance, studies of cells from cancer prone Li-Fraumeni patients indicate that germ line mutations of the p53 gene, which codes for an important cell-cycle check point protein, cause progressive chromosomal instability and the cells become spontaneously immortalized in culture.

To understand these interrelated cellular responses, we are using an SV40 large $T$ antigen-human fibroblast model of carcinogenesis. In this model, ongoing expression of the large $T$ antigen causes ongoing chromosomal instability that drives the cell lineages through the multiple steps of the neoplastic process, finally culminating in blatantly tumorigenic cell populations. We now have numerous cryopreserved cell populations that are at specific stages in the neoplastic process. In conjunction with the Human Genome Center, these cell populations are being used to identify and isolate human genes that are important in human cancer. For instance, newly immortal cell populations have been shown to have deletions and translocations of the long arm of chromosome \#6. Mega YAC (CEPH libraries) are being used to isolate and characterize relevant breakpoints. Other projects concern genetic differences between high passage, "transformed" cells and cells that have further progressed to be tumorigenic in nude mice. We have shown that this step involves abrogation of a kinase dependent process in G1 cell cycle control. Subtractive hybridization of messenger RNA is being used to identify gene expression differences between the two phenotypes.

The mechanism by which the expressed $\mathrm{T}$ antigen causes chromosomal instability has also proven to be of interest in regard to the interrelated cellular processes described above. Mutational analyses of large $T$ antigens have shown that mutant $\mathrm{T}$ antigens that have impaired binding domains for $\mathrm{p} 53$ are incapable of causing both clastogenic and aneuploidogenic chromosome damage.

\section{Development of an Ultrasensitive and Rapid DNA Repair Assay (DOE, LDRD)}

\section{Principal Investigator: M. S. Park}

The objective of this study is to develop an ultrasensitive and rapid DNA repair assay. This assay will enable us to screen individuals with higher risks of skin cancer, to identify potential environmental mutagens, and to aid in the purification and characterization of DNA excision repair proteins. The assay is based upon the experimental observation that the quantity of full-size in vitro transcripts synthesized from DNA templates decreases as a function of chemical- or 
radiation-induced damage in the DNA due to inhibition of transcription beyond these damaged sites. If the DNA damage is repaired, the amount of the synthesized full-size transcripts increases proportionately. Potential advantages of this novel assay over conventional radioactive resynthesis assays currently employed are ease of use, versatility, increased sensitivity, and user-safety. The goals of the project are (1) to optimize the incorporation kinetics of nonisotopic ribonucleotide analogs in the in vitro transcription reaction and (2) to refine this assay in a form that can be readily converted into a "DNA Repair Assay Kit" in cooperation with an industrial partner. In addition, the development of this assay has an immediate application in the purification and characterization of biological functions of the human DNA repair protein, ERCC5/XPGC.

\title{
Applications of Strand-Specific in Situ Hybridization (LANL)
}

\author{
Principal Investigator: E. H. Goodwin
}

Co-Investigator: J. Meyne

Fluorescence in situ hybridization (FISH) is an effective tool for mapping DNA sequences to their corresponding chromosomal locations. In the Life Sciences Division of LANL, a variation of FISH was developed that makes in situ hybridization strand-specific. The advantage of this process is that, in addition to location, the relative orientation of two or more target sequences on the same chromosome can be determined. The new procedure has been named "chromosomal orientation FISH" (CO-FISH). Using CO-FISH, we have observed that the tandemly repeated units of many, but not all, satellite DNA sequences are arranged head-to-tail, whereas dispersed repeats show no preferential orientation at the level of light microscopy. The TTAGGG telomeric repeats are known to have a 5'-to-3' direction pointing towards the end of the chromosome. Therefore, the absolute direction of any other sequence can be learned from its orientation with respect to telomeres. The objective of this research effort is to expand the range of applications of strand-specific in situ hybridization. We intend to develop $\mathrm{CO}-\mathrm{FISH}$-based methods to examine altered gene expression, investigate mechanisms of gene amplification, and facilitate genomic mapping.

\section{Research Accomplishments}

- We have obtained the sequence of a $3.0 \mathrm{~Kb}$ genomic DNA segment including the mERCC5 first exon. Knock out mutation constructs containing an insertion of a neo ${ }^{r}$ and hygr gene (and deleting the first exon entirely) are now being introduced into ES cells.

- A fully equipped and operational transgenics facility has been commissioned at Life Sciences Division.

- The embryonic expression (mRNA) of the mERCC5 gene has been examined through in situ hybridization with riboprobes specific to mERCC5 in fixed mouse embryo sections. 
- Functional ERCC5/XPGC minigenes in RSV and CMV transcription units have been constructed from full length segments of human ERCC5 cDNA.

- Site specific mutations are being introduced into the ERCC5 minigene to test noncomplemention of XP-G and other ERCC5 deficient human and $\mathrm{CHO}$ cell genetic backgrounds.

- A single-strand conformation polymorphism (SSCP) method has been utilized to identify a homoallelic mutation in the ERCC5 gene of a xeroderma pigmentosum, group $G$ patient. These results suggest a genetic basis for this syndrome.

- We have found that the ERCC5 protein is located in the nucleus as speckles. Confocal microscopy and biochemical fractionation experiments suggest that the ERCC5 protein is associated with the nuclear matrix.

- We made four polyclonal antibodies specific to ERCC5 protein and detected ERCC5 protein in human cells by indirect fluorescent microscopy, western analysis, and immunoprecipitation. ERCC5 appears to migrate slightly faster $(120 \mathrm{kDa})$ that the predicted molecular weight (136 kDa) on SDS gel. Native gel electrophoresis results suggest that ERCC5 forms dimeric structure.

- We developed a secondary structure model for the helix-loop-helix motif (HLH) of the evolutionary conserved putative functional domain of the ERCC5 protein. We found that HLH motifs of human, mouse, and yeast homologs of ERCC5 protein form the identical secondary structure despite the differences in the primary structure.

- We demonstrated that a 36-amino acid long synthetic peptide containing the HLH motif forms a homodimeric structure in vitro. Dimerization appears to be a rapid (i.e., within $5 \mathrm{~min}$ at the concentration of $>10 \mu \mathrm{M}$ of peptide) process.

- We established a bacterial expression system to overproduce a 52-amino acid long peptide containing the HLH motif and purified the peptide to $99 \%$ homogeneity for future structural analyses using CD and NMR.

- We established an insect overexpression system to produce ERCC5 holoenzyme in large quantity. We confirmed that the insect culture contained the baculoviral-ERCC5 recombinant DNA molecules.

- Denaturing gradient gel electrophoresis has been utilized to identify mutational hotspots induced in exons 2, 3, and 4 of the human HPRT gene following exposure of human lyphoblastoid cells to ionizing radiation. There appears to be a specificity for the kinds and positions of mutations induced that suggest specific mechanisms by which $\mathrm{x}$-rays can induce mutations in human cells.

- A new mutation has been uncovered in exon 9 of the human B-glucocerebrosidase gene at cDNA bp 1237 (Gly 377 to Ser). The genotype/phenotype of this patient suggests that this mutation will most likely be associated with the mild form of Gaucher Disease.

- We have cloned a number of synthetic oligonucleotide sequences and used them to examine the induction of closely-opposed dimers at defined potential sites. 
- We have found that transfection of mammalian cells resembles the formation of chromosomal exchange aberrations in that it is also mediated, at least in part, by a lesion-lesion interaction mechanism.

- We have demonstrated that the transfection of mammalian cells can be induced by the presence of single-strand breaks in the transfecting DNA and that transfection stimulated either by single- or double-strand breaks is mediated, at least in part, by topoisomerase II-cleavable complexes.

- We have shown that the mechanism by which the SV40 T antigen transforms human cells involves iterative cycles of chromosome damage and selection. The chromosomal damage appears to be an indirect effect of complex formation involving wild type p53 and large $T$ antigen.

- The loss of a staurosporine-sensitive G1 control point has been shown to be a late step in the transformation of human fibroblasts with the SV40 large T antigen. Recent results show that this loss is coupled to the acquisition of tumorigenicity rather than to the in vitro indicators of neoplastic transformation, such as growth in low serum or anchorage independence.

- Immortalization, a rate limiting step in carcinogenesis, has been shown to involve genes located at 6q21 in human fibroblasts. Mega YAC (CEPH) clones mapping to this region have been isolated and are being used for breakpoint analyses in three newly immortalized cell populations with clonal translocations at this locus.

- Newly immortalized human cells do not form normal quartenary complexes of the cyclin-dependent kinases. These complexes are thought to be important in normal cell cycle control. 


\title{
PULMONARY BIOLOGY
}

\section{Mechanisms of Pulmonary Damage (DOE)}

\author{
Principal Investigator: $B$. E. Lehnert
}

Co-Investigator: J. A. Steinkamp

The objective of this project is to delineate the biophysical, cellular, and molecular mechanisms involved in lung defense, lung injury, and lung repair. Work in the area of lung defense mechanisms focuses on the further refinement of an alveolar macrophage-based model of particle clearance from the lung, including particle clearance during the condition of particle overload. The lung injury component of the project is concerned with the regulation of production of proinflammatory cytokines and other mediators of inflammation by pulmonary macrophages. The lung repair component of the project focuses on the elucidation of cytokine-mediated cell-cell dialogues that underlie particle-induced pulmonary fibrosis. These latter investigations particularly address pulmonary macrophagelung fibroblast interactions using rodent and human cells, with emphasis on how gene expression for the profibrogenic cytokines that are produced by these cells is regulated. The experimental approaches used in this project include multiparameter flow cytometry for the identification and isolation of subpopulations of pulmonary macrophages and fibroblasts for in vitro studies, phase sensitive flow cytometry for the investigation of cell surface antigens and receptors, and a variety of molecular biological techniques for assessing gene expression, e.g., reverse transcriptionpolymerase chain reaction, in situ hybridization.

\section{Mechanism(s) of Lung Injury Caused by Perfluoroisobutylene and Related Agents (DoD)}

\section{Principal Investigator: B. E. Lehnert}

The inhalation of perfluoroisobutylene and some other halogenated hydrocarbons can cause acute hyperpermeability changes in the lungs and thereby cause life-threatening pulmonary edema. The mechanisms by which these toxic gases mediate lung injury are unknown, and there is currently no satisfactory therapeutic strategy to treat the pneumoedematogenic effects they elicit. During the last year, this project has been redirected to specifically focus on the toxic gas phosgene, with the driving objectives being (1) to investigate the cellular bases of phosgene-induced lung injury and (2) to develop a mechanistically based therapeutic approach for treating such injury. The experimental approaches used in this project include in vivo and in vitro models, an advanced phosgene exposure system, quantitative analyses of proinflammatory cytokine production by lavaged cells, and electron microscopic/ultrastructural analyses of lung tissues and cells. 


\section{Research Accomplishments}

- We demonstrated that the cytokines produced by lung fibroblasts that stimulate the proliferation of alveolar macrophages are Granulocyte/Macrophage Colony Stimulating Factor (GM-CSF) and Macrophage Colony Stimulating Factor (M-CSF).

- We demonstrated that the gene expression for and the production of GM-CSF by lung fibroblasts is up-regulated by tumor necrosis factor- $\alpha$ and interleukin-1, which are alveolar macrophage-derived proinflammatory cytokines produced in response to the deposition of profibrogenic particles in the lungs. These findings suggest that cytokines produced by alveolar macrophages can up-regulate the production of a cytokine by fibroblasts that in turn exerts a promitogenic effect on the macrophages.

- We demonstrated that two flow cytometrically isolated subpopulations of lung fibroblasts (thy $1^{+}$and thy $1^{-}$) are equivalently capable of producing cytokines that stimulate the proliferation of alveolar macrophages.

- The cytokine interleukin-4 (IL-4), which is produced by activated T-lymphocytes, has been shown to inhibit GM-CSF and M-CSF stimulated proliferation of alveolar macrophages. IL-4 also has been shown to markedly inhibit the ability of alveolar macrophages to produce tumor necrosis factor- $\alpha$ in response to endotoxin. Thus, IL-4 may be therapeutically useful for managing lung disease processes in which alveolar macrophages are both activated and increased in number.

- The sizes of the alveolar macrophage and pulmonary interstitial macrophage populations in the lungs of mice have been characterized. As in the rat model, the interstitial macrophages have been found to represent $\sim 40 \%$ of all lung macrophages.

- Ultrastructural analyses of lung tissue following phosgene exposure have revealed that the primary site of injury is essentially restricted to the most peripheral terminal bronchiole-first generation alveolar duct region. This observation has led to evaluations of therapeutic approaches that preferentially target this main site of injury.

- Evidence has been obtained that tumor necrosis factor- $\alpha$ (TNF- $\alpha$ ) production by alveolar macrophages is not involved in the early component of phosgeneinduced permeability pulmonary edema. Additionally, the absence of abnormally elevated concentrations of TNF- $\alpha$ in the lung's extracellular fluid lining after phosgene exposure has further indicated that this proinflammatory cytokine does not play a role in mediating the pulmonary edematous response to phosgene.

- Evidence has been obtained that indicates that the translocation of particleladen macrophages onto the conducting airways via the bronchus-associated lymphoid tissue is not an important route for macrophage-mediated particle clearance from the lung. 
- Further refinements have been made in an alveolar macrophage-based model of particle clearance from the lung's alveoli. A new hypothesis that has been incorporated in the model is that the diminishing rates of particle clearance from successive airway generations is also applicable to the translocation of alveolar macrophages that reside in the numerous generations of alveolar ducts in the lung.

- Using ultrastructural/morphometric analyses of lung tissue following the deposition of a heavy burden of particles, an association has been made between reduced alveolar phase clearance and the anatomical loss of the alveolar pores of Kohn, which may otherwise represent short-cut pathways for alveolar macrophages translocated to more proximally-located alveoli.

- In situ autolysis of particle-containing alveolar macrophages and the rephagocytosis of freed particles by other macrophages has been identified as a major mechanism underlying the particle redistribution phenomenon that was previously observed in our laboratory during investigations of alveolar phase clearance of particles. This finding suggests that free particles can be essentially continuously present on the alveolar surface at times well after they were originally deposited in the lungs and phagocytized by resident phagocytes.

- Phase sensitive flow cytometry has been successfully used to resolve fluorescence signals from propidium iodide and phycoerythrin-labeled cells, i.e., overlapping fluorescence emissions, based on differences in the fluorescence lifetimes of the two fluorochromes. 


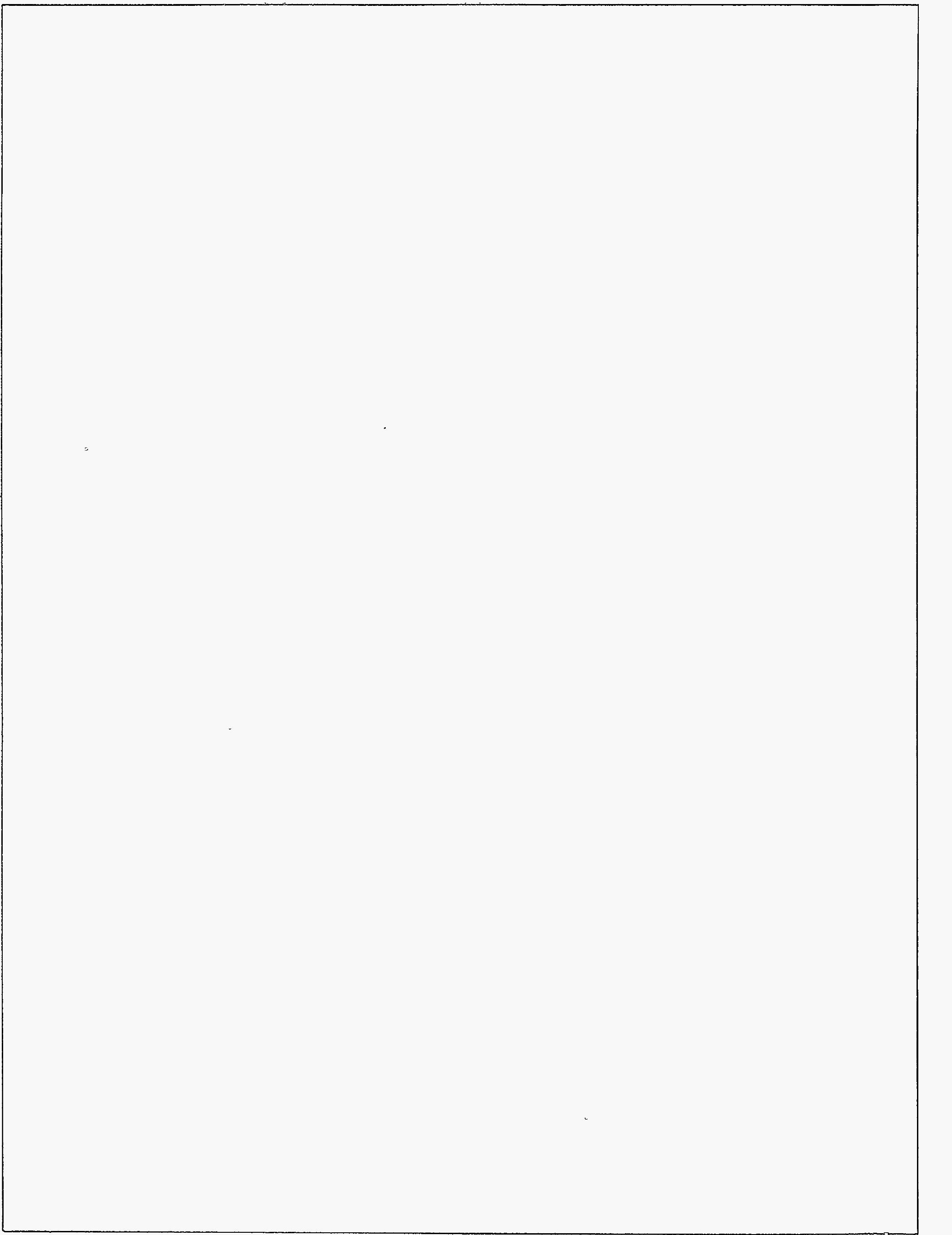




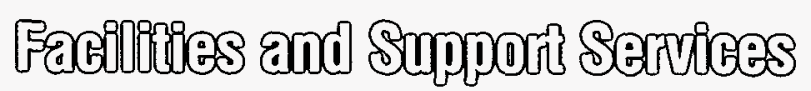




\section{NATIONAL FLOW CYTOMETRY RESOURCE}

J. Jett, L. S. Cram, G. C. Salzman, J. Martin, L. Sklar, M. Smyth, J. Steinkamp, and H. Crissman

The National Flow Cytometry Resource (NFCR) was established to make state-of-the-art flow cytometric instrumentation available to the biomedical research community. The NFCR is supported by the Biomedical Research Technology Program, the National Center for Research Resources of NIH, and by the Office of Health and Environmental Research, Department of Energy. The focus of the NFCR is to provide an active and dynamic program of collaborative research, develop new instrumentation capabilities and biological techniques based on identified user need, train scientists in the use of flow cytometry, and serve as an interface between the academic, private, and government sectors. To this end the Resource has the following five major goals:

- Technological Research and Development. Develop and make available advanced flow cytometric instrumentation and relevant methodology in response to specific needs of the biomedical community, collaborators, and service users. Identify new investigative and clinical uses for flow cytometry.

- Collaborative Research. Establish research projects between NFCR staff and scientists at other institutions that enhance and enlarge the frontiers of flow cytometry for answering significant biomedical questions.

- Service Projects. Provide support for short-term projects to the user community that will help facilitate the availability of general flow cytometric techniques and technology.

- Training. Students, postdoctoral appointees, and scientists are trained in the operation and application of flow instruments and in related technologies.

- Dissemination. Information about the availability of the NFCR and its activities is disseminated through the Flow Systems Newsletter, postdoctoral training, brochures, and transfer of technology to other institutions.

Unique capabilities either exist or are being established in the following areas: chromosome analysis and sorting, high resolution analysis, super high-speed sorting, Fourier transform cytometry, phase sensitive detection cytometry, and multilaser excitation systems. Techniques include analysis of fluorescence polarization, kinetic measurements, correlated data analysis procedures, high resolution DNA studies, staining protocol development, fluorescence distribution analysis, and multiparameter procedures. Research fields include cellular and molecular biology, tumor biology, infectious disease, parasitology, genetics, and radiobiology. Biomedical research investigators from around the nation are involved in the use and management of this designated user facility. 


\section{HIGH, MEDIUM, AND LOW DOSE-RATE GAMMA-RAY IRRADIATION FACILITY}

\section{G. F. Strniste}

Delivery of a high dose-rate Mark I 137Cs Irradiator manufactured by J. L. Shepherd and Associates is anticipated in January 1994. This unit, containing $\sim 7,000 \mathrm{Ci} 137 \mathrm{Cs}$, will provide sample irradiation with $0.66 \mathrm{MeV}$ gamma rays at dose rates up to $17.5 \mathrm{~Gy} / \mathrm{min}$. This new unit will complement our existing dual irradiation facility, which contains a medium dose-rate 60Co irradiator that currently (as of 11/93) produces fluxes of $1.17 \mathrm{MeV}$ gamma rays at dose rates between 0.75 and $3.0 \mathrm{~Gy} / \mathrm{min}$ and a low dose-rate 137Cs irradiator (specially designed Model 81-12 manufactured by J. L. Shepherd and Associates) that produces fluxes of $0.66 \mathrm{MeV}$ gamma-rays between 0.2 and $200 \mathrm{cGy} / \mathrm{hr}$. These three irradiators will provide research personnel with a dynamic range in fluxes of gamma rays $>500,000$-fold. Our radiation facility is used extensively by radiobiologists in the Life Sciences Division, in both molecular and cellular experimentation. In addition, source time has been provided to other Laboratory personnel in studies concerning radiation physics and dosimetry, radiation chemistry, and plant biology.

\section{IMAGE MICROSCOPY}

\section{B. L. Marrone}

The image microscopy facility is a laboratory resource for digital image acquisition, analysis, processing, and hard copy output. Two microscope systems are available for image acquisition. The Zeiss Axiophot microscope is fitted with a Photometrics (Tucson, AZ) slow-scan cooled CCD camera containing a $1 \mathrm{~K} \times 1 \mathrm{~K}$ Kodak KAF-1400 Grade 1 chip. The camera is interfaced via a VME bus-to-S-bus adapter to a Sun Sparc 2GX computer running Inovision dsp/os/ISee software for image acquisition and microscope control (Inovision, Corp., Research Triangle Park, NC). This microscope also is equipped with a motorized excitation filter wheel, for multicolor imaging, and a motorized $x, y, z$ stage. A Zeiss LSM-10 laser scanning confocal microscope is equipped with a $10 \mathrm{~mW}$ argon laser $(488 \mathrm{~nm}$, $514 \mathrm{~nm}$ excitation) and a HeNe laser. The computers controlling image acquisition are part of an ethernet network dedicated to image processing. Image processing is performed with the image processing software package KHOROS (University of New Mexico, copyrighted). For image analysis, images are stored on a Sun Sparc 1 file server and accessed over the network via NFS/Share (Intercon, Herndon, VA) by a Macintosh computer. The Macintosh has a 24-bit video card and a 20-inch Supermatch color monitor for highest resolution image display. Other image processing and analysis software includes IP Lab Spectrum, NIH image, and Adobe Photoshop. An HP laserjet printer, and two Tektronix color printers (IIPXe and IIsdx) are also on the network to provide a complete range of high quality printed image output. The software and printing capabilities are also available over the ethernet to users of the Bioimage system and the image scanners. 

Orgamization 


\section{Life Sciences Division Organization Chart}

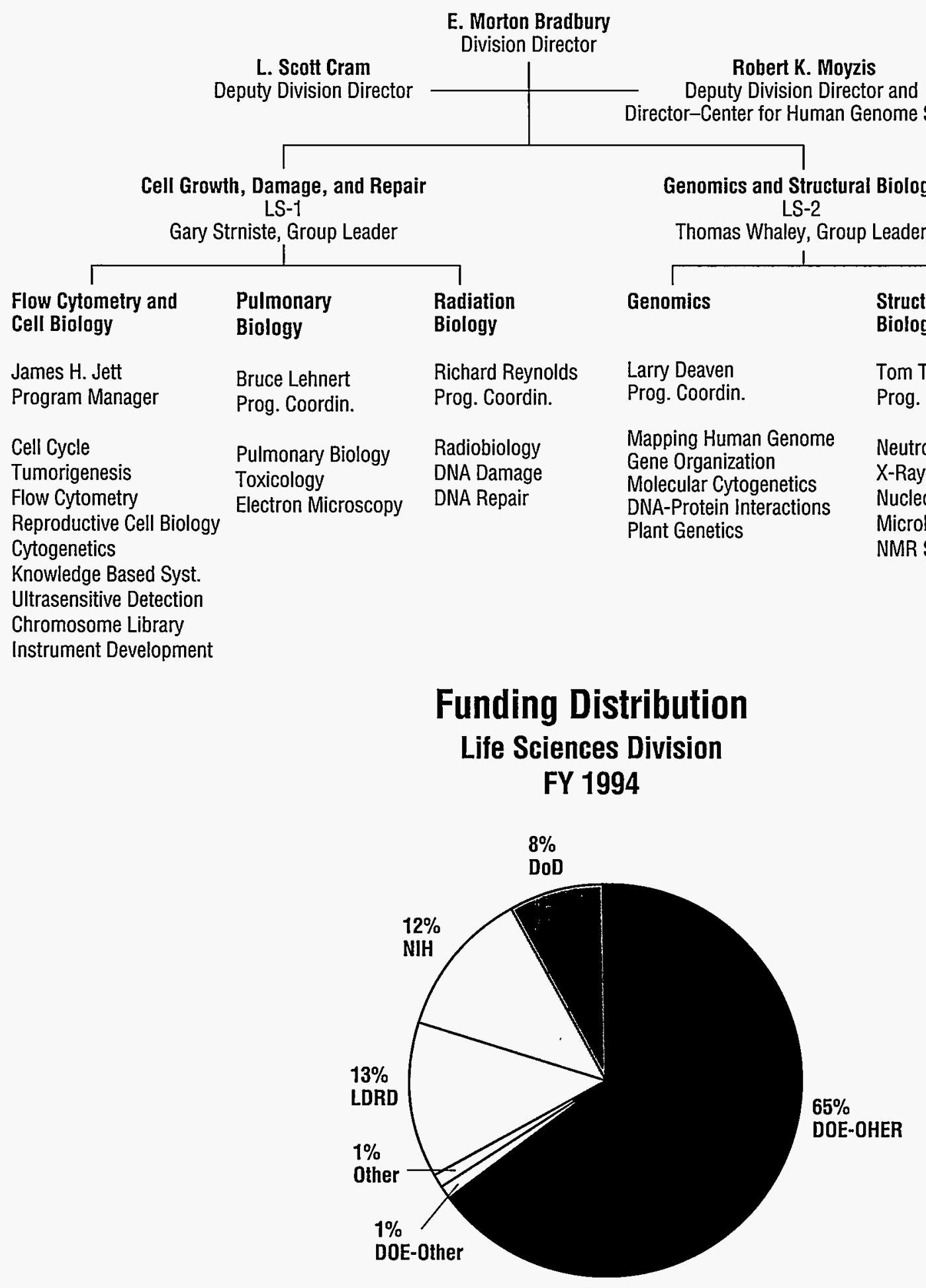




\title{
LIFE SCIENCES DIVISION (LS-DO)
}

\author{
Morton Bradbury, Division Director \\ Scott Cram, Deputy Division Director \\ Robert Moyzis, Deputy Division Director \\ Carolyn Stafford, Staff Assistant
}

Gary Strniste, Group Leader, LS-1

Thomas Whaley, Group Leader, LS-2

Russell Durrer, Facility Manager

Fawn Gore, Division Office Administrator

John Horne, Building Manager

Cheryl Straub, Budget Fiscal Specialist, BUS-8

Kathy Montoya, Secretary

Scott Downing, Waste Management Coordinator

Lori Wolfe, Property Administrator, BUS-6

Rebekah Rice, High School Co-op

Laboratory Associate

Donald F. Petersen

\section{CENTER FOR HUMAN GENOME STUDIES (CHGS)}

Robert K. Moyzis, Direcior

Larry L. Deaven, Deputy Director

Monica H. Fink, Administrative Assistant

Lynn M. Clark, Technical Administrator 


\title{
CELL GROWTH, DAMAGE, AND REPAIR GROUP (LS-1)
}

\author{
Gary F. Strniste, Group Leader \\ James H. Jett, Program Manager \\ Bruce Lehnert, Program Coordinator \\ Richard Reynolds, Program Coordinator \\ Ruby Archuleta, Group Office Administrator \\ Dusty Deaguero, Secretary
}
Staff Members
E. Campbell
D. Chen
H. Crissman
J. Freyer
E. Goodwin
P. Kraemer
B. Lehnert
M. MacInnes
B. Marrone
J. Martin
R. Okinaka
M. Park
F. Ray
R. Reynolds
G. Salzman
L. Sklar
M. Smyth
J. Steinkamp
W. Wharton
M.Wilder

\section{Postdoctoral Fellows}

S. Amundson

C. Deka

M. Englen

D. Gadbois

J. Knauf

L. Kunz

J. Nolan

M. Roslaniec

M. Stackhouse

Y. Takiguchi

C. Wistrom

\section{Technical Staff}

D. Archuleta

S. Bailey

C. Bell-Prince

L. Bustos

M. Campbell

J. Dickson

J. Fawcett

R. Habbersett

P. Jewett

N. Lehnert

A. Martinez

P. Pardington

J. Parson

P. Schor

R. Sebring

K. Shera

Y. Valdez

M. Waltman

Distinguished Visitors

Y. Yamada

National Institute of

Radiological Sciences

Chiba, Japan
Students and Assistants

D. Adair

A. Archuleta

L. Biddison

F. Chen

K. Cloud

G. Crane

A. Deshpande

J. Fulwyler

J. Greene

M. Hankins

B. Harvet

L. Hii

G. Hirons

D. Kim

J. Kim

K. Laubscher

H. Lindford

B. Liu

S. Minter

M. Naivar

A. Nauman

T. Nguyen

T. Olivier

J. Ortiz

R. Palmer

S. Pendergrass

A. Pierce

C. Potter

D. Scott

A. Sena

B. Stone

S. Tan 


\section{GENOMICS AND STRUCTURAL BIOLOGY GROUP (LS-2)}

Thomas Whaley, Group Leader

Paul Jackson, Deputy Group Leader, Acting Larry Deaven, Program Coordinator Thomas Terwilliger, Program Coordinator Tricia Lewis, Group Office Administrator

Faye Viarrial, Secretary
Staff Members

M. Altherr

J. D'Anna

M. Brooks

N. Doggett

J. Gatewood

D. Grady

W. Gu

L. Hersman

E. Hildebrand

B. Imai

C. Kuske

J. Longmire

J. Meyne

R. Nanni

R. Ratliff

B. Schoenborn

R. Wagner

J. Wilson

Postdoctoral Fellows

R. Affleck

P. Catasti

$X$. Chen

H. C. Chi

J. DeWitt

D. Leschnitzer

A. Perez

E. Peterson

S. Peterson

M. Skinner
Technical Staff

N. Brown

D. Bruce

J. Buckingham

K. Denison

L. Duesing

A. Ford

M. Jones

R. Lehndorf

C. Lemanski

R. Lobb

T. Lucero

L. Meincke

C. Munk

C. Naranjo

D. Robinson

L. Saunders

J. Tesmer

S. Thompson

$\mathrm{K}$. Umbarger

J. Valdez
Students and Assistants

K. Banton

P. Goudreau

G. Green

K. Hill

J. Houts

A. Jennison

J. Liu

X. Liu

M. Lowenstein

W. Sawhill

J. Siino

Q Simmons

R. Tagett

C. Tape

M. Valdez 

Commonofibations 


\section{Center for Human Genome Studies (CHGS)}

\section{Publications}

Baxendale, S., M. E. MacDonald, R. Mott, F. Francis, C. Lin, S. F. Kirby, M. James, G. Zehetner, H. Hummerich, J. Valdes, F. S. Collins, L. L. Deaven, J. F. Gusella, H. Lehrach, and G. P. Bates, Construction of cosmid contigs and high resolution restriction maps of a $2 \mathrm{Mbp}$ region containing the Huntington's disease gene, Nature Genetics 4 (2), 181-186 (1993).

Brayton, K. A., Z. Chen, G. Zhou, P. L. Nagy, A. Gavalas, J. M. Trent, L. L. Deaven, J. E. Dixon, and H. Zalkin, Two genes for de novo purine nucleotide synthesis on human chromosome 4 are closely linked and divergently transcribed, J. Biol. Chem, in press (1994).

Chang, K.-S., S. A. Stass, D.-T. Chu, L. L. Deaven, J. M. Trujillo, and E. J. Freireich, Characterization of a fusion cDNA (Rara/myl) transcribed from the $t(15 ; 17)$ translocation breakpoint in acute promyelocytic leukemia, Molec. and Cell. Biology 12, 800-810 (1992).

Cram, L. S., J. J. Fawcett, and L. L. Deaven, Flow cytogenetics: fundamentals and new developments, NATO ASI Series, Vol. H67, 259-268 (1993).

Doggett, N. A., D. L. Grady, J. L. Longmire, and L. L. Deaven, Generation and mapping of chromosome specific sequence-tagged sites (STSs), in DNA Sequencing Protocols: A Guide to Methods and Applications (J. Craig Venter, ed.), Academic Press Limited, London, UK, in press (1993).

Lyn, D., L. L. Deaven, N. L. Istock, and M. Smulson, The polymorphic ADP-ribosyltransferase $\left(\mathrm{NAD}^{+}\right)$pseudogene 1 in humans interrupts an endogenous pol-like element on 13q34, Genomics 18, 206-211 (1993).

McCormick, M. K., E. W. Campbell, L. L. Deaven, and R. K. Moyzis, Low-frequency chimeric yeast artificial chromosome libraries from flow-sorted human chromosomes 16 and 21, Proc. Natl. Acad. Sci. 90, 1063-1067 (1993).

Myers, R. L., R. A. Payson, M. A. Chotani, L. L. Deaven, and I.-M. Chiu, Gene structure and differential expression of acidic fibroblast growth factor mRNA: Identification and distribution of four different transcripts, Oncogene 8, 341-349 (1993).

Myers, R. L., R. A. Payson, W.-P. Wang, L. L. Deaven, and I.-M. Chiu, Tissue and differentiation specific expressiontiple human aFGF transcripts containing different upstream nontranslated exons, Molecular and Cellular Biology, in press (1992).

Sanford, J., B. -W. Kim, L. L. Deaven, C. Jones, M. J. Higgins, N. J. Nowak, and T. B. Shows, A human chromosome 11 Not1 end clone library, Genomics 15, 653-658 (1993).

Ward, J. R. T., S. Cottrell, H. J. W. Thomas, T. A. Jones, C. M. Howe, G. M. Hampton, L. L. Deaven, D. Sheer, W. F. Bodmer, E. Solomon, and A.-M. Frischauf, A long range restriction map of human chromosome 5q21-23, Genomics 17, 15-24 (1993).

Wood, S., M. Schertzer, H. Drabkin, D. Patterson, J. L. Longmire, and L. L. Deaven, Characterization of a human chromosome 8 cosmid library constructed from flow-sorted chromosomes, Cytogenetics and Cell Genetics 59, 243-247 (1992).

\section{Report}

McPherson, J. D. and L. L. Deaven, Report of the committee on the genetic constitution of chromosome 5, in chromosome coordinating meeting, A. J. Cuticchia, P. L. Pearson, and H. P. Klinger (eds), Genome Priority Reports, Vol. 1., pp. 249-268, Basel, Karger (1993). 


\section{Cell Growth, Damage, and Repair Group (LS-1)}

\section{Publications}

Bernardin, M. P., and B. E. Lehnert. Alveolar macrophage-based model of the alveolar clearance of a low lung burden of insoluble, non-cytotoxic particles, American Journal of Physiology: Lung Cellular and Molecular Physiology, in press (1994).

Brandt, M. M., E. Lynam, and L. A. Sklar. Blockade of neutrophil priming in blood by corticosteroids, Journal of Surgical Research, in press (1994).

Brandt, M. M., E. Lynam, and L. A. Sklar. Methyloprednisolone inhibits three classes of neutrophil receptors in human blood in vitro, Journal of Surgical Research 99, 632 (1993).

Butcher, B., L. A. Sklar, L. Seamer, and R. Glew. Cytometric analysis of Leishmania monocyte interaction, J. Immunology 148, 2879-2886 (1992).

Chambers, J. D., S. Simon, E. Berger, L. A. Sklar, and K.-E. Arfors, Endocytosis of $\beta_{2}$-integrins by stimulated human neutrophils analyzed by flow cytometry, Journal of Leukocyte Biology 53, 462 (1993).

Chen, D. J., R. T. Okinaka, and K. Tsuboi. Detection of point mutations in human HPRT cDNA by cDNA-driven PCR and mismatch analysis, Mutation Research, in press (1994).

Chen, D. J., M. S. Park, E. W. Campbell, M. Oshimura, P. Liu, Y. Zhao, B. White, and M. Siciliano. Assignment of a human DNA double-strand break repair gene (XRCC5) to human chromosome 2, Genomics, in press (1994).

Chen, D. J., and K. Tsuboi. Non-radioactive chemical cleavage technique to detect point mutations, Nucleic Acid Research, in press (1994).

Chen, D. J., K. Tsuboi, T. T. Nguyen, and T. C. Yang. Charged-particle mutagenesis II: Mutagenic effects of high energy charged particles in normal human fibroblasts, Advances in Space Research, in press (1994).

Cornforth, M. N., and E. H. Goodwin. Terminal deletions and the contribution of unrepaired damage to the fixation of radiation-induced cytogenetic lesions, Radiation Research, in press (1994).

Crowell, R. E., E. Heaphy, C. Mold, and B. E. Lehnert. Alveolar and interstitial macrophage populations in the murine lung, Exp. Lung Research 18, 435-446 (1992).

Dive, C., T. M. Yoshida, D. J. Simpson, and B. L. Marrone. Flow cytometric analysis of steroidogenic organelles in differentiating granulosa cells, Biology of Reproduction, in press (1994).

Fay, S. P., M. Domalewski, and L. A. Sklar. Evidence for protonation of ligand in the binding pocket of the formylpeptide receptor, Biochemistry 32, 1627-1631 (1993).

Gadbois, D. M., H. A. Crissman, R. A. Tobey, and E. M. Bradbury. Multipoint kinase control of progression through G1 phase of the cell cycle, Proc. Natl. Acad. Sci., USA 89, 8626-8630 (1992).

Goodwin, E. H., and E. A. Blakely. Heavy-ion-induced chromosomal damage and repair, Advances in Space Research 12, 81-89 (1992).

Goodwin, E. H., and M. N. Cornforth. RBE: mechanisms inferred from cytogenetics, Advances in Space Research, in press (1994).

Goodwin, E. H., and J. Meyne. Strand-specific FISH reveals orientation of chromosome 18 alphoid DNA, Cytogenetics and Cell Genetics 63, 126-127 (1993).

Gurley, L. R., J. E. London, G. L. Tietjen, A. J. van der Kogel, L. A. Dethloff, and B. E. Lehnert. Lung hyperpermeability and biochemical constituent changes in bronchoalveolar lavage fluids following thoracic $\mathrm{x}$-irradiation, Radiat. Research 134, 151-159 (1993). 
Hamaguchi, J. R., R. A. Tobey, J. Pines, H. A. Crissman, T. Hunter, and E. M. Bradbury. Requirement for $\mathrm{p} 34 \mathrm{cdc} 2$ kinase is restricted to mitosis in the mammalian cdc2 mutant FT2110, J. Cell Biology 117, 1041-1053 (1992).

Jett, J. Some considerations in the analysis of clinical DNA histogram data, clinical applications of flow cytometry and image analysis, Excertpa Medica International Congress Series, in press (1994).

Kraemer, P. M., and E. M. Bradbury. Abrogation of a kinase mediated G1 cell cycle arrest point is a late event in the neoplastic progression of human fibroblasts transfected with the SV40 large T antigen gene, Experimental Cell Research 207, 206-210 (1993).

Lehnert, B. E. Defense mechanisms against inhaled particles and associated particle-cell interactions, Reviews in Minerology, in press (1994).

Lehnert, B. E. The particle redistribution phenomenon as a factor complicating microdosimetry in the lung, Radiation Protection Dosimetry 38, 237-244 (1992).

Lehnert, B. E. Pulmonary and thoracic macrophage subpopulations and clearance of particles from the lung, Environ. Health Perspect. 97, 17-46 (1992).

Lehnert, B. E., D. C. Archuleta, T. Ellis, W. S. Session, N. L. Lehnert, L. R. Gurley, and D. M. Stavert. Lung injury following exposure of rats to relatively high mass concentrations of nitrogen dioxide, Toxicology, in press (1994).

Lehnert, B. E., D. C. Archuleta, M. J. Behr, and D. M. Stavert. Lung injury after acute inhalation of perfluoroisobutylene: Exposure concentration-response relationships, Inhal. Toxicol. 5, 1-32 (1993).

Lehnert, B. E., J. B. Ortiz, J. A. Steinkamp, G. L. Tietjen, R. J. Sebring, and G. Oberdörster. Mechanisms underlying the "particle redistribution phenomenon," J. Aerosol Med. 5 (4), 261-277 (1992).

MacInnes, M. A., J. A. Dickson, R. R. Hernandez, D. Learmonth, G. Y. Lin, J. S. Mudgett, M. S. Park, S. Schauer, R. J. Reynolds, G. F Strniste, and J. Y. Yu, Human ERCC5 cDNACosmid Complementation for Excision Repair and Bipartite Amino Acid Domains Conserved with $R A D$ proteins of Saccharomyces cerevisiae and Schizosaccharomyces pombe, Molecular and Cellular Biology 13, 6393-6402 (1993).

Marusic, M., Z. Bajzer, J. P. Freyer, and S. Vuk-Pavlovic. Analysis of growth of multicellular tumor spheroids by mathematical models, Cell Proliferation, in press (1994).

Marusic, M., Z. Bajzer, S. Vuk-Pavlovic, and J. P. Freyer. Tumor growth in vivo and as multicellular spheroids compared by mathematical models, Math. Biosciences, in press (1994).

Mueller, H., R. Weingarten, L. Ransnas, G. M. Bokoch, and L.A. Sklar. Differential amplification of antagonistic receptor pathways in neutrophils, Journal of Biological Chemistry, in press (1994).

Muraiso, C., J. S. Mudgett, H. Matsudaira, and G. F. Strniste. A shuttle vector system for studying ionizing radiation-induced mutagenesis in mammalian cells, Journal Radiation Research 34, 148-156 (1993).

Nagasawa, H., J. B. Little, E. Saunders, J. Tesmer, and G. F. Strniste. Effect of dose-rate on the survival of irradiated human skin fibroblasts, Radiation Research 132, 375-379 (1992).

Neubig, R., and L. A. Sklar. Subsecond modulation of ternary complex dynamics by GTP(S), Mol. Pharm. 43, 734-740 (1993).

Nickoloff, J. A., and R. J. Reynolds. Electroporation-mediated gene transfer efficiency is reduced by linear plasmid carrier DNAs, Analytical Biochemistry 205, 237-243 (1992). 
Oberdörster, G., J. Ferin, and B. E. Lehnert. Correlation between particle size, in vivo particle persistence and lung injury. Environ. Health Perspect., in press (1994).

Okinaka, R. T., S. L. Anzick, A. Oller, and W. G. Thilly. Analysis of large x-ray-induced mutant populations by denaturing gradient gel electrophoresis, Radiation Research 135 , 212-221 (1993).

Posner, R. G., S. P. Fay, M. D. Domalewski, and L. A. Sklar. Continuous spectrofluorometric analysis of ternary complex dynamics: Formyl-peptide receptor, Mol. Pharm., in press (1994).

Posner, R. G., S. P. Fay, M. D. Domalewski, and L. A. Sklar. Real-time analysis of ternary complex assembly and disassembly by spectrofluorometric methods, Mol. Pharm., in press (1994).

Ray, F. A., and P. M. Kraemer. Frequent deletions in nine newly immortal human cell lines, Cancer Genetics and Cytogenetics 59, 39-44 (1992).

Ray, F. A., and P. M. Kraemer. Iterative chromosome mutation and selection as a mechanism of complete transformation of human diploid fibroblasts by SV40 T antigen, Carcinogenesis 14, 1511-1516 (1993).

Ray, F. A., J. Meyne, and P. M. Kraemer. SV40 T antigen induced chromosomal changes reflect a process that is both clastogenic and aneuploidogenic and is ongoing throughout neoplastic progression of human fibroblasts, Mutation Research 284, 265-273 (1992).

Rochon, Y., S. Simon, E. Lynam, and L. A. Sklar. A role for lectin-like interactions during human neutrophil aggregation, J. Immunol. 52, 1385 (1994).

Schwart, J. L., J. Rotmensh, R. W. Atcher, R. F. Jostes, F. T. Cross, T. E. Hui, D. J. Chen, and $\mathrm{S}$. Carpenter. Interlaboratory comparison of different radon sources: Cell survival and RBE, Health Physics, in press (1994).

Sebring, R. J., and B. E. Lehnert. Morphologic and ultrastructural comparisons of rat alveolar macrophages, pulmonary interstitial macrophages, and blood monocytes, Exp. Lung Res. 18, 479-496 (1992).

Simon, S. I., D. J. Chambers, E. Butcher, and L. A. Sklar. Neutrophil aggregation in $\beta_{2}$-integrin L-selectin dependent in blood and isolated cells, J. Immunology 149, 2765-2771 (1992).

Simon, S. I., Y. Rochon, D. C. Anderson, C. W. Smith, and L. A. Sklar. $\beta_{2}$-Integrin and L-selectin are obligatory receptors in neutrophil aggregation, Blood 82, 1097-1106 (1993).

Sklar, L. A. Flow cytometry-high speed approaches to detecting cellular structure, mechanism, and function, Alternative Methods in Toxicology 9, 163-174 (1993).

Smyth, M. J., and W. Wharton. Differentiation of A31T proadipocytes to adiopocytes: A flow cytometric analysis, Experimental Cell Research 199, 29-38 (1992).

Smyth, M. J., B. Runnels, and W. Wharton. Cholera toxin potentiates TPA-induced mitogenesis and $c$-fos expression in BALB/c-3T3-derived proadipocytes, Journal of Cellular Biochemistry 50, 210-218 (1992).

Smyth, M. J., R. L. Sparks, and W. Wharton. Proadipocyte cell lines: models of cellular proliferation and differentiation, Journal of Cell Science 106, 1-9 (1993).

Smyth, M. J., and W. Wharton. Multiparameter flow cytometric analysis of the effects of indomethacin on adipocyte differentiation in A31T6 cells, Cell Proliferation 26, 103-114 (1993).

Steinkamp, J. A. Lasers and optics in flow cytometry, Optics and Photonics News 3 (10), 41-44 (1992). 
Steinkamp, J. A. and H. A. Crissman. Resolution of fluorescence signals from cells labeled with fluorochromes having different lifetimes by phase-sensitive flow cytometry, Cytometry 14, 210-216 (1993).

Steinkamp, J. A., T. Yoshida, and J. C. Martin. Flow cytometer for resolving signals from heterogeneous fluorescence emissions and quantifying lifetime in fluorochrome-labeled cells/particles by phase-sensitive detection, Review of Scientific Instruments 64, 3440 (1993).

Weingarten, R., L. A. Sklar, J. Mathison, S. Omidi, T. Ainsworth, S. Simon, R. J. Ulevitch, and $\mathrm{P}$. Tobias. Interactions of lipopolysaccharide with neutrophils in blood via CD14, Journal of Leukocyte Biology 53, 518-524 (1993).

\section{Abstracts}

Amundson, S. A., J. E. Fortunato, and H. L. Liber. Radiation induced loss of APRT ${ }^{+}$phenotype in human lymphoblastoid cell lines, Radiation Research Society-41st Annual Meeting, Dallas, Texas, March 20-25 (1993).

Anzick, S. L., W. G. Thilly, and R. T. Okinaka. Denaturing gradient gel electrophoretic analysis of mutant clones induced by ionizing radiation, 4th Annual Biomedical Sciences Graduate Student Research Day, Albuquerque, New Mexico, March 26 (1992).

Archuleta, D. C., S. M. Schauer, D. M. Stavert, and B. E. Lehnert. Changes in $\mathrm{VO}_{2 \max }$ and lung injury following the exposure of nose and pseudo-mouth breathing rats to $\mathrm{HCl}$, Society of Toxicology 1993 Annual Meeting, Washington, D.C., March (1993); The Toxicologist 13, 518 (1993).

Bell-Prince, C., J. A. Dickson, J. H. Jett, A. P. Stevenson, and L. A. Sklar. National flow cytometry resource, XVI Congress of the International Society for Analytical Cytology, Colorado Springs, Colorado, March 21-26 (1993).

Bernardin, M. P., and B. E. Lehnert. Alveolar macrophage-based model of the alveolar clearance of a low lung burden of insoluble, non-cytotoxic particles, 1992 Annual Meeting of the American Thoracic Society, Miami Beach, Florida, May 17-20, 1992; Am. Rev. Respir. Dis., A800 (1992).

Brainard, J. R., S. A. Kinkead, G. O. Wood, D. M. Stavert, and B. E. Lehnert. Potential involvement of hydrofluoric acid in perfluoriosbutylene-induced lung injury, 1992 Annual Meeting of the Society of Toxicology, Seattle, Washington, February 23-27 (1992); The Toxicologist 12 (1), A843 (1992).

Campbell, M. L., M. K. McCormick, P. L. Schor, J. J. Fawcett, A. Martinez, L. L. Deaven, and R. K. Moyzis. Chromosome 5 specific yeast artificial chromosome library from flow sorted chromosomes: Construction and characterization, Human Genome Workshop, Santa Fe, New Mexico, February 7-11 (1993).

Chen, D. J., A. Jaberaboansari, and E. H. Goodwin. Charged particle mutagenesis in normal human cells, 3rd Annual Investigators Meeting on Space Radiation Research, NASA Johnson Space Center, Houston, Texas, April 14-15 (1992).

Chen, D. J., K. Sato, and R. L. Warters. Identification of two mouse radiation sensitive mutants deficient in DNA double-strand break rejoining, Radiation Research Society-41st Annual Meeting, Dallas, Texas, March 20-25 (1993).

Chen, D. J., K. Tsuboi, A. Jaberaboansari, and T. Yang. Mutagenic effects of high energy charged particles in normal human fibroblasts, World Space Congress, Washington, D.C., August 28-September 5 (1992). 
Clark, P. E., L. C. Seamer, and L. A. Sklar. NeXT computer system as a platform for flow cytometry data management, XVI Congress of the International Society for Analytical Cytology, Colorado Springs, Colorado, March 21-26 (1993).

Crissman, H. A. Applications of flow cytometry to studies on differences in cell cycle regulation and growth of normal and malignant cells, European Course on Quantitative Pathology, Gargnano, Italy, May 27-29 (1992).

Crissman, H. A. Development of new strategies for improving cancer therapy and diagnosis, Biotechnology Workshop, Santa Fe, New Mexico, February 26-28 (1992).

Crissman, H. A. Improved cell kinetics analysis by advances in flow cytometry, Cell Kinetics Society Meeting, New Orleans, Louisiana, March 27-29 (1992).

Crissman, H. A., D. M. Gadbois, R. A. Tobey, and E. M. Bradbury. Differential effects of staurosporine on the cell cycle of normal and transformed cells: Implications for improved cancer diagnosis and therapy, 4th Annual Symposium on Structural Biology, Santa Fe, New Mexico, April 24 (1992).

Crissman, H. A., D. M. Gadbois, R. A. Tobey, A. P. Stevenson, P. M. Kraemer, L. D. Bustos, J. A. Dickson, and E. M. Bradbury. Differences in kinase-mediated regulation of cell cycle progression in normal and transformed cells, XVI Congress of the International Society for Analytical Cytology, Colorado Springs, Colorado, March 21-26 (1993).

Englen, M. D., Y. E. Valdez, N. M. Lehnert, B. E. Lehnert. Proliferation of alveolar macrophages on confluent lung fibroblasts, 29th National Meeting of the Society for Leukocyte Biology, Charleston, South Carolina, December 2-5 (1992); J. Leuk. Biol. 3, 88 (1992).

Fay, S. P., R. C. Habbersett, R. G. Posner, M. D. Domalewski, R. J. Freer, E. Pierson, J. Whittaker, R. P. Haugland, and L. A. Sklar. Multiparameter flow cytometry of a pH sensitive ligand bound to receptors and inside cells, XVI Congress of the International Society for Analytical Cytology, Colorado Springs, Colorado, March 21-26 (1993).

Fay, S. P., T. M. Yoshida, R. Habbersett, R. G. Posner, M. D. Domalewski, R. J . Freer, E. Pierson, J. Whittaker, R. P. Haugland, D. Magde, and L. A. Sklar. Human neutrophil formyl peptide receptor-ligand interaction involves a binding pocket protonation, FASEB (1992).

Ferin, J., G. Oberdörster, R. J. Sebring, and B. E. Lehnert. Is the bronchus-associatedlymphatic tissue interconnecting the pulmonary particle clearance pathways? Am. Rev. Respir. Dis. 4, A387 (1993).

Freyer, J. P. Loss of mitochondria from quiescent cells isolated from multicellular tumor spheroids, 84th Annual Meeting of the American Association for Cancer Research, Orlando, Florida, May 19-22 (1993).

Freyer, J. P. A flow cytometric method for isolating mutants sensitive to radiation, XVI Congress of the International Society for Analytical Cytology, Colorado Springs, Colorado, March 21-26 (1993).

Freyer, J. P. Oxygen consumption rates of proliferating and quiescent cells isolated from multicellular tumor spheroids, 20th International Meeting-Society for Oxygen Transport to Tissue, Mainz, FRG, August 25-30 (1992).

Freyer, J. P., M. Neeman, K. A. Jarrett, and L. O. Sillerud. Effect of ionizing radiation on energy metabolism of multicellular tumor spheroids measured by phosphorous MRS, XV International Conference on Magnetic Resonance in Biological Systems, Jerusalem, Israel, August 16-21 (1992). 
Gadbois, D. M., H. A. Crissman, and E. M. Bradbury. Kinase-mediated control of progression through G1 phase of the cell cycle, Cell Kinetics Society Meeting, New Orleans, Louisiana, March 27-29 (1992).

Goodwin, E. H. RBE: Mechanisms inferred from cytogenetics, World Space Congress, Washington, D.C., August 28-September 5 (1992).

Goodwin, E. H., and Bailey S. M. Staurosporine prevents bromodeoxyuridine sensitization of normal but not tumor cells in vitro, Radiation Research Society-41st Annual Meeting, Dallas, Texas, March 20-25 (1993).

Goodwin, E. H., M. N. Cornforth, and S. M. Bailey. The sensitivity of the PCC technique, 40th Annual Meeting-Radiation Research Society, Salt Lake City, Utah, March 15-18 (1992).

Gurley, L. R., D. M. Stavert, T. Ellis, W. S. Session, and B. E. Lehnert. Biochemical changes in lavage fluids from rested and exercised rats prior to overt pulmonary edema induced by perfluoroisobutylene, 1992 Annual Meeting of the Society of Toxicology, Seattle, Washington, February 23-27, 1992; The Toxicologist 12, (1), A844 (1992).

Habbersett, R. C., and Jett, J. H. Flow data display and analysis: A new approach, XVI Congress of the International Society for Analytical Cytology, Colorado Springs, Colorado, March 21-26 (1993).

Hammond, M. L., B. L. Marrone, A. Haces, and R. S. Lasken. Enzymatic synthesis and exonucleolytic degradation of fluorescent DNA containing rhodamine and fluorescein nucleotides, Keystone Symposia--DNA Replication and Recombination, Taos, New Mexico, January 25-February 1 (1992).

Hirons, G. T. Evaluation of two new fluorochromes, TOTO and YOYO, for DNA content analysis in cells and chromosomes by flow cytometry, XVI Congress of the International Society for Analytical Cytology, Colorado Springs, Colorado, March 21-26 (1993).

Hirons, G. T., J. J. Fawcett, and H. A. Crissman. TOTO and YOYO: New ultrasensitive fluorochromes for DNA content analyses by flow cytometry, Cell Kinetics Society Meeting, Richland, Washington, April 15-18 (1993).

Jaberaboansari, A., D. J. Chen, and M. R. Raju. Mutation induction by low energy ( $\leq 1 \mathrm{MeV}$ ) $\alpha$-Particles, Microdosimetry Conference, Gatlinburg, Tennessee, September 14 (1992).

Jaberaboansari, A., K. Tsuboi, and D. J. Chen. Analysis of $\alpha$-ray-induced point mutations at the human HPRT locus, 40th Annual Meeting-Radiation Research Society, Salt Lake City, Utah, March 15-18 (1992).

Jett, J. H. What is the state-of-the-art in flow cytometry and how will it change in the future? Armed Forces Institute of Pathology Conference on Quantitative Histopathology, Rockville, Maryland, September 9-13 (1992).

Jett, J. H., L. S. Cram, R. A. Keller, J. C. Martin, G. C. Saunders, L. A. Sklar, and J. A. Steinkamp. Ultrasensitive flow cytometric analyses, Biomedical Optics '93, Los Angeles, California, January 16-22 (1993).

Johnson, M. E., P. M. Goodwin, W. P. Ambrose, J. C. Martin, B. L. Marrone, and R. A. Keller.'Detection of single lambda DNA fragments by flow cytometry, XVI Congress of the International Society for Analytical Cytology, Colorado Springs, Colorado, March 2126 (1993).

Knauf, J. A., and L. J. Romano. The fole of single-stranded DNA binding protein in the replication of unmodified and aminofluorene-modified DNA, Environmental Mutagen Society Annual Meeting, Norfolk, Virginia, April 17-22 (1993). 
Kraemer, P. M., and E. M. Bradbury. Abrogation of a kinase mediated G1 cell cycle arrest point is a late event in the neoplastic progression of human fibroblasts transfected with the SV40 large T antigen gene, Keystone Symposium, Keystone, Colorado, January 17-24

(1993).

Laubscher, K. H., R. H. Glew, R. E. Lee, and R. T. Okinaka, A new exon 9 mutation in Gaucher disease detected by denaturing gradient gel electrophoresis, Am. J. Hum. Genet. 53, Abst., 1190 (1993).

Laubscher, K. H., T. J. Gribble, R. H. Glew, and R. T. Okinaka. Detecting mutations in Gaucher's patients by denaturing gradient gel electrophoresis, American Society of Human Genetics, San Francisco, California, November 9-13 (1992).

Laubscher, K. H., V. Gopalan, R. H. Glew, and R. T. Okinaka. DGGE analysis of mutations causing Gaucher's disease, Keystone Symposia-Molecular Biology of Human Genetic Disease, Copper Mountain, Colorado, April 3-10 (1992).

Laubscher, K. H., T. J. Scallen, R. H. Glew, and R. T. Okinaka. DGGE analysis of mutations causing Gaucher's disease, 4th Annual Graduate Student Research Day, Albuquerque, New Mexico, March 26 (1992).

Lehnert, B. E., D. C. Archuleta, T. Ellis, W. S. Session, N. M. Lehnert, D. M. Stavert, and L. R. Gurley. Relationship between the hyperpermeability response to nitrogen dioxide and increases in lavageable inflammatory cells, 1993 ALA/ATS International Conference, San Francisco, California, May 16-19 (1993).

Lehnert, B. E., D. C. Archuleta, and D. M. Stavert. Relationship between the hyperpermeability response to nitrogen dioxide and increases in lavageable inflammatory cells, 1993 American Thoracic Society International Conference, San Francisco, California, May 1619 (1993); Am. Rev. Respir. Dis. 147, A386 (1993).

Lehnert, B. E., D. C. Archuleta, and D. M. Stavert. Ventilatory changes during and pulmonary injurious response following brief, high concentration exposures to nitrogen dioxide, 1993 ALA/ATS International Conference, San Francisco, California, May 16-19 (1993); Am. Rev. Respir. Dis. 147, A382 (1993).

Lehnert, B. E., R. J. Sebring, and G. Oberdörster. Lung clearance and the occlusion of the pores of Kohn after the deposition of ultra-fine titanium dioxide $\left(\mathrm{TiO}_{2}\right)$, Society of Toxicology 1993 Annual Meeting, Washington, D.C., March (1993); The Toxicologist 13, 72 (1993).

Lehnert, B. E., R. J. Sebring, and G. Oberdörster. Particle-cell relationships and cellular and anatomical changes in the lung following the deposition of relatively high burdens of fine and ultra-fine titanium dioxide, 1992 Annual Meeting of the American Thoracic Society, Miami Beach, Florida, May 17-20 (1992); Am. Rev. Respir. Dis., A800 (1992).

Lehnert, B. E., R. J. Sebring, and G. Oberdörster. Pulmonary macrophages: Phenomena associated with the particle "overload" condition, 4th International Inhalation Symposium, Hannover, FRG, February 28-March 5 (1993).

Lehnert, B. E., D. M. Stavert, T. Ellis, W. S. Session, and L. R. Gurley. Kinetics of lung free cell and biochemical changes in lavage fluids following exposure to a high concentration of nitrogen dioxide $\left(\mathrm{NO}_{2}\right), 1992$ Annual Meeting of the Society of Toxicology, Seattle, Washington, February 23-27 (1992); The Toxicologist 12 (1), A848 (1992).

Lehnert, B. E., Y. E. Valdez, and N. M. Lehnert. Lung fibroblast-stimulated proliferation of pulmonary macrophages, American Thoracic Society/American Lung Association, Miami, Florida, May 17-20 (1992). 
Lehnert, B. E., Y. E. Valdez, N. M. Lehnert, and M. D. Englen. Stimulation of alveolar macrophage proliferation by lung fibroblasts and specific cytokines, 1993 ALA/ATS International Conference, San Francisco, California, May 16-19 (1993); Am. Rev. Respir. Dis. 147, A276 (1993).

Lynam, E., S. I. Simon, and L. A. Sklar. Analysis of neutrophil function in blood using flow cytometry, XVI Congress of the International Society for Analytical Cytology, Colorado Springs, Colorado, March 21-26 (1993).

MacInnes, M. A., R. R. Hernandez, J. A. Knauf, M. S. Park, A. V. Castro-Perez, R. J. Reynolds, and G. F. Strniste. Functional relationships between DNA repair genes of human and yeast: ERCC5 and RAD2, Enironmental Mutagen Society Annual Meeting, Norfolk, Virginia, April 17-22 (1993).

MacInnes, M. A., J. A. Knauf, R. T. Okinaka, M. S. Park, A. V. Castro-Perez, R. J. Reynolds, and G. F. Strniste. Structural and functional relationships between DNA repair genes of human and yeast: ERCC5 and RAD2, 6th International Conference on Environmental Mutagens, Melbourne Australia, February 21-26 (1993).

MacInnes, M. A., J. S. Mudgett, and M. S. Park. Recombination-mediated ERCC5 DNA repair gene correction of mutant rodent cells, Keystone Symposia-Molecular Biology of Human Genetic Disease, Copper Mountain, Colorado, April 3-10 (1992).

Marrone, B. L., E. W. Campbell, T. M. Yoshida, S. L. Anzick, M. K. McCormick, and L. L. Deaven. High-precision mapping of YAC clones onto chromosome 21 by fluorescence in situ hybridization and image analysis, Human Genome Workshop, Santa Fe, New Mexico, February 7-11 (1993).

Marusic, M., Z. Bajzer, J. P. Freyer, and S. Vuk-Pavlovic. Viable rim thickness as criterion for testing the mathematical models of prevascular tumor growth, American Association for Cancer Research, San Diego, California, May 20-23 (1992).

Neeman, M., T. A. Zawodzinski, T. E. Springer, and L. O. Sillerud. Diffusion barriers in pulsed gradient spin echo NMR microscopy, 1992 11th Annual Scientific Meeting, Society of Magnetic Resonance in Medicine, Berlin, Germany, August 8-14 (1992).

Oberdörster, G., J. Ferin, R. Baggs, D. M. Stavert, and B. E. Lehnert. Health hazards from thermal degradation events: Particulate vs. gas phase effects, International Conference on Environmental Systems, Aerospace Medical Association, Seattle, Washington, July (1992).

Okinaka, R. T., S. L. Anzick, G. F. Strniste, K. Sato, and W. G. Thilly. Mutations detected by denaturing gradient gel electrophoresis in human cells following exposure to ionizing radiation, 35th Annual Meeting of Japan Radiation Research Society, Ohtsu, Japan, October 28-30 (1992).

Okinaka, R. T., S. L. Anzick, G. F. Strniste, and W. G. Thilly. Denaturing gradient gel analysis of mutations induced in human cells by long-term, low dose-rate exposure to gamma rays, 9th International Congress of Radiation Research, Germany, in press (1994).

Okinaka, R. T., S. L. Anzick, and W. G. Thilly. DGGE analysis of specific exons in X-ray induced, large HPRT mutant populations of human cells, International Seminar on Molecular Mechanisms in Radiation Mutagenesis and Carcinogenesis, The Netherlands, April 19-22 (1993).

Okinaka, R. T., K. H. Laubscher, and A. P. Sena, Evidence for mutations within the ERCC5 gene in a xeroderma pigmentosum group G patient, Am. J. Hum. Genet. 53, Abst., 340 (1993). 
Park, M. S., M. A. MacInnes, and G. F. Strniste. Overexpression, purification, and antibody production of the helix-loop-helix domain of the human nucleotide excision repair protein, ERCC5, 41st Annual Meeting of the Radiation Research Society, Dallas, Texas, March 20-25 (1993).

Park, M. S., J. S. Mudgett, and M. A. MacInnes. Molecular cloning and analysis of the mouse homologue of the ERCC5 DNA excision repair gene, 40th Annual MeetingRadiation Research Society, Salt Lake City, Utah, March 15-18 (1992).

Parson, J. D., T. L. Olivier, R. C. Habbersett, J. C. Martin, M. E. Wilder, and J. H. Jett. Characterization of digital signal processing in the didac data acquisition system, XVI Congress of the International Society for Analytical Cytology, Colorado Springs, Colorado, March 21-26 (1993).

Pendergrass, D., Y. E. Valdez, and B. E. Lehnert. GM-CSF stimulated proliferation of rat alveolar macrophages and the effects of differing particulate burden levels in alveolar macrophages on the proliferative response, 4th International Inhalation Symposium, Hannover, Germany, February 28-March 5 (1993).

Perez-Castro, A. V., and M. C. Nguyen-Huu. Cataracts and pancreatic tumor formation in transgenic mice expressing the cellular retinoic acid-binding protein I (CRABP I) under the control of the alpha-A-crystalline promoter, Environmental Mutagen Society Annual Meeting, Norfolk, Virginia, April 17-22 (1993).

Raju, M. R. Particle therapy: A brief review, International Conference in Medical Physics, Bombay, India, September 8-11 (1992).

Ray, F. A., M. J. Waltman, and P. M. Kraemer. Mapping the chromosome instability function of the SV40 T antigen, 5th International Workshop on Chromosomes in Solid Tumors, Tucson, Arizona, January 10-12 (1993).

Reynolds, R. J. Induction of closely-opposed dimers in synthetic oligodeoxynucleotides, 40th Annual Meeting-Radiation Research Society, Salt Lake City, Utah, March 15-18 (1992) and the Environmental Mutagen Society Annual Meeting, Norfolk, Virginia, April 17-22 (1993).

Reynolds, R. J., E. H. Goodwin, and M. N. Cornforth. Effects of $\mathrm{H}_{2} \mathrm{O}_{2}$ treatment on CHO cell transfection efficiency, Radiation Research Society-41st Annual Meeting, Dallas, Texas, March 20-25 (1993).

Rochon, Y. P., S. I. Simon, and L. A. Sklar. $\beta_{2}$-integrin and L-selectin are counter-ligands in neutrophil aggregation: Studies using adhesive-receptor derivatized beads, Society for Leukocyte Biology (1992).

Rochon, Y. P., S. I. Simon, and L. A. Sklar. Carbohydrate specificity of human neutrophil aggregation: A lectin-like interaction between L-selectin and $\beta_{2}$-integrin? FASEB, Experimental Biology (1993).

Runnels, B., M. J. Smyth, and W. R. Wharton. Cholera toxin potentiates TPA-driven mitogenic responses and C-FOS induction, Keystone Symposia, Keystone, Colorado, January 17-24 (1993).

Salzman, G. C., J. D. Parson, R. J. Beckman, S. J. Stewart, and C. C. Stewart. Autogate: A Macintosh cluster analysis program for flow cytometry data, XVI Congress of the International Society for Analytical Cytology, Colorado Springs, Colorado, March 21-26 (1993).

Simon, S. I., Y. P. Rochon, B. J. Hughes, M. Robinson, L. A. Sklar, and C. W. Smith. Neutrophil aggregation stimulated by mAb binding to $\beta_{2}$-integrin, FASEB, Experimental Biology (1993). 
Simon, S. I., Y. P. Rochon, and L. A. Sklar. Neutrophil aggregation studied using 2-color flow cytometry, XVI Congress of the International Society for Analytical Cytology, Colorado Springs, Colorado, March 21-26 (1993).

Simon, S. I., C. W. Smith, B. J. Hughes, A. R. Burnes, E. Crockett-Torabi, E. Lynam, and L. A. Sklar. L-selectin activates $\beta_{2}$-integrin dependent canine and human neutrophil adhesion, The American Society for Cell Biology (1993).

Sklar, L. A. Neutrophil aggregation in flow cytometry, International Cytometry Symposium, San Francisco, California (1993).

Sklar, L. A., J. D. Chambers, E. Butcher, and S. I. Simon. Neutrophil aggregation is $\beta_{2-}$ integrin and L-selectin dependent in blood, FASEB (1992).

Sklar, L. A., S. I. Simon, M. M. Brandt, and E. Lynam. Analysis of LPS-PMN interaction in blood, Keystone Symposium, Taos, New Mexico (1992).

Smyth, M. J., and W. Wharton. Loss of mitogenic responsiveness during adipocyte differentiation in A31T6 cells, Journal of Cellular Biochemistry, Supplement 16B, G136 (1992).

Smyth, M. J., and W. Wharton. Terminal growth arrest during adipocyte differentiation in A31T6 cells, Cell Proliferation 25, 365 (1992).

Stavert, D. M., W. S. Session, L. R. Gurley, and B. E. Lehnert. Lung injury after inhalation exposure to differing mass concentrations of phosgene, 1992 Annual Meeting of the Society of Toxicology, Seattle, Washington, February 23-27 (1992); The Toxicologist 12 (1), A847 (1992).

Steinkamp, J. A., and H. A. Crissman. Resolution of heterogeneous fluorescence emission signals and decay lifetime measurement on fluorochrome-labeled cells by phase-sensitive FCM, SPIE Biomedical Optics '93 Conference on Advances in Fluorescence Sensing Technology, Los Angeles, California, January 20-21 (1993).

Steinkamp, J. A., J. C. Martin, and H. A. Crissman. Phase-sensitive flow cytometer, XVI Congress of the International Society for Analytical Cytology, Colorado Springs, Colorado, March 21-26 (1993).

Stevenson, A. P., L. D. Bustos, J. A. Dickson, R. C. Habbersett, and H. A. Crissman. Kinetics of staurosporine-arrest of human diploid fibroblasts, XVI Congress of the International Society for Analytical Cytology, Colorado Springs, Colorado, March 21-26 (1993).

Vilven, J. C., R. D. Ye, M. D. Domalewski, S. P. Fay, A. L. Hall, and L. A. Sklar. Spectroscopic analysis of $\mathrm{N}$-formyl peptide receptors in human and rabbit neutrophils, HL60 cells, and FPR transfectants, American Society for Cell Biology (1992).

Xia, F., H. L. Liber, and S. A. Amundson. Involvement of recombination in X-ray-induced mutagenesis of human cells, Seminar (International) on Molecular Mechanisms in Radiation Mutagenesis and Carcinogenesis, The Netherlands, April 19-22 (1993).

\section{Conference Proceedings and Reports}

Brainard, J. R., S. A. Kinkead, E. M. Kober, R. J. Sebring, D. M. Stavert, and B. E. Lehnert. Preliminary observations of lung injury produced by instillation of HF in acidic and neutral buffer, Proceedings of the 1990 U.S. Army Chemical Research, Development, and Engineering Center Scientific Conference on Chemical Defense Research, pp. 187-193 (1992). 
Chen, D. J., S. Carpenter, and T. Hanks. Mutagenic effect of alpha-particles in normal human fibroblasts, Proceedings for the 29th Hanford Symposium on Health and the Environment, Hanford, Washington, in press (1994).

Cram, L. S., J. C. Martin, J. A. Steinkamp, T. M. Yoshida, T. N. Buican, B. L. Marrone, J. H. Jett, G. C. Salzman, and L. A. Sklar. New flow cytometric capabilities at the National Flow Cytometry Resource, Proceedings of the Institute of Electrical and Electronics Engineers, in press (1994).

Crissman, H. A., A. P. Stevenson, L. D. Bustos, J. A. Dickson, D. M. Gadbois, P. M. Kraemer, and E. M. Bradbury. Differences in kinase-mediated regulation of progression through G1 phase of normal and transformed cells, XIII Washington International Spring Symposium on Regulators, Targets, and Clinical Applications, Washington, D.C., May 9-15, 1993.

Deka, C., J. A. Steinkamp, and L. A. Sklar. Fluorescence lifetime measurements in a flow cytometer by amplitude demodulation using digital data acquisition technique, Proceedings of the Optical Society of America Conference on Laser Applications to Chemical Analysis, Technical Digest Series, Vol. 5, Optical Society of America, Jackson Hole, Wyoming, March 8-11, 1994.

Lehnert, B. E. Lung cell injury and hyperpermeability pulmonary edema in response to inhaled toxic gases. Medical Defense Bioscience Review, U.S. Army Medical Research Institute of Chemical Defense, Baltimore, Maryland, May 10-13, 1993.

Lehnert, B. E. Lung injury following exposure of rats to relatively high mass concentrations of nitrogen dioxide. Symposium: Effects of Exposure to Nitrogen Dioxide, Walter Reed Army Institute of Research, Department of Respiratory Research, Washington, D.C., October 23, 1992.

Lehnert, B. E. Lung macrophage-fibroblast cytokine networks in pulmonary fibrogenesis: A new hypothesis, Workshop on Interactions of Particles with the Lung, 1993 American Thoracic Society International Conference, San Francisco, California, May 15, 1993.

Lehnert, B. E. Physiological and biochemical endpoints in inhalation toxicology. International Programme on Chemical Safety, World Health Organization, Hannover, FRG, October 6-October 9, 1992.

Lehnert, B. E. Post-exposure potentiation of lung injury by exercise and work performance degradation following the inhalation of pyrolysis products. National Aeronautics and Space Administration, Johnson Space Center, Houston, Texas, November 13, 1992.

Lehnert, B. E. Pulmonary macrophages. Toxic and Carcinogenic Effects of Solid Particles in the Respiratory Tract, 4th Inhalation Symposium, Co-Sponsored by the International Life Sciences Institute Research Foundation/Hannover Medical School/Fraunhofer Institute of Toxicology and Aerosol Research, Hannover, FRG, March 1-5, 1993.

Lehnert, B. E. Pulmonary macrophages and lung clearance. Toxicology Program, Department of Pharmacology, University of Texas Medical School at Houston, Houston, Texas, November 12, 1992.

Lehnert, B. E., R. J. Sebring, and G. Oberdörster. Pulmonary macrophages: Phenomena associated with the particle "overload" condition, in Proceedings of the 4th International Inhalation Symposium, Toxic and Carcinogenic Effects of Solid Particles in the Respiratory Tract, U. Mohr, ed., International Life Sciences Institute, Washington, D.C., in press (1993). 
Lehnert, B. E., and D. M. Stavert. Ultrastructural changes in the lung following exposure to perfluoroisobutylene (PFIB) and potentiation of PFIB-induced lung injury by exercise, Proceedings of the 1990 U.S. Army Chemical Research, Development, and Engineering Center Scientific Conference on Chemical Defense Research, pp. 179-186 (1992).

Nagasawa, N. H., A. I. Kassis, R. M. Berman, S. K. Sahu, J. A. Nickoloff, R. T. Okinaka, S. J. Adelstein, and J. B. Little. Comparison of mutation induction by external and internal radiation sources in synchronized Chinese hamster ovary $(\mathrm{CHO})$ cells, Second International Symposium on Biophysical Aspects of Auger Processes, in press (1994).

Oberdörster, G., J. Ferin, J. Finkelstein, R. Baggs, D. M. Stavert, and B. E. Lehnert. Potential health hazards from thermal degradation events: Particulate vs. gas phase effects, SAE Technical Paper Series, The Engineering Society for Advancing Mobility Land Sea Air and Space, pp.1-15 (1992).

Oberdörster, G., and B. E. Lehnert. Toxicological aspects of the pathogenesis of fiberinduced pulmonary effects, Proceedings of the NATO Advanced Research Workshop on Mechanisms in Fibre Carcinogenesis, in press (1994).

Pendergrass, D., Y. E. Valdez, and B. E. Lehnert. GM-CSF stimulated proliferation of rat alveolar macrophages and the effects of differing cellular burdens of particles on the proliferative response, Proceedings of the 4th International Inhalation Symposium, Toxic and Carcinogenic Effects of Solid Particles in the Respiratory Tract, U. Mohr, ed., International Life Sciences Institute, Washington, D.C., in press (1993).

Reynolds, R. J. Molecular biology of UV damage and repair, 41st Annual MeetingRadiation Research Society, Dallas, Texas, March 20-25, 1993.

Sklar, L. A. Lasers in cytometry and biotechnology, Proceedings of the Symposium on Compact Blue-Green Lasers, Th-A2, Optical Society of America (1992).

Sklar, L. A., G. Jones, and T. Houghton. Cellular and biological applications of laser induced fluorescence, OSA Meeting, Laser Applications to Chemical Analysis, Technical Digest Series, Vol. 5, Optical Society of America, Jackson Hole, Wyoming, March 8-11, 1994.

Steinkamp, J. A. Phase-sensitive flow cytometry: New technology for analyzing biochemical, functional, and structural features in fluorochrome-labeled cells/particles, Proceedings of the Optical Society of America Conference on Laser Applications to Chemical Analysis, in press.

Steinkamp, J. A. and H. A. Crissman. Resolution of heterogeneous fluorescence emission signals and decay lifetime measurement on fluorochrome-labeled cells by phase-sensitive FCM, SPIE Proceedings of the Society of Photo-Optical Instrumentation Engineers 1885, 278-289 (1993).

\section{Review Articles}

Crissman, H. A. Bromodeoxyuridine procedures for analysis of DNA synthesis, in New Developments in Flow Cytometry (A. Jacquemin-Sablon, ed.), NATO ASI Series, SpringerVerlag, Berlin, Heidelberg, New York, Tokyo, p. 245 (1993).

Crissman, H. A., Z. Darzynkiewicz, J. A. Steinkamp, and R. A. Tobey. Simultaneous fluorescent labeling of DNA, RNA, and protein, in Method in Cell Biology, Volume 33 (Z. Darzynkiewicz and H. Crissman, eds.), Academic Press, in press (1994).

Crissman, H. A., and J. A. Steinkamp. Detection of BrdUrd labeled cells by differential fluorescence analysis of DNA fluorochromes, in Methods in Cell Biology, Volume 33, (Z. Darzynkiewicz and H. Crissman, eds.), Academic Press, in press (1994). 
Freyer, J. P. Spheroids in radiobiology research, in Spheroid Culture in Cancer Research, Bjerkvig R., ed. (CRC Press), pp. 217-275 (1992).

Guttmann, G. D., E. H. Goodwin, M. S. Mendonca, and J. Swain. Imaging living CHO-SC1 cells by soft $\mathrm{X}$-ray contact microscopy, in X-Ray Microscopy III, Springer-Verlag, in press (1994).

Lehnert, B. E. Lung defense mechanisms against deposited dusts, in Current Issues in Respiratory Public Health, 2nd Issue, Lippincott Series on Respiratory Public Health, in press (1994).

Lehnert, B. E. Physiological and lavage fluid cytological and biochemical endpoints of toxicity in the rat, in International Symposium on Respiratory Toxicology and Risk Assessment, World Health Organization/International Life Sciences Institute, Washington, D.C., in press (1994).

Lehnert, B. E. Toxicology of nitric oxide and nitrogen dioxide, in Handbook of Hazardous Materials (M. Corn, ed.), Academic press, San Diego, California, in press (1994).

Lehnert, B. E., A. C. Archuleta, T. Ellis, W. S. Session, N. L. Lehnert, L. R. Gurley, and D. M. Stavert. Lung injury following exposure of rats to relatively high mass concentrations of nitrogen dioxide, in Toxicology (in press), 1993.

Lehnert, B. E., and G. Oberdörster. Fate of fibers in the lower respiratory tract, in Fiber Toxicology. D. B. Warheit, ed., Academic Press, Orlando, Florida, pp. 349-394 (1993).

Lehnert, B. E., J. B. Ortiz, J. A. Steinkamp, G. L. Tietjen, R. J. Sebring, and G. Oberdörster. Mechanisms underlying the redistribution of particles among the lung's alveolar macrophages during alveolar phase clearance, in Inhaled Particles VII, Ann. Occupational Hyg., in press (1994).

Nagasawa, N. H., A. I. Kassis, R. M. Berman, S. K. Sahu, J. A. Nickoloff, R. T. Okinaka, S. J. Adelstein, and J. B. Little. Comparison of mutation induction by external and internal radiation sources in synchronized Chinese hamster ovary (CHO) cells, in Biophysical Aspects of Auger Processes, R. W. Howell, V. R. Narra, KSR Sastry, and D. V. Rao, eds., American Institute of Physics, Woodbury, New York, pp. 194-209 (1992).

Neeman, M., J. P. Freyer, and L. O. Sillerud. Effects of the imaging gradients, in Diffusion and Perfusion: Magnetic Resonance Imaging, D. LeBihan and B. Rosen, eds. (Raven Press), in press (1994).

Okinaka, R. T., S. L. Anzick, and W. G. Thilly, DGGE analysis of specific exons in x-ray of the HPRT gene from x-ray induced mutant populations, in Molecular Mechansims in Radiation Mutagenesis and Carcinogenesis, K. Chadwick, ed., in press (1994).

Salzman, G. C., R. J. Beckman, C. C. Stewart, and S. J. Stewart. Expert assistance for flow immunophenotyping, in NATO Advanced Study Institute Programme, New Developments in Flow Cytometry (H. A. Crissman and A. Jacquemin-Sablon, eds.), Springer-Verlag, p. 413 (1993).

Salzman, G. C., and P. H. Bartels. Expert systems for cytometry data analysis, in Clinical Flow Cytometry, Principles and Application. (K. D. Bauer, R. E. Duque, and T. V. Shankey, eds.), Williams and Wilkins, Baltimore, Maryland, in press (1994).

Sklar, L. A. Kinetics of ligand-receptor interactions, in Cellular and Molecular Mechanisms of Inflammation, 3 (C. G. Cochrane and M. Gimbrone, eds.) Academic Press, pp. 1-23 (1992).

Steinkamp, J. A. Phase-sensitive detection methods for resolving fluorescence emission signals and quantifying lifetime directly. Flow Cytometry, 2nd ed., in Methods in Cell Biology Series, (Z. Darzynkiewicz, J. Robinson, and H. Crissman, eds.), Academic Press, New York, in press (1994). 


\section{Genomics and Structural Biology Group (LS-2)}

\section{Publications}

Allitto, B. A., A. I. McClatchey, G. Barnes, M. Altherr, J. Wasmuth, A. M. Frischauf, M. E. MacDonald, and J. Gusella. 1992. Assay by polymerase chain reaction of multiallele ploymorphisms in the Huntington's disease region of chromosome 4. Molec. Cell. Probes. 6, 513-520.

Altherr, M. R., J. F. Gusella, J. J. Wasmuth, M. A. Kummer, S. W. McKercher, and V. P. Johnson. 1992. Molecular detection of a 4p deletion using PCR-based polymorphisms: A technique for the rapid detection of the Wolf-Hirschhorn syndrome. Am. J. Med. Genet. 44, 449-454.

Altherr, M. R., J. J. Wasmuth, M. F. Seldin, J. H. Nadeau, W. Baehr, and S. J. Pittler. 1992. Chromosome mapping of rod photoreceptor cGMP phosphodiesterase b-subunit gene in mouse and man: Tight linkage to the Hungtington's disease region (4p16.3). Genomics $12,750-754$.

Altherr, M. R., S. Plummer, G. Bates, M. MacDonald, S. Taylor, H. Lehrach, A.-M. Frischauf, J. Gusella, M. Boehnke, and J. J. Wasmuth. 1992. Radiation hybrid map spanning the Huntington disease gene region of chromosome 4. Genomics 13, 1040-1046.

Ambrose, C., M. James, G. Barnes, C. Lin, G. Bates, M. Altherr, M. Duyao, N. Groot, D. Church, J. H. Wasmuth, H. Lehrach, D. Housman, A. Buckler, J. F. Gusella, and M. E. MacDonald. 1992. A novel G protein-coupled receptor kinase gene cloned from 4p16.3. Hum. Molec. Genet. 1, 697-704.

Bates, G. P., J. Valdes, H. Hummerich, S. Baxendale, D. L. Le Paslier, A. P. Monaco, D. Tagle, M. E. MacDonald, M. Altherr, M. Ross, B. H. Brownstein, D. Bentley, J. J. Wasmuth, J. F. Gusella, D. Cohen, F. Collins, and H. Lehrach. 1992. Characterization of a yeast artificial chromosome contig spanning the Huntington's disease gene candidate region. Nature Genetics 1, 180-189.

Callen, D. F., N. A. Doggett, R. L. Stallings, L. Z. Chen, S. A. Whitmore, S. A. Lane, J. K. Nancarrow, S. Apostolou, A. D. Thompson, N. M. Lapsys, H. J. Eyre, E. G. Baker, Y. Shen, R. I. Richards, K. Holman, H. Phillips, and G. R. Sutherland. High resolution cytogenetic-based physical map of human chromosome 16. Genomics 13, 1178-1185 (1992).

Doggett, N. A. The polymerase chain reaction and sequence-tagged sites. Los Alamos Science 20, 128-134 (1992).

Doggett, N. A., C. L. Smith, and C. R. Cantor. The effect of DNA concentration on electrophoretic mobility in pulsed field gels. Nucleic Acids Research 20, 859-864 (1992).

Doggett, N. A., D. F. Callen, Z. L. Cheng, S. Moore, J. Tesmer, L. Duesing, and R. L. Stallings. Identification and regional localization of a human IMP dehydrogenaselike locus (IMPDHL1) at 16p13.13. Genomics 18, in press (1993).

Doggett, N. A., R. L. Stallings, C. E. Hildebrand, and R. K. Moyzis. The mapping of chromosome 16. Los Alamos Science 20, 182-215 (1992).

Eubanks, J. H., M. Altherr, C. Wagner-McPherson, J. D. McPherson, J. J. Wasmuth, and G. A. Evans. 1992. Localization of the D5 dopamine receptor gene to human chromosome 4p15.1-15.33, centromeric to the Huntington's disease locus. Genomics 12, 510-516.

Goodwin, P. H., B. Xue, C. R. Kuske, and M. K. Sears. 1993. Detection of the aster yellows mycoplasmalike organism by the polymerase chain reaction. Annals Appl. Biol., in press.

Griggs, R. C., R. Tawil, D. Storvick, J. Mendel, and M. R. Altherr. 1993. The genetics of facioscapulohumeral muscular dystrophy: New mutations in sporadic cases. Neurology 43, 2369-2372. 
Gusella, J. F., M. R. Altherr, A. I. McClatchey, L. Doucette-Stamm, D. Tagle, S. Plummer, N. Groot, F. S. Collins, D. E. Housman, H. Lehrach, M. E. MacDonald, G. Bates, and J. J. Wasmuth. 1992. Sequence tagged sites (STSs) spanning 4p16.3 and the Huntington's disease candidate region. Genomics 13, 75-80.

Huntington's Disease Collaborative Research Group, The. 1993. A novel gene containing a trinucleotide repeat that is expanded and unstable on Huntington's disease chromosomes. Cell. 72, 971-983.

Jackson, P. J., W. L. Anderson, J. G. DeWitt, H.-Y. D. Ke, C. R. Kuske, R. M. Moncrief, and G. D. Rayson. 1993. Accumulation of toxic metal ions on cell walls of Datura innoxia suspension cultures. In Vitro - Plant, in press.

Johnson, V. P., M. R. Altherr, J. M. Blake, and L. D. Keppen. FISH detection of WolfHirschhorn syndrome: Exclusion of D4F26 as critical site. Am. J. Med. Genet., in press (1993).

Kaiser, U. B., H. Dushkin, M. R. Altherr, D. R. Bier and W. W. Chin. Chromosomal localization of the gonadotropin-releasing hormone receptor gene to human chromosome 4q13.1-21.1 and mouse chromosome 5. Genomics, submitted (1993).

Liang, H., W. S. Sandberg, and T. C. Terwilliger. 1993. Genetic fusion of subunits of a dimeric protein substantially enhances its stability and rate of folding. Proc. Natl. Acad. Sci. USA 90, 7010-7014.

Liptay, S, R. M. Schmid, N. D. Perkins, P. Meltzer, M. R. Altherr, J. D. McPherson, J. J. Wasmuth, and G. J. Nabel. 1992. Related subunits of NF-jB map to two distinct loci associated with translocations in leukemia, NFKB1 and NFKB2. Genomics 13, 287-292.

MacDonald, M. E., A. Novelletto, C. Lin, D. Tagle, G. Barnes, G. Bates, S. Taylor, B. Allitto, M. Altherr, R. Myers, H. Lehrach, F. S. Collins, J. J. Wasmuth, M. Frontali, and J. F. Gusella. 1992. The Huntington's disease candidate region exhibits many different haplotypes. Nature Genetics 1, 99-105.

Mills, K. A., K. H. Buetow, J. L. Weber, M. R. Altherr, J. J. Wasmuth, and J. C. Murray. 1992. Genetic and physical maps of human chromosome 4 based on dinucleotide repeats. Genomics 14, 209-219.

Mitchison, H., A. D. Thompson, J. C. Mullley, H. M. Kozman, R. I. Richards, D. F. Callen, R. L. Stallings, N. A. Doggett, J. Attwood, T. R. McKay, G. R. Sutherland, and R. M. Gardiner. Fine genetic mapping of the Batten disease locus (CLN3) by haplotype analysis and demonstration of allelic association with chromosome 16p microsatellite loci. Genomics 16, 455-460 (1993).

Narayanswami, S., N. A. Doggett, C. E. Hildebrand, L. M. Clark, and B. A. Hamkalo. Cytological and molecular characterization of centromeres in mus domesticus and mus spretus. Mammalian Genome 2, 186-194 (1992).

Pittler, S. J., A. K. Lee, M. Altherr, M. F. Seldin, R. L. Hurwitz, J. J. Wasmuth, and W. Baehr. 1992. Primary structure and chromosomal localization of human and mouse rod photoreceptor cGMP-gated cation channel. J. Biol. Chem. 267, 6257-6262.

Robinson, N. J., A. M. Tommey, C. R. Kuske, and P. J. Jackson. 1993. Plant metallothioneins. Biochem. J. 295, 1-10.

Sandberg, W. S., and T. C. Terwilliger, 1993. Engineering multiple properties of a protein by combinatorial mutagenesis. Proc. Natl. Acad. Sci. USA 90, 8367-8371.

Shen, Y., K. Holman, N. A. Doggett, D. F. Callen, G. R. Sutherland, and R. I. Richards. Three dinucleotide repeat polymorphisms on human chromosome 16p13.11 - p13.3. Human Molecular Genetics 2, 1504 (1993). 
Shen, Y., K. Holman, N. A. Doggett, D. F. Callen, G. R. Sutherland, and R. I. Richards. Five dinucleotide repeat polymorphisms on human chromosome 16q24.2 - q24.3. Human Molecular Genetics 2, 1504 (1993).

Shen, Y., K. Holman, N. A. Doggett, D. F. Callen, G. R. Sutherland, and R. I. Richards. Six dinucleotide repeat polymorphisms on human chromosome 16q12.1 - q24.1. Human Molecular Genetics 2, 1505 (1993).

Skinner, M. M., H. Zhang, D. H. Leschnitzer, H. Bellamy, R. M. Sweet, C. M. Gray, R. N. H. Konings, A. H.-J. Wang, and T. C. Terwilliger. 1993. Structure of the gene V protein of bacteriophage $\mathrm{f} 1$ determined by multiwavelength $\mathrm{x}$-ray diffraction on the selenomethionyl protein. Proc. Natl. Acad. Sci. USA, in press.

Snell, R. G., L. A. Doucette-Stamm, K. M. Gillespie, S. A. M. Taylor, L. Riba, G. P. Bates, M. R. Altherr, M. E. MacDonald, J. F. Gusella, J. J. Wasmuth, H. Lehrach, D. E. Housman, P. S. Harper, and D. Shaw. 1993. The isolation of cDNAs within the Huntington disease region by hybridization of yeast artificial chromosomes to a cDNA library. Hum. Molec. Genet. 2, 305-309.

Spritz, R. A., K. M. Strunk, S.-T. Lee, J. M. Lu-Kuo, D. C. Ward, D. LePaslier, M. R. Altherr, T. E. Dorman, and D. T. Moir. A YAC contig spanning a cluster of human Type III receptor protein tyrosine kinase genes (PDGFRA-KIT-KDR) in chromosome segment 4q12. Genomics, submitted (1993).

Stallings, R. L., N. A. Doggett, D. Callen, S. Apostolou, P. Harris, H. Michison, M. Breuning, J. Sarich, C. E. Hildebrand, and R. K. Moyzis. Evaluation of a cosmid contig physical map of human chromosome 16. Genomics 13, 1031-1039 (1992).

Stallings, R. L., N. A. Doggett, K. Okumura, and D. Ward. Chromosome 16 specific repetitive DNA sequences that map to chromosome regions known to undergo breakage/rearrangement in leukemia cells. Genomics 13, 332-338 (1992).

Stallings, R. L., S. A. Whitmore, N. A. Doggett, and D. F. Callen. Refined physical mapping of chromosome 16 low abundance repetitive DNA sequences. Cytogenet. Cell. Genet. 63, 97-101 (1993).

Tawil, R., D. Storvick, B. Weiffenbach, M. R. Altherr, T. E. Feasby, and R. C. Griggs. 1993. Chromosome $4 \mathrm{q}$ DNA rearrangement in one member of a pair of monozygotic twins discordant for FSH muscular dystrophy. Human Mutation 2, 492-494.

Taylor, S. A. M., R. G. Snell, A. Buckler, C. Ambrose, M. Duyao, D. Church, C. S. Lin, M. Altherr, G. P. Bates, N. Groot, G. Barnes, D. J. Shaw, H. Lehrach, J. J. Wasmuth, P. S. Harper, D. E. Housman, M. E. MacDonald, and J. F. Gusella. 1992. Cloning of the a-adducin gene from the Huntington's disease candidate region of chromosome 4 by exon amplification. Nature Genet. 2, 223-229.

Terwilliger, T. C. 1993. MAD phasing: Bayesian estimates of Fa. Acta Cryst. D, in press.

Terwilliger, T. C. 1993. MAD phasing: Treatment of dispersive differences as isomorphous replacement information. Acta Cryst. D, in press.

Terwilliger, T. C., H. B. Zabin, M. P. Horvath, W. S. Sandberg, and P. M. Schlunk. 1993. In vivo characterization of mutants of the bacteriophage $\mathrm{f} 1$ gene $\mathrm{V}$ protein isolated by saturation mutagenesis. J. Mol. Biol., in press.

Weiffenbach, B., J. Dubois, S. Manning, N. S. Ma, B. C. Schutte, S. T. Winokur, M. R. Altherr, S. J. Jacobsen, V. P. Stanton, Jr., K. Yokoyama, and D. Moir. YAC contigs for 4q35 in the region of the facioscapulohumeral muscular dystrophy (FSHD) gene. Genomics, in press (1993). 
Weiffenbach, B., J. Dubois, D. Storvick, R. Tawil, S. J. Jacobsen, J. Gilbert, C. Wijmenga, J. R. Mendell, S. Winokur, M. R. Altherr, P. Schultz, S. Olandt, R. R. Frants, M. PericakVance, and R. C. Griggs. 1993. Mapping the facioscapulohumeral muscular dystrophy gene is complicated by chromosome 4q35 recombination events. Nature Genetics 4, 165-173.

Wijmenga, C., S. T. Winokur, G. W. Padberg, M. I. Skraastad, M. R. Altherr, J. J. Wasmuth, J. C. Murray, M. H. Hofker, and R. R. Frants. 1993. The human skeletal muscle adenine nucleotide translocator gene maps to chromosome $4 \mathrm{q} 35$ in the region of the facioscapulohumeral muscular dystrophy locus. Human Genetics 92, 198-203.

Wilcox, A. S., J. A. Warrington, K. Gardiner, R. Berger, P. Whiting, M. R. Altherr, J. J. Wasmuth, D. Patterson, and J. M. Sikela. 1992. Human chromosomal localization of genes encoding the $\mathrm{c} 1$ and $\mathrm{c} 2$ subunits of the $\mathrm{GABA}_{\mathrm{A}}$ receptor indicates members of this gene family are often clustered in the genome. Proc. Nat. Acad. Sci. USA 13, 5857-5861.

Winokur, S. T., U. Bengtsson, J. Feddersen, K. D. Matthews, B. Weiffenbach, H. Bailey, R. P. Markovich, J. C. Murray, J. J. Wasmuth, M. R. Altherr, and B. C. Schutte. The DNA rearrangement associated with facioscapulohumeral muscular dystrophy involves a heterochromatin associated repetitive element: Implications for a role for chromatin structure in the pathogenesis of the disease. Chromosome Research, in press (1993).

Winokur, S. T., B. Schutte, B. Weiffenbach, S. S. Washington, D. McElligott, A. Chakravarti, J. J. Wasmuth, and M. R. Altherr. 1993. A radiation hybrid map of fifteen loci on the distal long arm of chromosome 4 , the region containing the gene responsible for facioscapulohumeral muscular dystrophy. Am. J. Hum. Genet. 53, 874-880.

Youngman, S., G. P. Bates, S. Williams, A. I. McClatchey, S. Baxendale, Z. Sedlacek, M. Altherr, J. J. Wasmuth, M. E. MacDonald, J. F. Gusella, D. Sheer, and H. Lehrach. 1992. The telomeric $60 \mathrm{~kb}$ of chromosome $4 \mathrm{p}$ is homologous to telomeric regions on $13 \mathrm{p}, 15 \mathrm{p}$, $21 \mathrm{p}$, and 22p. Genomics 14, 350-356.

\section{Abstracts}

Bruce, D. C., P. A. Medvick, T. J. Beugelsdijk, N. A. Doggett, C. E. Hildebrand, and R. K. Moyzis. High density gridding robot: Engineering and biology. Cold Spring Harbor Meeting on Genome Mapping and Sequencing, p. 37 (1993).

Doggett, N. A., D. F. Callen, R. L. Stallings, M. K. McCormick, C. E. Hildebrand, M. R. Altherr, D. C. Torney, J. W. Fickett, M. Cinkowsky, L. L. Deaven, G. R. Sutherland, and R. K. Moyzis. Construction of a cosmid, YAC, and STS physical map of human chromosome 16. Cold Spring Harbor Meeting on Genome Mapping and Sequencing, p. 60 (1993).

Doggett, N. A., L. A. Duesing, J. G. Tesmer, D. F. Callen, R. I. Richards, R. L. Stallings, C. E. Hildebrand, and R. K. Moyzis. Construction of a 1.6 megabase average resolution STS map of human chromosome 16. Genome Sequencing and Analysis Conference IV, Abstract B6 (1992).

Doggett, N. A., H. Mitchison, M. O. Mundt, D. F. Callen, D. C. Torney, L. L. Deaven, G. R. Sutherland, S. A. Mole, R. M. Gardiner, and R. K. Moyzis. Construction of cosmid, YAC, and STS maps in the Batten disease region of chromosome 16. Amer. J. Hum. Genet. 53, Suppl., 1285 (1993).

Doggett, N. A., R. L. Stallings, C. E. Hildebrand, M. K. McCormick, L. L. Deaven, D. C. Torney, D. F. Callen, K. Okumura, D. C. Ward, and R. K. Moyzis. A cosmid and YAC physical map of human chromosome 16. Amer. J. Hum. Genet. 51, Suppl., 77 (1992). 
Doggett, N. A., R. L. Stallings, C. E. Hildebrand, M. K. McCormick, L. L. Deaven, D. C. Torney, D. F. Callen, K. Okumura, D. C. Ward, and R. K. Moyzis. Progress toward closure of the physical map of human chromosome 16. Cold Spring Harbor Meeting on Genome Mapping and Sequencing, p. 41 (1992).

Mitchison, H. M., A. M. O'Rawe, A. D. Thompson, M. Knight, D. F. Callen, N. Doggett, R. M. Gardiner, and S. E. Mole. Genetic mapping of the Batten disease locus (CLN3) to the interval D16S288-D16S383 by analysis of haplotypes and allelic association. Amer. J. Hum. Genet. 53, Suppl., 1047 (1993).

Mundt, M., V. Faber, C. Soderlund, R. Rivenburgh, M. Goldberg, R. Pecherer, A. Ford, D. Bruce, N. Doggett, and D. Torney. Connected component analysis, interval graphs, and other graph algorithms for construction of physical maps and contig editing. Cold Spring Harbor Meeting on Genome Mapping and Sequencing, p. 173 (1993).

Nakamura, H., M. Sakamoto, C. Collins, N. Doggett, J. C. Gingrich, M. Wheelock, K. Johnson, F. Waldman, D. Pinkel, and J. W. Gray. Expression, gene copy number, and aberrations of the human E-cadherin gene in breast cancer. Amer. J. Hum. Genet. 53, Suppl., 27 (1993).

Rappaport, B., J. Gatewood, C. Fields, and N. Doggett. Software tools for primer site prediction and sequence homology searches. Genome Sequencing and Analysis Conference IV, Abstract C16 (1992).

Stallings, R. L., N. A. Doggett, D. F. Callen, G. R. Sutherland, K. Okumura, D. C. Ward, C. E. Hildebrand, and R. K. Moyzis. Integration of a cosmid contig map with cytogenetic and linkage maps of human chromosome 16. Second International Workshop on Human Chromosome 16, held in Adelaide, Australia (1992).

Terwilliger, T. C., and P. N. Goudreau. 1993. Structural basis for gene V protein cooperativity. Biophys. J. 64, A249.

\section{Book Chapters}

Doggett, N. A., D. L Grady, J. L. Longmire, and L. L. Deaven. Generation and mapping of chromosome specific sequence-tagged sites (STSs). In DNA Sequencing Protocols: A Guide to Methods and Applications (J. Craig Venter, ed.), Academic Press Limited, London, UK, in press (1993).

Hildebrand, C. E., R. L. Stallings, D. C. Torney, J. W. Fickett, N. A. Doggett, D. A. Nelson, A. A. Ford, and R. K. Moyzis. Human genome mapping and sequencing: Applications in pharmaceutical science. In Biotechnology and Pharmacy (J. M. Pezzuto et al., eds.), pp. 193-226, Chapman \& Hall, New York (1993).

Rappaport, B., J. Gatewood, C. Fields, and N. Doggett. Software tools for primer site prediction and sequence similarity searches. In DNA Sequencing protocols: A Guide to Methods and Applications (J. Craig Venter, ed.), Academic Press Limited, London, UK, in press (1993).

Stallings, R. L., N. A. Doggett, A. Ford, J. Longmire, C. E. Hildebrand, L. L. Deaven, and R. K, Moyzis. Applications of cosmid libraries in genome mapping and sequencing efforts. In DNA Sequencing protocols: A Guide to Methods and Applications (J. Craig Venter, ed.), Academic Press Limited, London, UK, in press (1993).

Stallings, R. L., N. A. Doggett, K. Okumura, A. G. Matera, and D. C. Ward. Are repetitive DNA sequences involved with leukemia chromosome breakpoints? In Genome Analysis Vol. 7: Genome Rearrangement and Stability (K. Davies and S. Warren, eds.), pp. 1-16, CSHL Press, Cold Spring Harbor, New York (1993). 


\section{Papers}

Grosson, C. L. S., S. Roffler-Tarlov, J. Jagadeesh, M. Altherr, C. M. Ambrose,

S. V. Cheng, M. P. Duyao, M. James, B. Martin, R. Snell, S. A. M. Taylor, J. Wasmuth, M. E. MacDonald, and J. F. Gusella. 1992. Comparative mapping of the Huntington's disease region of human chromosome 4 on mouse chromosome 5. Annual Meeting: American Society of Human Genetics.

Schutte, B. C., K. D. Matthews, J. A. Feddersen, H. L. Bailey, S. T. Winokur, B. Weiffenbach, and M. R. Altherr. 1993. Identification of a heterochromatin-associated repetitive element that maps near the facioscapulohumeral dystrophy locus. Annual Meeting: American Society of Human Genetics.

Upadhyaya, M. W. Maramutse, M. Altherr, J. Maynard, J. Farnham, R. Elswarapu, P. Lunt, P. S. Harper, and J. Ikeda. 1992. Further genetic mapping of facioscapulohumeral muscular dystrophy. Annual Meeting: American Society of Human Genetics.

Weiffenbach, B., B. Schutte, J. Dubois, S. Manning, N. Ma, S. J. Jacobsen, R. Tawil, R. C. Griggs, and M. R. Altherr. 1993. Isolation and mapping of rearrangements associated with facioscapulohumeral muscular dystrophy (FSHD). Annual Meeting: American Society of Human Genetics.

Winokur, S. T., U. Bengtsson, R. Markovich, J. J. Wasmuth, and M. R. Altherr. 1993. Mildly repetitive sequences closely linked to the facioscapulohumeral muscular dystrophy gene on distal chromosome $4 \mathrm{q}$ cross-hybridize to regions of heterochromatin. Annual Meeting: American Society of Human Genetics. 